Aus der Klinik für Nephrologie und Rheumatologie

(Prof. Dr. med. G. A. Müller)

der Medizinischen Fakultät der Universität Göttingen

\title{
Evaluation der Prognose des akuten Nierenversagens nach kardiopulmonaler Reanimation und milder therapeutischer Hypothermie
}

\author{
INAUGURAL-DISSERTATION
}

zur Erlangung des Doktorgrades

der Medizinischen Fakultät der

Georg-August-Universität zu Göttingen

vorgelegt von

Alexander James Barclay-Steuart

aus

Münster

Göttingen 2015 
Dekan:

1. Berichterstatterin:

2. Berichterstatter:

3. Berichterstatterin:
Prof. Dr. rer. nat. H. K. Kroemer

Prof. Dr. med. S. Blaschke

Prof. Dr. med. A. Bräuer

Prof. Dr. med. C. Unterberg-Buchwald

Tag der mündlichen Prüfung: 11. Februar 2016 


\section{Inhaltsverzeichnis}

\section{Abkürzungsverzeichnis}

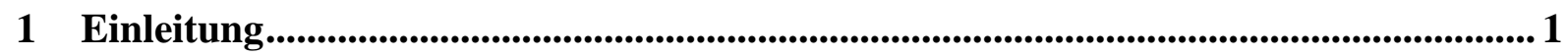

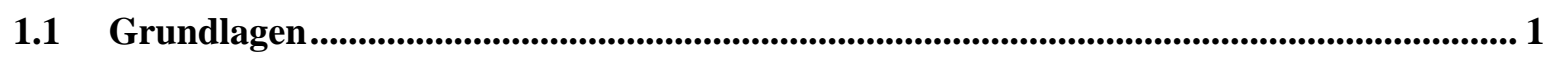

1.2 Definition des akuten Nierenversagens ....................................................................................... 3

1.3 Inzidenz des akuten Nierenversagens .............................................................................5 5

1.4 Pathophysiologie des akuten Nierenversagens .................................................................. 6

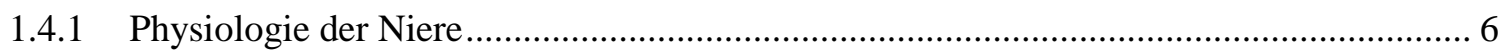

1.4.2 Allgemeine Pathophysiologie des akuten ischämischen Nierenversagens ....................... 7

1.4.3 Spezielle Pathophysiologie des akuten ischämischen Nierenversagens ........................... 7

1.5 Milde therapeutische Hypothermie ...................................................................................... 12

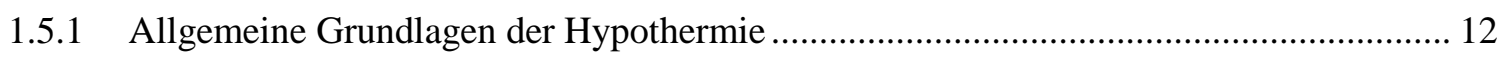

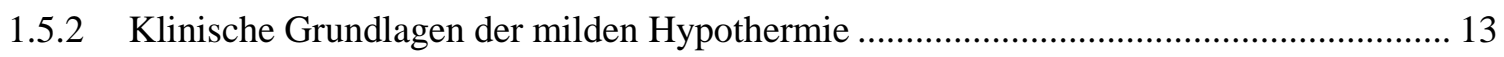

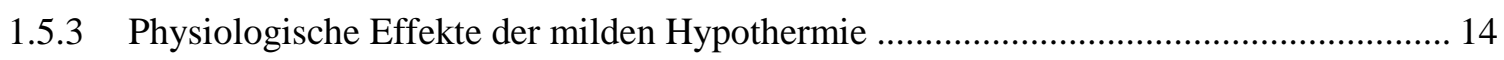

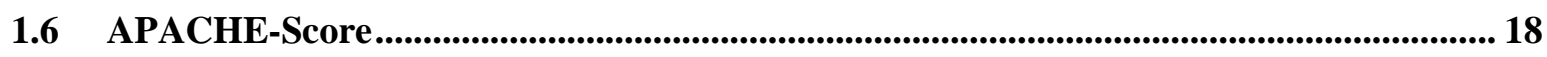

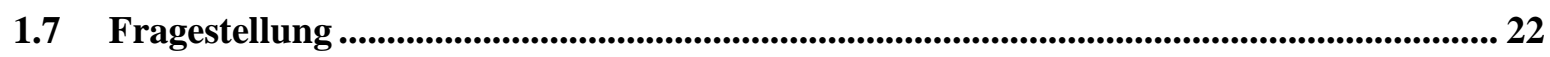

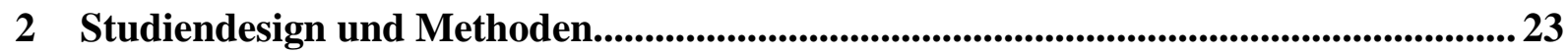

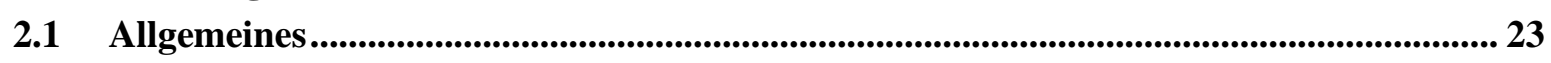

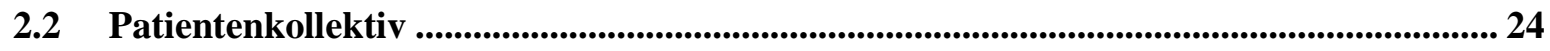

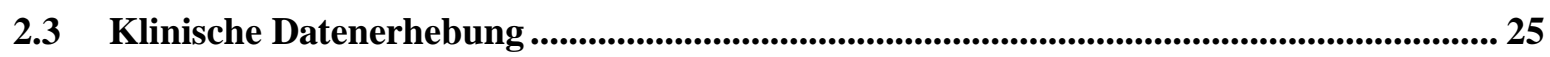

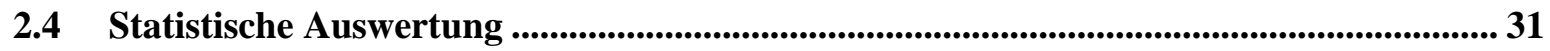

3 Ergebnisse ........................................................................................................................................... 32

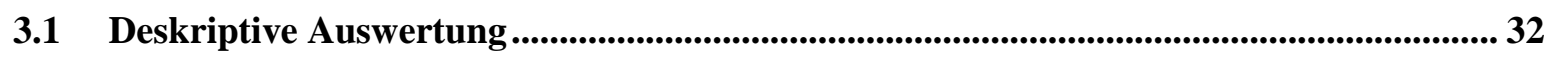

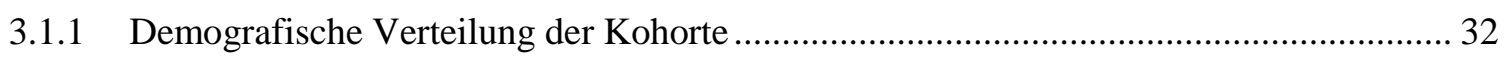

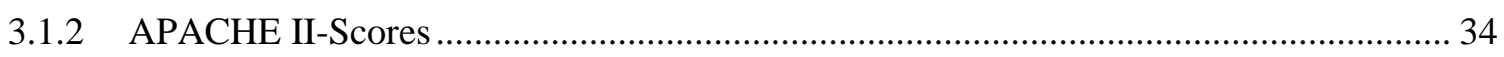

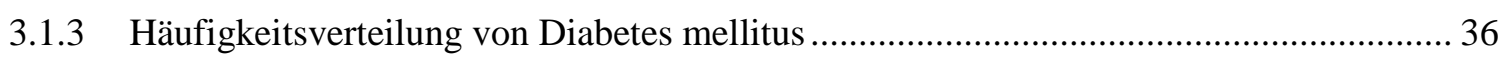

3.1.4 Häufigkeitsverteilung der Risikofaktoren für eine chronische Niereninsuffizienz.......... 37

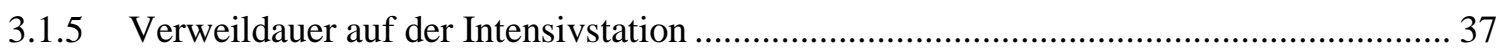

3.2 Häufigkeitsverteilung des akuten Nierenversagens ............................................................... 39

3.2.1 Globale Häufigkeitsverteilung des akuten Nierenversagens......................................... 39

3.2.2 Häufigkeitsverteilung des akuten Nierenversagens unter Berücksichtigung des

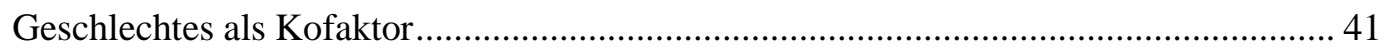

3.2.3 Häufigkeitsverteilung des akuten Nierenversagens unter Berücksichtigung von Diabetes

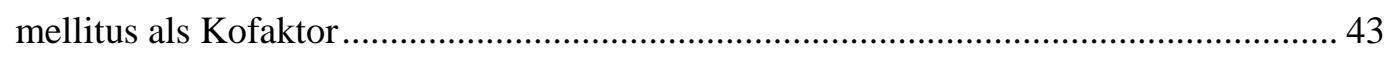

3.2.4 Häufigkeitsverteilung des akuten Nierenversagens unter Berücksichtigung der Risikofaktoren für eine chronische Niereninsuffizienz als Kofaktor ............................... 45

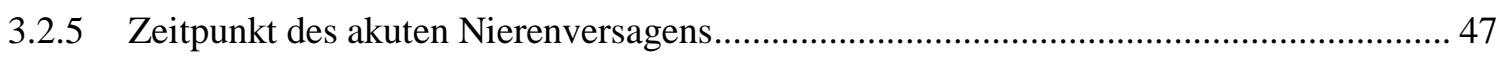

3.3 Zustand des Patienten zum Zeitpunkt der Entlassung.......................................................... 49

3.3.1 Globale Häufigkeitsverteilung des Outcomes............................................................. 49

3.3.2 Häufigkeitsverteilung des Outcomes unter Berücksichtigung des Geschlechtes als

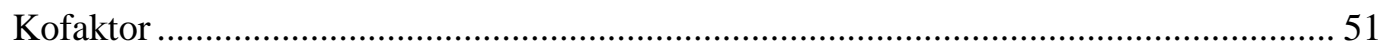

3.3.3 Häufigkeitsverteilung des Outcomes unter Berücksichtigung von Diabetes mellitus als

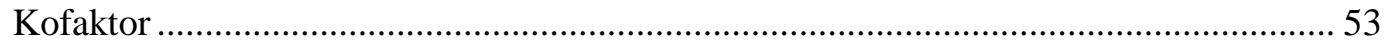


3.3.4 Häufigkeitsverteilung des Outcomes unter Berücksichtigung der Risikofaktorklassen als

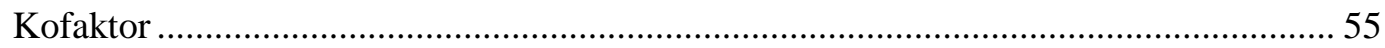

3.4 Verlauf der glomerulären Filtrationsrate ...............................................................5 58

3.4.1 Verlauf der glomerulären Filtrationsrate über die Zeit ................................................ 58

3.4.2 Verlauf der glomerulären Filtrationsrate über die Zeit und in Abhängigkeit vom

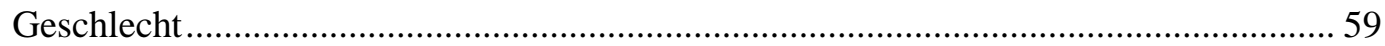

3.4.3 Verlauf der glomerulären Filtrationsrate über die Zeit und in Abhängigkeit von Diabetes

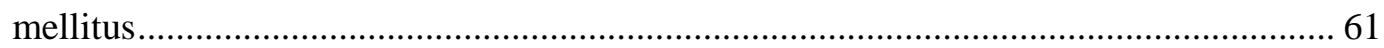

3.4.4 Verlauf der glomerulären Filtrationsrate über die Zeit und in Abhängigkeit von Risikofaktorklassen für eine chronische Niereninsuffizienz............................................ 64

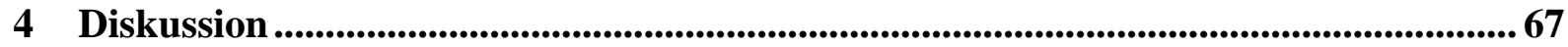

4.1 Einfluss der milden therapeutischen Hypothermie auf die Inzidenz des akuten Nierenversagens........................................................................................................................................ 67

4.2 Einfluss der milden therapeutischen Hypothermie auf das Outcome .................................. 74

4.3 Einfluss der milden therapeutischen Hypothermie auf die errechnete glomeruläre Filtrationsrate ..................................................................................................................................................... 79

5 Zusammenfassung.................................................................................................................... 84

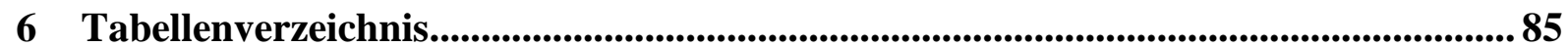

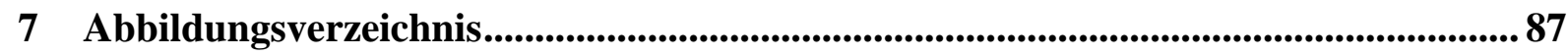

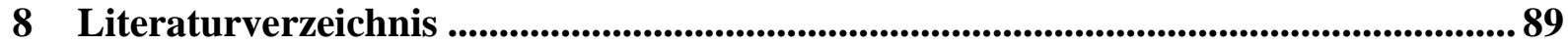




\section{Abkürzungsverzeichnis}

$\mathbf{A a D O}_{2}$ alveolo-arterielle Sauerstoffdruckdifferenz

ADH antidiuretisches Hormon

ADP Adenosindiphosphat

AKIN Acute Kidney Injury Network

AMP Adenosinmonophoshat

ANOVA analysis of variance

ANV akutes Nierenversagen

APACHE Acute Physiology and Chronic Health Evaluation

ARR absolute Risikoreduktion

ATN akute tubuläre Nekrose

ATP Adenosintriphosphat

CKI chronische Niereninsuffizienz

CNV chronisches Nierenversagen

CPR cardiopulmonary resuscitation

DM Diabetes mellitus

DNA Desoxyribonukleinsäure

ERC European Resuscitation Council

$\mathbf{F i O}_{2} \quad$ fraction of inspired oxygen

GCS Glasgow Coma Scale

GFR glomeruläre Filtrationsrate

HACA The Hypothermia after Cardiac Arrest Study Group

ICU intensive care unit

IGF insulin-like growth factor

ILCOR International Liaison Committee on Resuscitation

KDOQI Kidney Disease Outcomes Quality Initiative

KKT Körperkerntemperatur

MAP mittlerer arterieller Blutdruck

MDRD modification of diet in renal disease

mHT milde Hypothermie

NADPH Nicotinamidadenindinukleotidphosphat

NGAL neutrophil gelatinase-associated lipocalin 
NMDA N-Methyl-D-Aspartat

NYHA New York Heart Assosciation

POLAR Prophylactic Hypothermia to Lessen Traumatic Brain Injury

RAAS Renin-Angiotensin-Aldosteron-System

RBF renaler Blutfluss

RF Risikofaktor

ROSC return of spontaneous circulation

RRR relative Risikoreduktion

$\mathbf{S}_{\mathrm{cr}} \quad$ Serum-Kreatinin

SEM standard error of the mean

SOP standard operating procedure

TNFa Tumornekrosefaktor $\alpha$

UMG Universitätsmedizin Göttingen 


\section{$1 \quad$ Einleitung}

\subsection{Grundlagen}

In Europa erleiden ca. 350000 Menschen pro Jahr einen Herz-Kreislaufstillstand und müssen präklinisch wiederbelebt werden. Dies entspricht einer Inzidenz von 81,4 kardiopulmonaler Reanimationen (cardiopulmonary resuscitation $=\mathrm{CPR}$ ) pro 100000 Einwohner im Jahr. Der plötzliche Herztod ist die häufigste Todesursache in den westlichen Industrieländern (Berdowski et al. 2010). Ätiologisch liegen zumeist kardiovaskuläre Erkrankungen wie der Myokardinfarkt, eine maligne Arrhythmie oder eine fulminante Lungenembolie zugrunde (Pell et al. 2003). Diese Ereignisse implizieren für den menschlichen Körper eine lebensbedrohliche Situation, welche ohne sofortige Behandlung zum Tod führt. Der Organismus wird aufgrund des Herz-Kreislaufstillstandes nicht mehr ausreichend mit Sauerstoff versorgt. Je nach spezifischer Toleranz des Gewebes führt diese Hypoxie zu einer Gewebsischämie, welche irreversible Organschäden verursachen kann. Aufgrund des erhöhten Energiebedarfs besteht für neuronales Gewebe eine besonders gering ausgeprägte Ischämietoleranz und wird als der limitierende Faktor der kardiopulmonalen Reanimation gewertet (Weih et al. 2001, Trummer et al. 2009).

In zwei großen prospektiven Studien konnte aufgezeigt werden, dass die Durchführung einer milden therapeutischen Hypothermie (mHT) nach kardiopulmonaler Reanimation bei HerzKreislaufstillstand mit einer Zieltemperatur von 32-34 ${ }^{\circ} \mathrm{C}$ über 24 Stunden die Gesamtprognose des neurologischen Outcomes signifikant verbessern konnte (HACA 2002, Bernard et al. 2002).

Aufgrund dieser Ergebnisse wurde 2003 die standardmäßige Durchführung einer mHT in die Richtlinien der „International Liaison Committee on Resuscitation“ (ILCOR) integriert. 2005 folgte die Aufnahme der mHT in die Leitlinien der „European Resuscitation Council“ (ERC) (Nolan et al. 2005).

Eine im Jahr 2013 publizierte internationale multizentrische und randomisierte Studie stellte jedoch die bisherigen Ergebnisse infrage. Der Vergleich zwischen den beiden Patientenkollektiven mit $\left(33{ }^{\circ} \mathrm{C}\right)$ und ohne milde Hypothermie $\left(36{ }^{\circ} \mathrm{C}\right)$ während der Postreanimationsphase zeigte keinen signifikanten Unterschied bezüglich der Mortalität und des neurologischen Outcomes (Nielsen et al. 2013). Dies gibt Anlass dazu, die mHT als ein standardmäßiges Behandlungskonzept weiterhin genauer zu untersuchen. 
Das Risiko eines akuten Nierenversagens (ANV) nach kardiopulmonaler Reanimation wird je nach Studiendesign mit einer Häufigkeit von $12 \%$ bis zu $40 \%$ beziffert (Mattana und Singhal 1993, Domanovits et al. 2001, Hasper et al. 2009). Pathophysiologisch wird vermutet, dass das ANV durch ähnliche Mechanismen verursacht wird wie die zerebralen Schädigungen nach Herz-Kreislaufstillstand. Eine übergeordnete Rolle wird der initialen systemischen Ischämie (Störung der Nierenperfusion) und nachfolgenden Steigerung der Apoptoserate in der Reperfusionsphase zugeschrieben (Lameire et al. 2005).

Die positive Wirkung der milden therapeutischen Hypothermie bezüglich des verminderten Auftretens neurologischer Komplikationen gab Anlass dazu, in dieser retrospektiven Studie die Inzidenz und Prognose des akuten Nierenversagens bei Patienten nach erfolgreicher kardiopulmonaler Reanimation und Durchführung einer mHT im Vergleich zu einem Kontrollkollektiv zu untersuchen. 


\subsection{Definition des akuten Nierenversagens}

Gekennzeichnet ist das akute Nierenversagen durch eine rasche totale oder partielle Abnahme der Nierenfunktion, welche mehrere Tage persistieren kann, aber prinzipiell reversibel ist. Leitsymptom ist der Verlust der exkretorischen Harnsekretion mit der Folge eines Anstieges der harnpflichtigen Substanzen Kreatinin und Harnstoff im Serum. Die Zunahme des SerumKreatinins um $\geq 0,3 \mathrm{mg} / \mathrm{dl}$ oder ein prozentualer Anstieg von $\geq 50 \%$ des Ausgangswertes innerhalb von 48 Stunden definieren das akute Nierenversagen. Als zusätzliches Kriterium kann eine Verminderung der Urinausscheidung auf $<0,5 \mathrm{ml} / \mathrm{kg} / \mathrm{h}$ über mehr als 6 Stunden herangezogen werden (Mehta et al. 2007).

In ca. $30 \%$ der Fälle kommt es nach einer initialen Oligurie ( $<500 \mathrm{ml}$ Urin/d) oder Anurie $(<100 \mathrm{ml} \mathrm{Urin/d)} \mathrm{zu} \mathrm{einer} \mathrm{normo-}(>500 \mathrm{ml}$ Urin/d) oder polyurischen Phase $(>2000 \mathrm{ml}$ Urin/d) (Bellomo 2005).

Laut KELLER und GEBERTH (2010) kann die Einteilung des akuten Nierenversagens anhand der Ätiologie vorgenommen und wie folgt klassifiziert werden:

- Prärenales ANV: Das prärenale ANV ist charakterisiert durch eine der Niere vorgelagerte Ursache (Volumenmangelschock, Herz-Kreislaufstillstand, toxische renale Vasokonstriktion). Diese führen nicht direkt zu einer strukturellen Änderung, aber sekundär besteht das Risiko für ein Ischämie-induziertes akutes Nierenversagen.

- Intrarenales ANV: Beim intrarenalen ANV besteht die Ursache in einer Schädigung der kleinen und großen Nierengefäße, der Glomeruli, der Tubuli oder des Interstitiums. Auslöser dieser mikro- und makrovaskulären Schädigung ist zumeist eine $\mathrm{O}_{2}$-Minderversorgung bei reduzierter Nierenperfusion. Hauptursachen sind eine akute Tubulusnekrose, akute Glomerulonephritis oder eine akute interstitielle Nephritis.

- Postrenales ANV: Ursache für das postrenale Nierenversagen ist eine Abflussbehinderung im Bereich der ableitenden Harnwege. Sie kann durch Harnleitersteine, angeborene Stenosen oder Missbildungen sowie maligne Tumore bedingt sein. 
Eine internationale einheitliche Klassifikation und Stadieneinteilung wurde 2007 definiert. Das Akute Kidney Injury Network (AKIN) modifizierte die 2004 publizierten RIFLE-Stadien und veröffentlichte die sog. AKIN-Klassifikation. Sie teilt das ANV anhand des zeitlichen Verlaufes, des Anstieges des Serum-Kreatinins sowie der Urinausscheidung in drei unterschiedliche Stadien ein (Tab. 1) (Mehta et al. 2007).

\begin{tabular}{|c|l|l|}
\hline \multicolumn{3}{|c|}{ Stadieneinteilung der akuten Nierenschädigung } \\
\hline AKIN-Stadium & \multicolumn{1}{|c|}{ Serum-Kreatinin } & \multicolumn{1}{c|}{ Urin-Ausscheidung } \\
\hline 1 & $\begin{array}{l}\text { 1,5- bis 2-facher Kreatininan- } \\
\text { stieg oder Kreatininanstieg } \geq 0,3 \\
\text { mg/dl }\end{array}$ & $<0,5 \mathrm{ml} / \mathrm{kg} / \mathrm{h}$ für $6 \mathrm{~h}$ \\
\hline 2 & 2- bis 3-facher Kreatininanstieg & $<0,5 \mathrm{ml} / \mathrm{kg} / \mathrm{h}$ für $12 \mathrm{~h}$ \\
\hline 3 & $\begin{array}{l}>3 \text {-facher Kreatininanstieg oder } \\
\text { Serum-Kreatinin }>4 \mathrm{mg} / \mathrm{dl} \text { mit } \\
\text { einem akuten Anstieg } \geq 0,5 \\
\text { mg/dl }\end{array}$ & $\begin{array}{l}<0,3 \mathrm{ml} / \mathrm{kg} / \mathrm{h} \text { für } 24 \mathrm{~h} \text { oder } \\
\text { fehlende Urinausscheidung } \\
\text { (Anurie) für } 12 \mathrm{~h}\end{array}$ \\
\hline
\end{tabular}

Tabelle 1: Klassifikation des akuten Nierenversagens nach AKIN (nach Mehta et al. 2007, $\mathrm{R} 31)$ 


\subsection{Inzidenz des akuten Nierenversagens}

Die globale Inzidenz des akuten Nierenversagens liegt bei intensivstationären Patienten bei ca. $6 \%$ und geht mit einer Erhöhung der Morbidität sowie Mortalität einher. Etwa $72 \%$ ebendieser Patienten benötigen mindestens eine einmalige Dialyse aufgrund von Nierenfunktionsstörungen (Uchino et al. 2005).

Das Risiko für das Auftreten eines akuten Nierenversagens nach kardiopulmonaler Reanimation variiert je nach angewandtem Studienmodell und Klassifikationssystem signifikant.

Zwei aktuelle Studien analysierten die Inzidenz des ANV anhand zweier unterschiedlicher gängiger Bewertungsskalen. Nach AKIN-Klassifikation lag die Inzidenz für das Auftreten eines AKIN-Stadium 2 und 3 bei 22,7\% (Hasper et al. 2009). Bei der Verwendung der RIFLE-Kriterien bestand die Auftretenswahrscheinlichkeit 31,4\%. Den Unterschied begründeten die Autoren der zweiten Studie durch die Baseline-Arretierung mittels SerumKreatinin zum Zeitpunkt der Aufnahme (Chua et al. 2012). 


\subsection{Pathophysiologie des akuten Nierenversagens}

\subsubsection{Physiologie der Niere}

Die Niere weist mit etwa $20 \%$ des Herz-Zeit-Volumens ( $\approx 1,2$ 1/min) die höchste Blutdurchflussrate bezogen auf ihr Organgewicht im gesamten Organismus auf. Der hohe renale Blutdurchfluss (RBF) kommt überwiegend der Rindenregion zugute, in welcher ein Großteil des Sauerstoffes für Resorptionsprozesse verbraucht wird. Die Nierenperfusion und damit einhergehende glomeruläre Filtration (GFR) unterliegt einem Autoregulationsmechanismus, welcher für einen weitgehend konstanten, blutdruckunabhängigen renalen Blutfluss sorgt. Der Autoregulation liegen als bedeutendste Mechanismen ein tubuloglomeruläres Feedback im juxtamedullären Apparat, die myogene Aktivierung der präglomerulären Gefäße (BaylissEffekt) und der Renin-Angiotensin-Mechanismus zugrunde (Silbernagel 2010). Weitere Regulationsmechanismen, wie zum Beispiel die Sympathikusaktivierung und die Steuerung mittels antidiuretischem Hormon (ADH) als Rückmeldung der Serumosmolalität stehen zusätzlich zur Verfügung (Koushanpour und Kriz 1986).

Bei einem mittleren arteriellen Blutdruck (MAP) im Bereich von $80 \mathrm{mmHg}$ bis $170 \mathrm{mmHg}$ verhält sich die GFR aufgrund der Autoregulation weitgehend konstant. Kommt es zu einem Abfall des MAPs unter $80 \mathrm{mmHg}$, nehmen die GFR und der RBF linear signifikant ab. Ein Unterschreiten dieser Grenze kann zu einer Minderperfusion des Gewebes führen.

Die Rindenzone der Niere ist für die Filtration des Blutes zum sog. Primärharn verantwortlich und nimmt mit fast $90 \%$ den höchsten Anteil am renalen Blutfluss ein. Die äußere Markzone erhält ca. $10 \%$ und die innere Markzone lediglich 1-2 \% des RBF. Die renale arteriovenöse $\mathrm{O}_{2}$-Differenz beträgt aufgrund der hohen Durchblutung im Vergleich zu anderen Organen lediglich etwa $7 \%$. Der Sauerstoff wird hauptsächlich für die primär-aktive Resorption von $\mathrm{Na}^{+}$benötigt. Sinkt die renale Durchblutung und konsekutiv auch die GFR, vermindert sich der $\mathrm{O}_{2}$-Bedarf ebenfalls. Bei einer nicht filtrierenden und folglich nicht resorbierenden Niere kommt es zum Abfall des basalen Sauerstoffbedarfs auf ca. $10 \%$ des normalen Ausgangswertes. Die renale Durchblutung bestimmt demzufolge maßgeblich den Bedarf an Sauerstoff und nicht umgekehrt (Seldin und Giebisch 2000). 


\subsubsection{Allgemeine Pathophysiologie des akuten ischämischen Nierenversagens}

Das akute prärenale Nierenversagen ist gekennzeichnet durch einen Abfall der Nierenperfusion unterhalb des Toleranzbereiches, mit nachfolgender Verminderung der glomerulären Filtrationsrate. Primär sind keine strukturellen Nierenschädigungen vorhanden und nach Beseitigung der ursächlichen Faktoren ist diese in der Regel reversibel (Keller und Geberth 2010). Zur Kompensation einer Minderperfusion steigert die Niere die Natrium- und Wasserrückresorption, um das effektive Blutvolumen zu erhöhen. Der Organismus reagiert mit der Freisetzung von ADH, aktiviert das Renin-Angiotensin-Aldosteron-System (RAAS) und erhöht die Freisetzung von Katecholaminen. Zusätzlich wird versucht, die Perfusion durch Dilatation der afferenten Arteriolen mittels Prostaglandinen und Stickstoffmonoxid (NO) und durch Vasokonstriktion der efferenten Arteriolen mithilfe von Angiotensin II aufrecht-zuerhalten. Als Folge steigt der glomeruläre Filtrationsdruck an und stabilisiert über die gesteigerte Filtrationsfraktion zunächst die GFR (Stahl et al. 2006).

Bei lang anhaltendem oder plötzlichem Abfall der Nierendurchblutung kommt es zum Verlust der Kompensationsmechanismen und die Niere ist nicht mehr in der Lage, ihre Funktion aufrechtzuerhalten. Konsekutiv fällt die GFR rasch ab und es entsteht ein akutes ischämisches Nierenversagen prärenaler Genese. Definiert wird dieses als eine durch Minderperfusion hervorgerufene beidseitige Tubulusepithelschädigung, welche zu einem Versagen der Nierenfunktion führt (Thadhani et al. 1996). Der Pathogenese liegt meist eine durch einen kardiogenen Schock oder hohen Blutverlust verursachte unzureichende peritubuläre Zirkulation mit konsekutiver Ischämie im Hypoxieempfindlichen proximalen Tubulusepithel zugrunde. Die Regenerationsfähigkeit der Epithelien ist bei ischämischer Tubulopathie und einer adäquaten Therapie hoch, sodass ein Ischämie-induziertes ANV in der Regel reversibel ist (Stahl et al. 2006).

\subsubsection{Spezielle Pathophysiologie des akuten ischämischen Nierenversagens}

Für die Entstehung und Aufrechterhaltung des akuten Nierenversagens konnten laut LAMEIRE und VANHOLDER (2001) sowie THADHANI et al. (1996) vier pathophysiologische Faktoren als Ursachen identifiziert werden.

- Glomeruläre Permeabilitätskapazität: Experimentelle Studien zeigten einen direkten Konnex zwischen dem Rückgang der GFR und der glomerulären Permeabilitäts- 
kapazität bei ANV. Die Mechanismen sind nicht genau geklärt. Es wird jedoch angenommen, dass eine Schädigung der Endothelzellen mit nachfolgender verminderter glomerulärer Permeabilität die Ursache ist. Eine zusätzliche Angiotensin IIinduzierte Kontraktion des glomarulären Mesangiums wird diskutiert.

- Rückfluss von Glomerulusfiltrat: Durch nicht intakte bzw. gelöste Zell-Zell-Kontakte des Tubulusepithels ist es möglich, dass der im Glomerulus gebildete Primärharn direkt zurück in die peritubuläre Zirkulation fließen kann.

- Tubuläre Obstruktion: Eine durch die Hypoxie verursachte Integrindysfunktion der Tubuluszellen führt zur Umverteilung der zelleigenen basolateralen Integrinrezeptoren. Durch diesen Verlust und die damit verbundene insuffiziente Verankerung der Tubuluszellen mit der Basalmembran kann es zur Einschwemmung einzelner Tubuluszellen in das Lumen mit konsekutiver Zellaggregation und Lumenobstruktion kommen. Die durch den Rückstau entstehende Erhöhung des proximalen Druckverhältnisses führt zu einem weiteren Abfall der GFR.

- Veränderung der Hämodynamik: Aufgrund eines regulatorischen Ungleichgewichtes zwischen Vasodilatation und -konstriktion kommt es zu einem renalen Perfusionsmissverhältnis. Speziell eine verminderte Freisetzung des vasodilatatorisch wirkenden Stickstoffmonoxides und eine steigerte Synthese des vasokonstriktorisch wirkenden Endothelins gelten als Ursache der übermäßigen Vasokonstriktion renaler Arteriolen.

Des Weiteren wird angenommen, dass als Folge des proximalen Tubulusschadens eine erhöhte Natriumkonzentration im distalen Teil der Henle-Schleife erreicht wird und es dort im Bereich der Macula densa zu einer Aktivierung des juxtaglomerulären Apparates kommt. Über die aktivierenden Mediatoren des Renin-Angiotensin-Systems entsteht eine Vasokonstriktion afferenter Arteriolen mit einem weiteren Abfall der glomerulären Perfusion (Thurau-Mechanismus) (Thurau und Schnermann 1965).

Die ursächlichen Mechanismen, welche zu einer sekundären Schädigung des Tubulusepithels führen, sind mannigfaltig und können nicht isoliert in ihrer Wirkung betrachtet werden. Eine Kaskade biochemischer und struktureller Prozesse wird aktiviert und führt letztlich zu einer 
akuten tubulären Nekrose (ATN) (Thadhani et al. 1996). Einige dieser Vorgänge konnten entschlüsselt werden:

- ATP-Depletion: Die proximalen Tubuluszellen benötigen eine große Menge an Adenosintriphosphat (ATP) für ihre basal liegenden $\mathrm{Na}^{+}-\mathrm{K}^{+}$-ATPase. Zur Deckung des Energiebedarfes besitzen die proximalen Tubuluszellen mit etwa $30 \%$ der Zellmasse die höchste Dichte an Mitochondrien im renalen Epithel und sind auf die aerobe Glykolyse angewiesen. Liegt eine Ischämie vor, verringert sich das Sauerstoffangebot und konsekutiv erhöht sich die Konzentration von Adenosindi- (ADP) und Adenosinmonophosphat (AMP). Beide Produkte werden bei lang anhaltender Hypoxie zu den membranpermeablen Metaboliten. Diese Produkte können die Zelle verlassen, was bei einer erneuten Zufuhr von Sauerstoff zu einem Mangel der regenerationsfähigen Reserven von $\mathrm{ADP}$ und $\mathrm{AMP}$ führt. Des Weiteren entstehen beim Abbau der Di- und Monophosphate zytotoxisch reaktive Radikale, was zu einer Schädigung der Zellorganellen führen kann (Bonventre 1993).

- Erhöhter intrazellulärer Calciumeinstrom: Der normale Konzentrationsgradient für Calcium von 1:10 000 kann aufgrund der Hemmung der ATP-abhängigen Calciumtransportsystems nicht aufrechterhalten werden. Der intrazelluläre Calciumgehalt steigt an und führt je nach Dauer und Konzentration zu einem zytotoxischen Effekt sowie zur Bildung freier Radikale. Eine akute Änderung der Calciumkonzentration kann zusätzlich zu einer direkten Induktion der Apoptose führen (Snowdowne und Borle 1985).

- Bildung von freien Sauerstoffradikalen: Besonders in der Reperfusionsphase der Niere kommt es zur Bildung großer Mengen an freien Sauerstoffradikalen. Enzyme wie die Cyclooxygenase und die Xanthin-Oxidase, aber auch die membranständige NADPHOxidase aktivierter neutrophiler Granulozyten spielen hierbei eine übergeordnete Rolle. Die Folge ist ein überproportionaler Verbrauch von Radikalfängern (SuperoxidDismutase) und führt zu einer vermehrten zellschädigenden Peroxidation von Lipiden, Oxidation von zellulären Proteinen und direkten DNA-Schäden (Johnson und Weinberg 1993). 
- Aktivierung der Phospholipase $\mathrm{A}_{2}$ : Die Phospholipase $\mathrm{A}_{2}$ hydrolysiert Phospholipide zu freien Fettsäuren und Lysophospholipiden. Dies führt zu einer Erhöhung der Membranpermeabilität sowie einer gesteigerten Vulnerabilität gegenüber der Phospholipase $\mathrm{A}_{2}$ (Sevanian und Kim 1985). Stoffwechselprodukte der Phospholipase wie Arachidonsäure werden $\mathrm{zu}$ Eicosanoiden umgewandelt und führen $\mathrm{zu}$ einer Vasokonstriktion und chemotaktischen Anlockung neutrophiler Granulozyten (Klausner et al. 1989).

- Migration von Entzündungszellen: Entzündungszellen, insbesondere neutrophile Granulozyten, wandern in der Reperfusionsphase durch die Gefäßwände ins Interstitium ein und beginnen mit dem Abbau von Zelltrümmern. Freigesetzte Proteasen, Elastasen und freie Sauerstoffradikale können zu weiteren Schäden des Parenchyms führen (Singbartl und Ley 2004).

- Verlust der Zellpolarität: Die Unversehrtheit des Zytoskelettes ist für die Aufrechterhaltung der Funktionsfähigkeit der Tubuluszellen von essenzieller Bedeutung. Eine Schädigung führt zum Zusammenbruch der Integrität, Verlust des Bürstensaums und Verlagerung der basolateralen $\mathrm{Na}^{+}-\mathrm{K}^{+}$-ATPasen nach apikal (Spencer et al. 1991, Molitoris et al. 1992). Durch analoge Störungen kommt es zur Umverteilung der basolateral sitzenden Integrinrezeptoren, welche mit Proteinen (Laminin, Fibronectin und Vitronectin) der extrazellulären Matrix interagieren (Goligorsky und DiBona 1993). Als Folge der Umordnung kommt es zur Ausschwemmung der Tubuluszellen, zur Bildung eines Detritus und ggf. zur Obstruktion des Tubuluslumen (Racusen et al. 1991).

- Nekrose und Apoptose: Akute toxische oder ischämische Einflüsse bewirken eine starke Schädigung der Tubuluszellen und können Nekrosen oder Apoptosen induzieren. Als Apoptose-Mechanismen der ATN gelten zytotoxische Mechanismen, ein Mangel an Wachstumsfaktoren (IGF) und ein Verlust der Zellpolarität. Zusätzlich ist eine direkte rezeptorvermittelte Induktion der Apoptose über TNF $\alpha$ oder Fas (CD95) induzierbar (Bonventre 1993). 


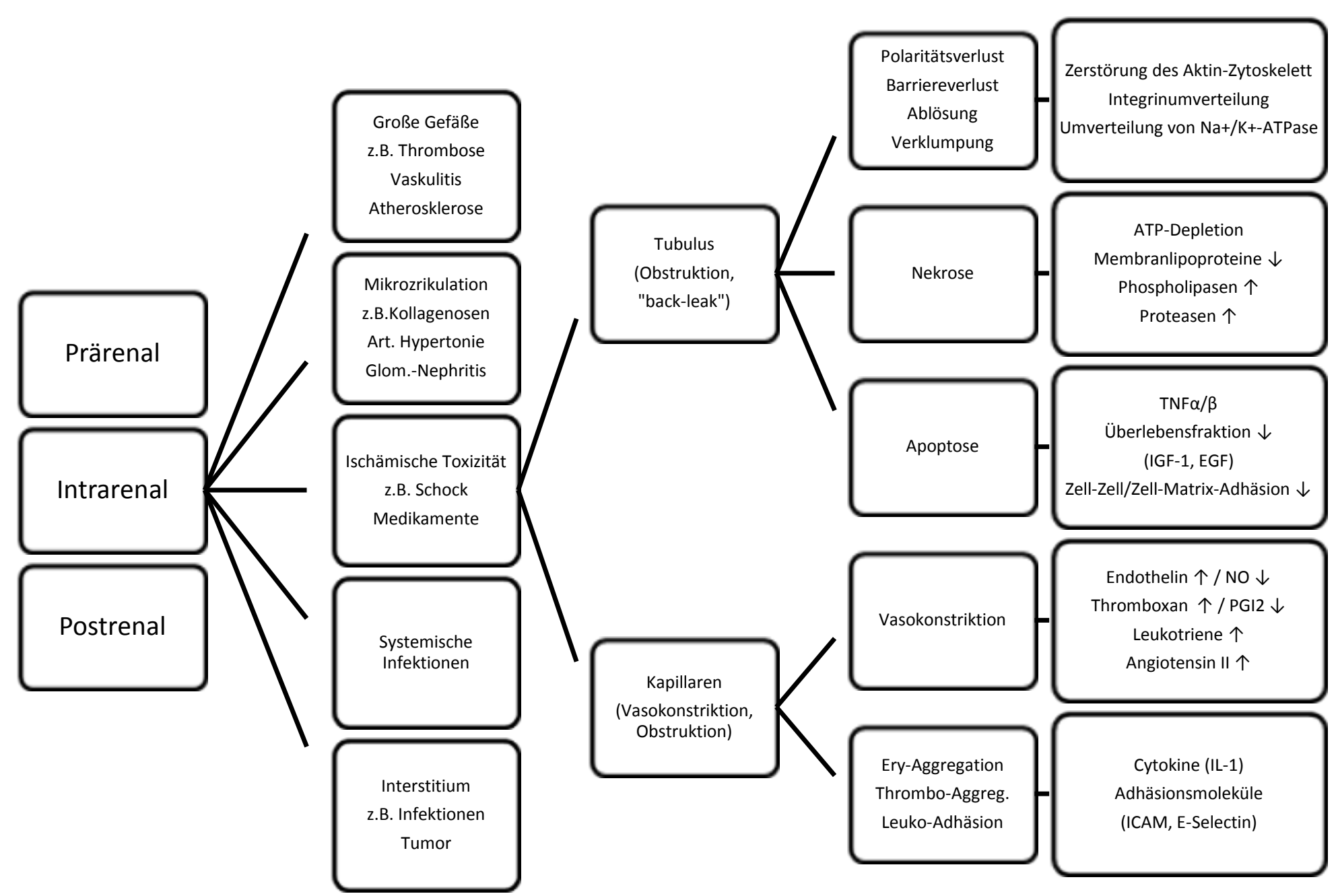

Abbildung 1: Schematische Darstellung der pathophysiologischen Aspekte des akuten Nierenversagens (modifiziert nach Haller und Schelling 2000, S. 350) 


\subsection{Milde therapeutische Hypothermie}

Bereits im frühen 19. Jahrhundert bemerkte der Leibarzt Napoleons I. Baron Larrey, dass schwer verwundete Soldaten, die näher am Feuer lagen, früher an ihrem Trauma verstarben als Soldaten, welche nicht gewärmt wurden (Larrey 1814). Erste klinische Fallbeschreibungen folgten jedoch erst 1940 mithilfe zahlreicher Tierexperimente. Sie zeigten auf, dass durch eine induzierte Hypothermie Zellschädigungen als Folge einer Ischämie und Reperfusion eingedämmt bzw. verhindert werden konnten. Eine klinische Anwendung konnte jedoch aufgrund unbeherrschbarer Nebenwirkungen und der damals eingeschränkten intensivmedizinischen Interventionen nicht durchgeführt werden. In den 1980er und 1990er Jahren konnten erstmals experimentelle Studien mit milder Hypothermie $\left(32-34{ }^{\circ} \mathrm{C}\right)$ nach kardiopulmonaler Reanimation eine bessere Überlebensrate aufzeigen (Sterz et al. 1991). Ursächlich hierfür waren zum einen die weniger ausgeprägten Nebenwirkungen durch eine moderatere Kühlung sowie die Weiterentwicklung in der intensivmedizinischen Behandlung schwerer Komplikationen. Welchen hohen Stellenwert die mHT für die neuroprotektive Wirkung hat, legte die „Hypothermia After Cardiac Arrest Study Group“ (HACA) sowie eine weitere prospektive Studie im Jahr 2002 nahe (HACA 2002, Bernard et al. 2002). In diesen Studien konnte gezeigt werden, dass bereits eine kurze Anwendung der mHT bei Patienten mit postanoxischem Koma nach primärem Herzkreislaufstillstand in bestimmten Fällen zu einer Verbesserung des neurologischen Outcomes führt (Brüx et al. 2005). Auf diesen Ergebnissen basierend führte die International Liaison Committee on Resuscitation (ILCOR) 2003 die milde therapeutische Hypothermie als Therapiekonzept in der Postreanimationsphase ein (Nolan 2003). Im Jahr 2005 erfolgte durch die American Heart Association die Implementierung der milden Hypothermie in die European Resusictation Council (ERC)-Richtlinien (Nolan et al. 2005).

\subsubsection{Allgemeine Grundlagen der Hypothermie}

Die Körperkerntemperatur (KKT) ist als Bluttemperatur im Hypothalamus definiert und unterliegt einer zirkadianen Schwankung von 0,6-1 ${ }^{\circ} \mathrm{C}$ mit ihrem Maximum zwischen 17:00 und 19:00 Uhr. Als klinischer Standard gilt ein an der A. pulmonalis gemessener Normwert von $36,8 \pm 0,38{ }^{\circ} \mathrm{C}$. Organspezifisch und stoffwechselbedingt treten Temperaturschwankungen von $0,2-1,2{ }^{\circ} \mathrm{C}$ im Körperkern auf. Übersteigt die Wärmeabgabe langfristig die endogene Wärmeproduktion, kommt es zur Absenkung der KKT unterhalb des Normbereiches. Dieser 
Zustand wird als hypotherm bezeichnet (Gekle und Singer 2014). Je nach Grad der Unterschreitung erfolgt eine Einteilung der Unterkühlung nach SAFAR et al. (2000) in fünf Stadien (Tab. 2). Auslöser einer Hypothermie können akzidentell, durch Funktionsstörungen im Hypothalamus oder therapeutisch induziert sein. Der Körper reagiert auf diese Normabweichung und versucht, dies durch diverse Mechanismen, wie z. B. das Kältezittern, zu kompensieren.

\begin{tabular}{|c|c|}
\hline Hypothermieeinteilung & Zieltemperatur $\left({ }^{\circ} \mathrm{C}\right)$ \\
\hline Mild & $32-34$ \\
Mäßig & $28-32$ \\
Tief & $15-28$ \\
Profund & $5-15$ \\
Ultraprofund & $>5$ \\
\hline
\end{tabular}

Tabelle 2: Einteilung der Hypothermiegrade (nach Safar et al. 2000)

\subsubsection{Klinische Grundlagen der milden Hypothermie}

Die mHT findet bereits in der Notfall- und Intensivmedizin sowie bei langwierigen Operationen Anwendung. Laut ERC sollen alle Patienten, welche einen Herz-Kreislaufstillstand durch ventrikuläres Kammerflimmern erleiden, nach der erfolgreichen Wiederherstellung des Spontankreislaufes (resuscitation of spontaneous circulation $=$ ROSC) und fortbestehendem Bewusstseinsverlust gekühlt werden. Das Postreanimationsprozedere beinhaltet dabei eine schnellstmögliche Kühlung auf eine Zieltemperatur von $32-34{ }^{\circ} \mathrm{C}$ über einen Zeitraum von 12-24 Stunden (Nolan et al. 2005). Für Patienten, die nicht in diese Gruppe fallen, gibt das ERC keine genaue Empfehlung. Es wird jedoch davon ausgegangen, dass diese Patienten ebenfalls von der Maßnahme profitieren (Deakin et al. 2010). Bei der Umsetzung dieser therapeutischen Maßnahme unterscheidet man grundsätzlich zwei Verfahren. Die oberflächliche Kühlung mittels Eispacks oder Kühldecken folgt dem Prinzip der transdermalen Senkung der Körpertemperatur. Sie bietet den Vorteil, dass sie ohne großen Aufwand fast omnipräsent verfügbar ist. Es besteht jedoch eine sehr begrenzte Steuerbarkeit. Invasive Kühlverfahren beruhen auf dem Prinzip der intravasalen Kühlung mittels kalter Infusionen oder via moderner Kühlkatheter. Diese Methode bietet den Vorteil einer optimalen Steuerbarkeit bei schneller Erreichbarkeit der Zieltemperatur und findet aus diesem Grund meist ihren Einsatz in der intensivmedizinischen Behandlung (Hoedemaekers et al. 2007). 
Als optimaler Zeitpunkt der Kühlung gilt ein möglichst rascher Beginn, jedoch konnten Studien keinen signifikanten Prognoseunterschied bezüglich des Zeitpunktes des Erreichens der Zieltemperatur und der verwendeten Methode konstatieren (Wolff et al. 2009, Hoedemaekers et al. 2007).

Aufgrund von Elektrolytverschiebungen und einer veränderten Stoffwechsellage, besonders während der Kühlungs- und Wiedererwärmungsphase, ist eine kontinuierliche Monitorüberwachung indiziert. In der Hypothermiephase kann es zu Kältezittern der Patienten kommen, was zu einem verzögerten Erreichen der Zieltemperatur und Steigerung des Stoffwechsels führt. Mittels Muskelrelaxantien und Sedierung lassen sich diese Kompensationsmechanismen verhindern - sie sollten frühzeitig verabreicht werden (Mahmood und Zweifler 2007). Die Wiedererwärmung der Patienten sollte aufgrund der hohen Komplikationsrate nicht schneller als $0,25-0,5^{\circ} \mathrm{C}$ pro Stunde erfolgen, da es wie in der Induktionsphase zu schweren, nicht beherrschbaren Gegenreaktionen kommen kann. Während der Hypothermie ist zu beachten, dass der Stoffwechsel verlangsamt und die renale Elimination reduziert ist. Dadurch sollte eine Anpassung der Medikamentendosis um bis zu $30 \%$ vorgenommen werden (Tortorici et al. 2007). Als generelle Ausschlusskriterien gelten eine Sepsis, ein Multiorganversagen und eine bereits bestehende Gerinnungsstörung (Deakin et al. 2010).

\subsubsection{Physiologische Effekte der milden Hypothermie}

Grundsätzlich können die Effekte der mHT in zwei Gruppen gegliedert werden. Einige Effekte beruhen auf dem Prinzip der Gegenregulation und Aufrechterhaltung der Normothermie. Die Aktivierung des vegetativen Nervensystems zur Steigerung des Stoffwechsels und Aktivierung der Muskelarbeit zählen zu diesen Effekten. Sie werden aufgrund der negativen Auswirkung meist medikamentös unterdrückt und spielen somit eine untergeordnete Rolle (Brüx et al. 2005).

Die zweite Gruppe beinhaltet Mechanismen, welche auf zellulärer Ebene stattfinden und wahrscheinlich für die protektive Wirkung der milden Hypothermie verantwortlich sind. Laut POPP et al. (2005) zählen zu diesen folgende:

- Reduktion des Zellmetabolismus: Die milde Hypothermie reduziert den generellen Zellmetabolismus und folglich den Sauerstoff- und Glukoseverbrauch. Eine Absenkung der Temperatur verringert den neuronalen Bedarf von Sauerstoff und Glukose um etwa 5-7 \%/ ${ }^{\circ} \mathrm{C}$ (Rosomoff und Holaday 1954). Dies führt zu einer 
längeren Verfügbarkeit der ATP-Reserven und verminderter Anreicherung der Metabolite Laktat und Pyruvat in der Zelle (Nillson et al. 1975).

- Reduktion der Apoptose: Mehrere Studien konnten zeigen, dass eine vermehrte Aktivierung von Proteasen und Caspasen nach Herz-Kreislaufstillstand eine Induktion des programmierten Zelltodes hervorruft. Die Hypothermie führt zu einer frühen direkten Inhibition der Caspasen sowie zu einer Verminderung der mitochondrialen Dysfunktion und konsekutiv zu einer indirekten Reduktion der Caspasen-Aktivität (Xu et al. 2002).

- Reduktion freier Radikale: Eine Reduktion der zumeist in der Reperfusionsphase entstehenden hochreaktiven freien Radikalen führt zu einer Verminderung unspezifischer Oxidation von intrazellulären Proteinen, Lipiden und Nukleinsäuren (Agardh et al. 1991). Der Grad der Reduktion an freien Radikalen ist annähernd linear zur Temperaturabnahme. Dies bedeutet: Je niedriger die Zieltemperatur ist, desto geringer ist der Anteil an freien Radikalen (Novack et al. 1996).

- Reduktion exzitatorischer Neurotransmitter und Ionenpumpen: Eine übermäßige Freisetzung von Glutamat und Aspartat in den synaptischen Spalt führt über eine Bindung am Neurotransmitter (NMDA-Rezeptor) zu einer intrazellulären Kalziumakkumulation. Aufgrund der ATP-Depletion in der ischämischen Phase können die $\mathrm{Na}^{+}-\mathrm{K}^{+}$-ATPase den Konzentrationsgradienten nicht mehr aufrecht erhalten und es kommt zu einer Kalziumüberladung in der Zelle. Ebendiese führt zu einer Aktivierung von Caspasen, Proteasen und mitochondrialer Dysfunktion. Zusätzlich bedingt der hohe intrazelluläre Kalziumgehalt die Induktion von ,immediate early genes“, die eine Depolarisierung der Zellmembran verursacht und eine weitere Freisetzung von exzitatorischen Neurotransmittern in den extrazellulären Raum nach sich zieht (Seisjö et al. 1989).

- Reduktion der Immunantwort: In einigen tierexperimentellen und klinischen Studien zeigte sich, dass die mHT die ischämiebedingte Entzündungsreaktion sowie Freisetzung von proinflammatorischen Zytokinen supprimiert. Eine besondere Bedeutung hat hierbei die Gruppe der Interleukine (Beilin et al. 1998). Zusätzlich verhindert die 
Kühlung eine Aktivierung der neutrophilen Granulozyten, der Makrophagen und reduziert nachweislich die Anzahl weißer Blutkörperchen im Blut (Polderman 2009).

- Reduktion von intra- und extrazellulären, sauren Valenzen: Der Integritätsverlust der Zellmembran, die Fehlfunktion von Ionenpumpen, die mitochondriale Dysfunktion und ein überproportionaler Anstieg der Enzymaktivität in der Zelle führt zum Anstieg des intrazellulären pH-Wertes. Konsekutiv kommt es zur Verstärkung einiger zuvor aufgeführter Mechanismen, welche jedoch durch die milde Hypothermie signifikant abgeschwächt wird. Zusätzlich reduziert die therapeutische Hypothermie die Bildung von Laktat während der Reperfusionsphase und vermindert somit eine extrazelluläre Azidose (Polderman 2009).

- Reduktion von Mikrothrombopathien: Die durch einen Herz-Kreislaufstillstand verursachte erhöhte Koagulationsneigung kann bereits durch eine Kühlung auf $\leq 35,0^{\circ} \mathrm{C}$ zu einer milden Plättchenfunktionsstörung führen und somit Mikrozirkulationsstörungen verhindern. $\mathrm{Ab}$ einer Temperatur $\leq 33,0{ }^{\circ} \mathrm{C}$ wird dieser Mechanismus durch eine Inhibition weiterer Gerinnungsfaktoren verstärkt. Zusätzlich kommt es zu einer direkten Reduktion von Thrombozyten während der milden Hypothermie (Polderman und Herold 2009).

- Reduktion von vasoaktiven Mediatoren: Obwohl die exakten Mechanismen nicht genau geklärt sind, wird angenommen, dass durch die moderate Hypothermie (32$33^{\circ} \mathrm{C}$ ) nach Schädelhirntrauma eine Reduktion von Prostanoiden auftritt. Insbesondere konnte das in der Postreanimationsphase entstehende Ungleichgewicht zwischen Thromboxan $\mathrm{A}_{2}$, einem starken Vasokonstriktor, und dem Vasodilator Prostaglandin $I_{2}$ verhindert werden (Aibiki et al. 2000). Eine Abnahme des vasokonstriktorischen Endothelin-1 wurde ebenfalls beobachtet (Chen et al. 2001).

Es wird vermutet, dass die physiologischen Mechanismen der Hypothermie wesentlich vielschichtiger sind als angenommen und eine genaue Entschlüsselung der Abläufe zum jetzigen Zeitpunkt nicht gegeben ist. Weitere Faktoren, auf die in dieser Arbeit nicht weiter eingegangen werden soll, sind in Abbildung 2 veranschaulicht. 


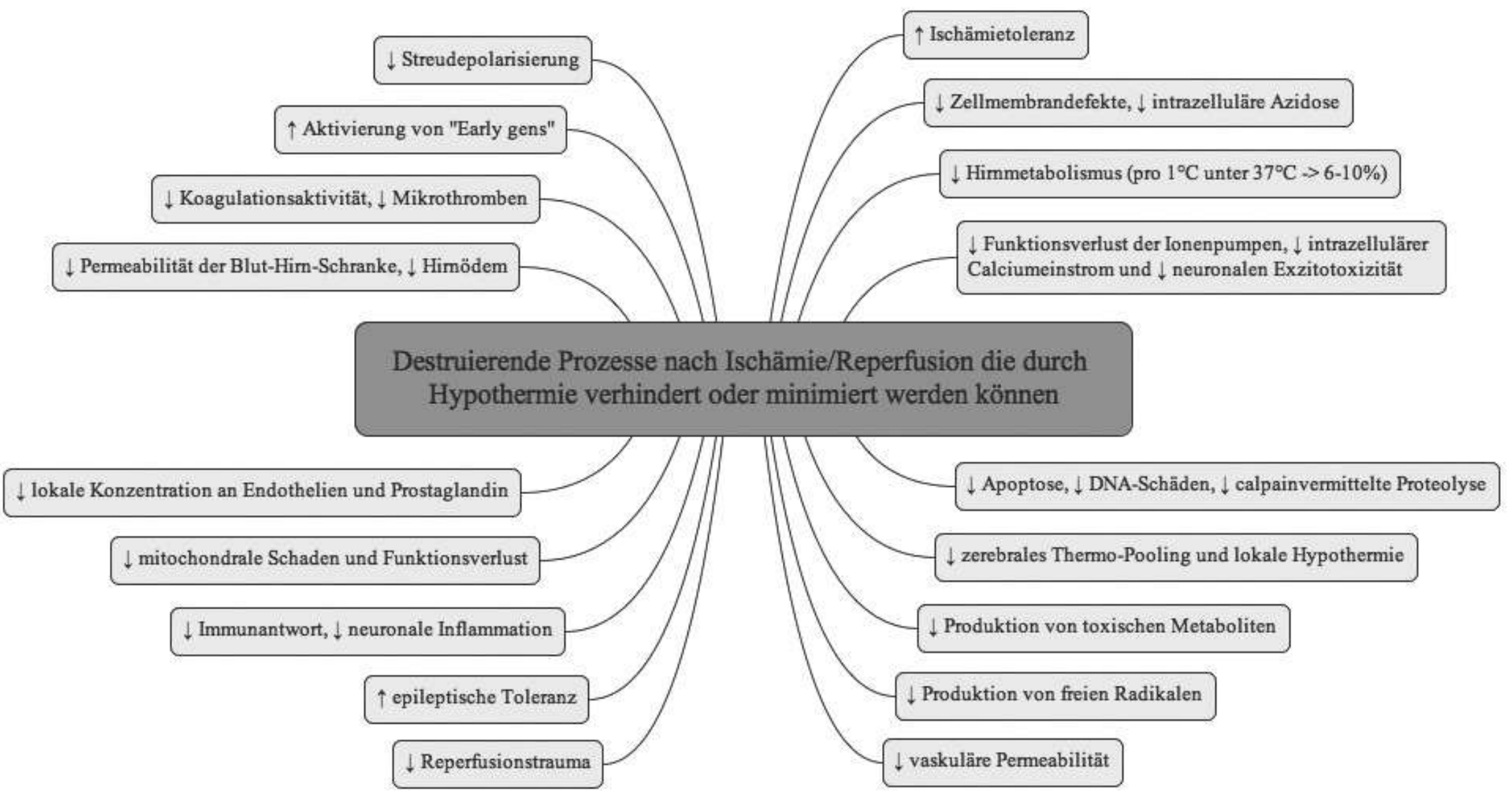

Abbildung 2: Schematische Darstellung der pathophysiologischen Effekte der milden therapeutischen Hypothermie (nach Polderman und Herold 2009, S. 1108) 


\subsection{APACHE-Score}

Der Acute Physiology and Chronic Health Evaluation Score (APACHE) dient als ein Instrument zur Abschätzung der Erkrankungsschwere von adulten Patienten auf Intensivstationen und bietet in diesem Kontext eine Aussage über die Mortalitätswahrscheinlichkeit. Er wurde erstmals im Jahre 1981 von KNAUS et al. publiziert. Die 1985 veröffentlichte erweiterte Version (APACHE II-Score) entwickelte sich $\mathrm{zu}$ einem der gebräuchlichsten Mortalitätsscores in der Intensivmedizin (Bierbrauer et al. 1998). Die Bewertung bedient sich vier differenter Bereiche, bei denen physiologische und biochemische Parameter mit Punktzählern belegt werden und bezüglich ihrer Abweichung vom Normalwert bewertet werden. Die vier Eingabebereiche nehmen Bezug auf den akuten physiologischen Gesundheitszustand, das Alter, die Bewusstseinslage sowie vorbestehende chronische Erkrankungen. Es fließen jeweils die schlechtesten Werte der ersten 24 Stunden in die Berechnung ein (Knaus et al. 1985).

- Akuter Physiologie-Score: Dieser berechnet sich aus den schlechtesten elf physiologischen und biochemischen Parametern innerhalb der ersten 24 Stunden nach Aufnahme auf der Intensivstation. Die präzise Berechnungsgrundlage visualisiert Tabelle 3.

\begin{tabular}{|c|c|c|c|c|c|c|c|c|c|}
\hline \multirow{2}{*}{$\begin{array}{l}\text { Erhobene Werte } \\
\text { Punkte }\end{array}$} & \multicolumn{9}{|c|}{ «- Nach oben abweichend } \\
\hline & 4 & 3 & 2 & 1 & $\mathbf{0}$ & 1 & 2 & 3 & 4 \\
\hline Temp. rektal ${ }^{\circ} \mathbf{C}$ & $\geq 41$ & $39-40,9$ & & $38,5-38,9$ & $36-38,4$ & $34-35,9$ & $32-33,9$ & $30-31,9$ & $\leq 29,9$ \\
\hline Art. Mitteldruck mmHg & $\geq 160$ & $130-159$ & $110-129$ & & 70-109 & & $50-69$ & & $\leq 49$ \\
\hline Herzfrequenz/min & $\geq 180$ & $140-179$ & $110-139$ & & 70-109 & & $55-69$ & $40-54$ & $\leq 39$ \\
\hline Atemfrequenz/min & $\geq 50$ & $35-49$ & & $25-34$ & 24-12 & $11-10$ & $9-6$ & & $\leq 5$ \\
\hline \multirow[t]{2}{*}{ Oxygenierung ${ }^{1)}$} & $\geq 500$ & $350-499$ & 200-349 & & $<200$ & & & & \\
\hline & & & & & $>70$ & $61-70$ & & $55-60$ & $<55$ \\
\hline pH & $\geq 7,7$ & $7,6-7,69$ & & $7,5-7,59$ & $7,33-7,49$ & & $7,25-7,32$ & $7,15-7,24$ & $<7,15$ \\
\hline Serum-Na ${ }^{+}$ & $\geq 180$ & $160-179$ & $155-159$ & $150-154$ & $130-149$ & & $120-129$ & $111-119$ & $\leq 110$ \\
\hline Serum- $\mathbf{K}^{+}$ & $\geq 7$ & $6,6-6,69$ & & $5,5-5,59$ & $3,5-5,4$ & $3,0-3,4$ & $2,5-2,9$ & & $\leq 2,5$ \\
\hline Serum-Kreatinin mg/dl ${ }^{2)}$ & $\geq 3,5$ & $2,0-3,4$ & $1,5-1,9$ & & $0,6-1,4$ & & $<0,6$ & & \\
\hline Hämatokrit \% & $\geq 60$ & & $50-59,9$ & $46-49,9$ & $30-45,9$ & & $20-29,9$ & & $<20$ \\
\hline 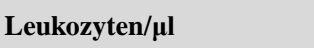 & $\geq 40 \mathrm{~T}$ & & $20-39,9 \mathrm{~T}$ & $15-19,9 \mathrm{~T}$ & $3-14,9 \mathrm{~T}$ & & $1-2,9 \mathrm{~T}$ & & $<1 \mathrm{~T}$ \\
\hline
\end{tabular}

Tabelle 3: Physiologische und biochemische Bewertungsparameter des APACHE II-Scores.

1) Falls die $\mathrm{FiO}_{2} \geq 0,5$ ist, muss die Alveolo-arterielle Sauerstoffdifferenz (AaDO2) berücksichtigt werden.

${ }^{2)}$ Bei einem akuten Nierenversagen (ANV) ist die Punktzahl zu verdoppeln (nach Knaus et al. 1985). 
- Patientenalter: Bei einem Lebensalter $\geq 45$ Jahre erhält der Patient entsprechend der Tabelle 4 zusätzliche Punkte.

\begin{tabular}{|c|c|}
\hline Alter & Punkte \\
\hline$\leq 44$ & 0 \\
$45-54$ & 2 \\
$55-64$ & 3 \\
$65-74$ & 5 \\
$\geq 75$ & 6 \\
\hline
\end{tabular}

Tabelle 4: Altersbewertung für den APACHE II-Scores (nach Knaus et al. 1985)

- Bewusstseinslage: Die Glasgow Coma Scale (GCS) wird zur Beurteilung der Bewusstseinslage herangezogen (Teasdale und Jennett 1974). Er berücksichtigt die Fähigkeit, die Augen zu öffnen, eine verbale Antwort $\mathrm{zu}$ formulieren sowie die Beurteilung der motorischen Fähigkeit. Es kann eine maximale Punktzahl von 15 Punkten und eine minimale Punktzahl von 3 Punkten erreicht werden. Eine Punktzahl kleiner als 9 Punkte gilt als Hinweis für eine schwere Hirnfunktionsstörung (Schwab et al. 2012). Die in den APACHE II-Score einfließende Punktzahl ergibt sich aus 15 (maximaler GCS) minus dem erreichten GCS. Die präzise Berechnungsgrundlage veranschaulicht Tabelle 5.

\begin{tabular}{|l|c|}
\hline Augen Öffnung & Punkte \\
\hline spontan & 4 \\
Aufforderung & 3 \\
Schmerz & 2 \\
keine & 1 \\
\hline
\end{tabular}

\begin{tabular}{|l|c|}
\hline Verbale Antwort & Punkte \\
\hline orientiert & 5 \\
desorientiert & 4 \\
inadäquat & 3 \\
unverständlich & 2 \\
keine & 1 \\
\hline
\end{tabular}

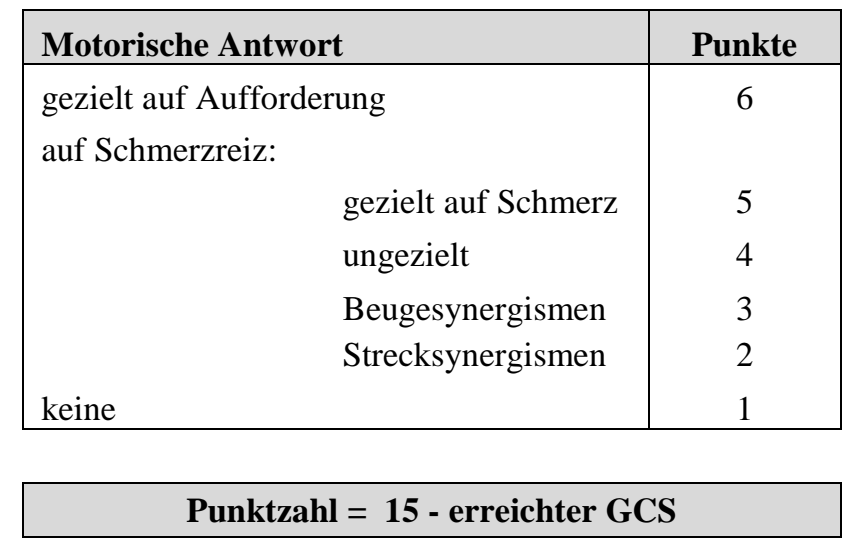

Tabelle 5: Berechnungsmethodik des Glasgow Coma Scale (nach Teasdale et Jennett 1974) 
- Chronische Erkrankungen: Vorbestehende chronische Erkrankungen, wie eine schwere Organinsuffizienz oder eine Immunschwäche, werden unter Berücksichtigung einer operativen Notwendigkeit bewertet. Es werden nach KNAUS et al. (1985) fünf unterschiedliche Grunderkrankungen berücksichtigt:

○ Leber: Als Leberinsuffizienz zählt eine durch Biopsie gesicherte Zirrhose in Kombination mit einem diagnostizierten portalen Hochdruck. Eine bekannte Blutung des oberen Gastrointestinaltraktes, ausgehend von einer Episode mit hepatischer Insuffizienz, einem hepatischen Koma oder einer hepatischen Enzephalopathie.

○ Kardiovaskulär: Eine nach New York Health Association Class IV (NYHA 4) vordiagnostizierte Herzinsuffizienz.

○ Atmung: Eine chronisch obstruktive, restriktive oder gefäßbedingte Erkrankung der Lunge, die bei leichten Aufgaben mit einer schweren Einschränkung einhergeht (z. B. hauswirtschaftliche Tätigkeiten oder Treppensteigen). Sowie eine vordiagnostizierte chronische Hyperkapnie, Hypoxie, massive pulmonale Hypertension (> $40 \mathrm{mmHg}$ ), erworbene Polyzystämie oder die Abhängigkeit von einer mechanischen Beatmung.

○ Niere: Eine Nierenfunktionsstörung mit chronischer Dialysepflichtigkeit.

○ Immunschwäche: Der Patient hat in der Vorgeschichte eine immunsuppressive Therapie erhalten (z.B. Bestrahlung, Chemotherapie, hochdosierte oder langfristige Steroide) oder eine Erkrankung, welche mit einer Immunschwäche einhergeht (z. B. AIDS, Lymphom, Leukämie).

\begin{tabular}{|c|c|c|}
\hline Operativer Status & Gesundheitsstatus & Punkte \\
\hline \multirow{2}{*}{ nicht operiert } & $\begin{array}{l}\text { Vorgeschichte mit schwerer Organinsuffizienz oder Immun- } \\
\text { schwäche }\end{array}$ & 5 \\
\hline & $\begin{array}{l}\text { Keine Vorgeschichte mit schwerer Organinsuffizienz oder Im- } \\
\text { munschwäche }\end{array}$ & 0 \\
\hline \multirow{2}{*}{$\begin{array}{l}\text { postoperativer Patient nach } \\
\text { elektivem Eingriff }\end{array}$} & $\begin{array}{l}\text { Vorgeschichte mit schwerer Organinsuffizienz oder Immun- } \\
\text { schwäche }\end{array}$ & 5 \\
\hline & $\begin{array}{l}\text { Keine Vorgeschichte mit schwerer Organinsuffizienz oder Im- } \\
\text { munschwäche }\end{array}$ & 0 \\
\hline \multirow{2}{*}{$\begin{array}{l}\text { postoperativer Patient nach } \\
\text { Notfall-OP }\end{array}$} & $\begin{array}{l}\text { Vorgeschichte mit schwerer Organinsuffizienz oder Immun- } \\
\text { schwäche }\end{array}$ & 5 \\
\hline & $\begin{array}{l}\text { Keine Vorgeschichte mit schwerer Organinsuffizienz oder Im- } \\
\text { munschwäche }\end{array}$ & 0 \\
\hline
\end{tabular}

Tabelle 6: Bewertungsskala des chronischen Gesundheitsstatus. Eine Organinsuffizienz oder immunsupprimierter Zustand muss vor dem gegenwärtigen Krankenhauszustand bekannt gewesen sein (nach Knaus et al. 1985). 
Die addierte Gesamtpunktzahl der vier Teilscores ermöglicht eine Aussage hinsichtlich der Mortalitätswahrscheinlichkeit. Minimal ist eine Punktzahl von 0 Punkten und maximal eine Punktzahl von 71 Punkten zu erreichen. Prinzipiell geht ein hoher Score mit einer schlechten Überlebenswahrscheinlichkeit einher (siehe Tabelle 7).

Die Testgüte des APACHE II-Scores wird mit eine Spezifität von > $98 \%$ und einer Sensitivität von ca. $80 \%$ angegeben (Knaus et al. 1985).

\begin{tabular}{|l|c|c|c|c|c|c|c|c|}
\hline Punktzahl & $0-4$ & $5-9$ & $10-14$ & $15-19$ & $20-24$ & $25-29$ & $30-34$ & $>34$ \\
\hline Todesrate & $4 \%$ & $8 \%$ & $15 \%$ & $25 \%$ & $40 \%$ & $55 \%$ & $75 \%$ & $85 \%$ \\
\hline
\end{tabular}

Tabelle 7: Prozentuale Überlebenswahrscheinlichkeit kategorisiert nach erreichter Punktzahl (nach Knaus et al. 1985) 


\subsection{Fragestellung}

Seit Einführung der milden therapeutischen Hypothermie in das Behandlungskonzept von Patienten nach erfolgreicher kardiopulmonaler Reanimation zeigten sich vermehrt Indizien, dass durch die Therapie möglicherweise das Auftreten eines akuten Nierenversagens nach ROSC positiv beeinflusst oder sogar verhindert werden kann. Pathophysiologisch ist das akute Nierenversagen vermutlich durch ähnliche Mechanismen der initialen systemischen Ischämie und nachfolgender Zunahme der Apoptoserate in der Reperfusionsphase bedingt (Lameire et al. 2005). Bisher publizierte Studien zeigen diesbezüglich kein eindeutiges Ergebnis. In der HACA-Studie (2002) trat ein akutes Nierenversagen als Komplikation in beiden Kohorten gleich häufig auf. In einer kleinen unkontrollierten Pilotstudie konnte jedoch eine Reduktion des Serum-Kreatinins unter milder therapeutischer Hypothermie von ca. $40 \%$ innerhalb von 36 Stunden beobachtet werden (Zeiner et al. 2000).

Das Hauptziel dieser retrospektiven Studie ist es, die Auftretenswahrscheinlichkeit von Nierenfunktionsstörungen nach präklinischer oder klinischer kardiopulmonaler Reanimation und induzierter milder therapeutischer Hypothermie im Vergleich zu einem Kontrollkollektiv ohne dieses Verfahren zu evaluieren. In der vorliegenden Arbeit sollen folgende Fragen eruiert werden.

1. Beeinflusst die mHT die Inzidenz des akuten Nierenversagens und in welchem Maße ist der Effekt von den Kofaktoren (Geschlecht, Diabetes mellitus (DM), Risikofaktoren) abhängig?

2. Hat die mHT einen Einfluss auf die Auftretenswahrscheinlichkeit des chronischen Nierenversagens und inwieweit ist dieser von den gegebenen Kofaktoren abhängig?

3. Welchen Einfluss übt die mHT auf die errechnete glomeruläre Filtrationsrate (GFR) aus und wie stellt sich der Verlauf in Abhängigkeit von der Zeit und den Kofaktoren dar? 


\section{Studiendesign und Methoden}

\subsection{Allgemeines}

In der vorliegenden retrospektiven Studie wurden Fälle evaluiert, in denen eine kardiopulmonale Reanimation mittels Thoraxkompression und/oder Defibrillation, ggf. in Kombination mit einer künstlichen Beatmung und der Applikation von Notfallmedikamenten, durchgeführt wurde. Die Durchführung erfolgte gemäß der zum Zeitpunkt jeweils geltenden Leitlinien des „European Resuscitation Council“.

Die therapeutische Hypothermie erfolgte nach den Richtlinien des Standard Operating Procedure (SOP) und gliedert sich in eine Induktionsphase, eine Phase der Aufrechterhaltung und eine Wiedererwärmungsphase. In der Induktionsphase wurde eine schnellstmögliche Senkung der Körperkerntemperatur auf $32-34{ }^{\circ} \mathrm{C}$ angestrebt. Diese wurde mittels $4{ }^{\circ} \mathrm{C}$ kalten Infusionslösungen $(30 \mathrm{ml} / \mathrm{kgKG})$, speziellen Kühlkathertersystemen (Coolgard) oder oberflächlichen Kühl- und Eisdecken (Arctic Sun) erreicht. Zusätzlich wurden zur Prophylaxe von Komplikationen (Kältezittern) Muskelrelaxantien in Kombination mit Sedativa appliziert. Die Aufrechterhaltungsphase verlief über einen Zeitraum von 12-24 Stunden und hatte zum Ziel, die KKT mithilfe der suppurativen Maßnahmen konstant zwischen dem Temperaturbereich von $32-33{ }^{\circ} \mathrm{C}$ zu halten. Nach Ablauf des Therapiezeitraumes erfolgte die langsame $\left(0,25-0,5^{\circ} \mathrm{C} / \mathrm{h}\right)$ passive oder aktive Wiedererwärmung der Patienten (GRC 2012). Eine Differenzierung zwischen oberflächlicher oder invasiver Kühltechnik wurde für die vorliegende Studie nicht vorgenommen. 


\subsection{Patientenkollektiv}

Im Rahmen der vorliegenden Studie wurden die Daten von 437 Patienten mit Zustand nach präklinischer und innerklinischer kardiopulmonaler Reanimation im Zeitraum vom 30.10.1998 bis zum 17.04.2011, welche in der Universitätsmedizin Göttingen (UMG) auf der Interdisziplinären Notaufnahme aufgenommen wurden, ausgewertet. Einschlusskriterien waren zum Zeitpunkt des Ereignisses Patienten mit Zustand nach präklinischer und innerklinischer kardiopulmonaler Reanimation mit einem Mindestalter von 18 Jahren. Es wurden alle vier Arten des Herz-Kreislaufstillstandes (Asystolie, pulslose elektrische Aktivität, pulslose ventrikuläre Tachykardie und Kammerflimmern) mit einbezogen. Ein generelles Ausschlusskriterium bestand nicht.

Das Gesamtkollektiv wurde in ein Patientenkollektiv, bei dem eine mHT nach ROSC initiiert wurde, sowie in ein Kontrollkollektiv ohne durchgeführte Kühlung unterteilt. Das Kontrollkollektiv beinhaltet ausschließlich Patienten vor Einführung der ERC-Richtlinien 2003 sowie Patienten, bei denen nach aktuellem Standard keine Kühlung indiziert oder möglich war. 


\subsection{Klinische Datenerhebung}

Grundlage der Analyse waren die Patientenakten der UMG. Diese beinhalten das entsprechende präklinische Notarzt-Protokoll der Einsätze inklusive des Reanimationsprotokolles sowie die innerklinische Dokumentation.

Die Erfassung erfolgte retrospektiv mittels Einsicht in die archivierten Akten. Hierzu wurden Notarzt-Protokolle, Aufnahmebögen, Verlaufskurven, intensivmedizinische Kurven, Laborund Blutgasanalyse-Ergebnisse, konsiliarische Befunde und Arztbriefe herangezogen sowie ausgewertet. Die erhobenen Verlaufsdaten dienten der Erstellung einer eigenen Cardiopulmonary-Resuscitation (CPR)-Datenbank, welche mithilfe von Microsoft Excel® erstellt wurde und die sämtliche studienrelevanten Informationen beinhaltete. Die Patientenerfassung und -auswertung erfolgte ausschließlich in pseudonymisierter Form mittels einer fortlaufenden Nummer. Die Untersuchungsbefunde sind in der Akte verblieben und eine Re-Identifikation ist ausschließlich für den Projektleiter möglich. Die retrospektive Studie wurde auf der Grundlage und nach Erhalt des positiven Votums der Ethikkommission Göttingen (Antragsnr. 7/8/11) durchgeführt.

Die beiden Kollektive wurden nach der gleichen Vorgehensweise ausgewertet. Folgende Daten wurden erhoben.

- Alter: Alter des Patienten zum Zeitpunkt der Reanimation. Es wird berechnet aus dem Datum der kardiopulmonalen Reanimation minus dem Geburtsdatum geteilt durch 365,2425 Tage. Dies ergibt das Alter inklusive der durchschnittlichen Schaltjahre. Die Angabe erfolgt in Lebensjahren.

- Geschlecht: Klassifikation anhand des biologischen Geschlechtes. Männliche Patienten wurden mit der Kodierung 0 und weibliche Patienten mit der Kodierung 1 versehen.

- Aufnahmedatum: Zeitpunkt der Aufnahme auf der Interdisziplinären Notaufnahme, den Normalstationen oder der Intensivstation (1022, 1026), der im Krankenhausinformationssystem dokumentiert ist. 
- ICU Verweildauer: Anzahl der Tage, welche der jeweilige Patient auf der Intensivstation verbrachte. Das Ende ist definiert als Verlegung auf eine Normalstation oder die Entlassung in eine andere Klinik, Rehabilitationseinrichtung oder nach Hause. Für während des Aufenthalts verstorbene Patienten gilt der Todestag als Entlassungstag.

- Ursache der CPR: Ursache der kardiopulmonalen Reanimation laut NotarztProtokoll oder Arztbrief.

- Patientenvorgeschichte: Diagnosen aus vorangegangenen Arzt-, Verlegungs- und Entlassungsbriefen inklusive der Ursache für die CPR.

- DM: gibt Auskunft über eine vordiagnostizierte DM-Erkrankung. Es fand keine Differenzierung zwischen Typ I- und Typ II-DM statt. Die Kodierung erfolgte für Diabetiker $=1$ und für Studienteilnehmer ohne vorbekannten $\mathrm{DM}=0$.

- Risikofaktoren: Faktoren, die das Auftreten eines chronischen Nierenversagens (CKI) begünstigen können. Zu den klinischen Faktoren, welche das Risiko erhöhen, zählen laut „The National Kidney Foundation KDOQI CKD Guidelines“ folgende Erkrankungen: DM, Hypertonie, Autoimmunerkrankungen, systemische Infektionen, Harnwegsinfektionen, Harnwegssteine, untere Harnwegsobstruktionen, Neoplasien, ein CKI in der Familiengeschichte, ein ANV in der Vorgeschichte, verminderte Nierengröße, einige Medikamente und ein niedriges Geburtsgewicht (Levey et al. 2003). Zusätzlich existieren soziodemografische Faktoren, welche mit dem Auftreten des CKI korrelieren. $\mathrm{Zu}$ diesen zählen: Hohes Alter, die ethnische Herkunft, der Kontakt mit einigen Chemikalien und kontaminierten Umgebungen sowie ein geringer sozioökonomischer Status. Limitiert durch das retrospektive Studiendesign war es nicht möglich, alle Faktoren zu erheben und die dokumentierten Risikofaktoren spiegeln lediglich die o. g. klinischen Faktoren mit Ausnahme des Geburtsgewichts wider. Die definierten Intervalle sind wie folgt kodiert: Keine Risikofaktoren $=0$, ein Risikofaktor $=1$, mehr als ein Risikofaktor $=2$.

- ANV: Zeitspanne zwischen der kardiopulmonalen Reanimation bis zum erstmaligen Auftreten eines akuten Nierenversagens. Das Auftreten einer Nierenschädigung wurde 
anhand der Richtlinie des Acute Kidney Injury Network (AKIN) klassifiziert. Dieses definiert das ANV durch eine abrupte Abnahme der Nierenfunktion mit einem absoluten Anstieg des Serum-Kreatinins $\geq 0,3 \mathrm{mg} / \mathrm{dl}(\geq 26,4 \mu \mathrm{mol} / \mathrm{l})$ oder einen prozentualen Anstieg des Serum-Kreatinins $\geq 50 \%$ (das 1,5-fache des Ausgangswertes) innerhalb von 48 Stunden (Mehta et al. 2007).

Es wurden sechs Untergruppen gebildet und diese wie folgt kodiert: Kein Auftreten eines $\mathrm{ANV}=0$, Auftreten eines ANV innerhalb der ersten 24 Stunden = 1, Auftreten eines ANV innerhalb von 72 Stunden $=3$, innerhalb einer Woche $=7$,

nach mehr als einer Woche $=\mathrm{n}$. Ein bereits zum Zeitpunkt der Aufnahme vorbestehendes ANV wurde mittels eines kleinen (a) gekennzeichnet.

- HD-Frequenz: Anzahl der durchgeführten Hämodialysen oder -diafiltrationen während der intensivmedizinischen Behandlung. Keine erforderliche Dialyse erhielt die Kodierung $=0$, eine einmalige Dialyse die Kodierung $=1$ und bei mehrmaliger Dialyse wurde die Chiffre $=2$ genutzt. Eine Unterteilung der Dialyseverfahren wurde nicht durchgeführt.

- Outcome: Zustand des Patienten zum Zeitpunkt der Entlassung bzw. Verlegung auf eine Normalstation oder den Tod. Diese Information wurde dem Abschlussbericht entnommen und wie folgt kodiert: Eine normale Nierenfunktion erhielt das Kürzel $=\mathrm{NKF}$, ein chronisches Niereninsuffizienz das Kürzel $=$ CKI. Verstorbene Patienten wurden mit der Abkürzung = Death versehen.

- Cooling Method: Angabe ob der Patient gekühlt wurde und im Falle einer Kühlung mit welcher Methode. Die gekühlten Patienten wurden in drei Untergruppen unterteilt. Die Untergruppen des gekühlten Kollektivs wurden mit folgender Chiffre verschlüsselt: =1 für die Kühlung mittels intravenösen Katheters, =2 für eine extrakorporale Kühlung und $=3$ für eine nicht nähere Bezeichnung des Kühlverfahrens. Nicht gekühlte Patienten wurden mit einer der Chiffre $=0$ gekennzeichnet.

- RR: gemittelter arterieller Blutdruck der ersten Stunden nach CPR. Eine Differenzierung zwischen invasiver und nicht-invasiver Blutdruckmessung wurde nicht vorgenommen. 
- MAP: mittlerer arterieller Blutdruck (MAP) errechnet sich wie folgt: $\mathrm{MAD}=\mathrm{BD}_{\text {diast }}+1 / 3 *\left(\mathrm{BD}_{\text {syst }}-\mathrm{BD}_{\text {diast }}\right)($ Wilhelm 2013$)$.

- $\mathbf{p O}_{2}$ : partieller Sauerstoffgehalt im arteriellen Blutkreislaufsystem. Die Werte wurden mittels Blutgasanalysegerät auf der Interdisziplinären Notaufnahme oder der Intensivstation bestimmt. Für 127 Patienten des milden Hypothermiekollektivs liegen die Messwerte lediglich für den Tag der Aufnahme sowie den dritten Postreanimationstag vor. Der partielle Sauerstoffgehalt für die folgenden Tage (T7, T14, TN) konnte im Anschluss nicht mehr eruiert werden.

- APACHE: Acute Physiology And Chronic Health Evaluation spiegelt die Überlebenswahrscheinlichkeit von erwachsenen Patienten mit intensivmedizinischem Behandlungsbedarf wider. Für die Studie wurde der APACHE II-Scores erhoben (s. Kap. 1.6). Zur Berechnung wurden die jeweils schlechtesten physiologischen und biochemischen Parameter der ersten 24 Stunden nach Aufnahme auf der Intensivpflegestation herangezogen (Knaus et al. 1985).

○ Temperatur: Körpertemperatur vor der Einleitung der milden Hypothermie. In 75 Fällen wurde vor Induktion der Hypothermie keine Körpertemperatur protokolliert, und sie musste mit $37^{\circ} \mathrm{C}$ (=0 Punkte) angenommen werden. Für die Kontrollgruppe wurde der erste auf Intensivstation gemessene Wert für die Berechnung verwendet.

○ Herzfrequenz/MAP: berücksichtigt wurde eine gemittelte Herzfrequenz der ersten Stunden nach CPR. Erneut aufgetretene Asystolien, Bradykardien unter 20/min und Tachykardien über 180/min wurden für die Berechnung nicht berücksichtigt. Der mittlere arterielle Blutdruck wurde wie zuvor unter MAP erläutert erhoben.

○ Atemfrequenz/Oxygenierung/pH/Na/K: Diese Messwerte wurden aus den Blutgasanalysen und den Verlaufsprotokollen der Intensivstation ausgelesen. Für beatmete Patienten mit einem $\mathrm{FiO}_{2}$-Wert von $50 \%$ bis $100 \%$ wurde die alveolär-arterielle Sauerstoffdifferenz $\left(\mathrm{AaDO}_{2}\right)$ mittels vereinfachter Approximierung berechnet. Die Formel lautete $\mathrm{AaDO}_{2}=700 \mathrm{FiO}_{2}-\mathrm{p}_{\mathrm{a}} \mathrm{CO}_{2}-\mathrm{p}_{\mathrm{a}} \mathrm{O}_{2}$ (Petroianu und Osswald 2000). Die exakte Berechnung war aufgrund des nicht 
rekonstruierbaren Atmosphärendruckes und des herrschenden Wasserdampfdruckes nicht möglich.

○ Hkt/Leukozyten/Kreatinin: Die Parameter wurden schnellstmöglich nach der CPR durch das Zentrallabor der UMG ermittelt.

Berechnung erfolgte in folgenden Kenngrößen: Hämatokritwert in Prozent, die Leukozytenzahl in Anzahl/ $\mu 1$ und das Serum-Kreatinin in mg/dl.

○ Glasgow Coma Scale: Score zur Validierung der Bewusstseinslage von Patienten (s. Kap. 1.6) (Teasdale und Jennett 1974). Dieser wurde für einen überwiegenden Teil der Patienten mit 3 festgelegt, da eine Sedierung und spätere Muskelrelaxation zum Erhalten der künstlichen Beatmung sowie Initiierung der therapeutischen Hypothermie eingeleitet wurde. Lediglich bei einer kleinen Minderheit der Kontrollgruppe war keine Sedierung und Relaxation nach CPR nötig. Bei diesen Patienten wurde die Glasgow Coma Scale dem Intensivpflegeprotokoll oder dem Notarztprotokoll entnommen.

○ Alter: Lebensalter wurde wie zuvor beschrieben errechnet.

○ Chronic Health Score: Dieser Wert wurde gemäß der vorhandenen Informationen aus dem vorbestehenden Arztbrief ermittelt. Punktvergabe erfolgte anhand der von KNAUS et al. 1985 beschriebenen Klassifikation. (s. Kap. 1.6) Bei keinem der Patienten ergab sich der intensivstationäre Aufenthalt aufgrund einer operativen Intervention. Lediglich bei einigen Patienten bestanden vorbestehende chronische Organschäden, welche als Risikofaktor berücksichtigt wurden.

Die Gesamtpunktzahl der Einzelscores berechnet sich wie in Kapitel 1.6 beschrieben. Minimal ist eine Punktzahl von 0 und maximal eine Punktzahl von 71 Punkten zu erreichen.

- MDRD: Modifikation of Diet in Renal Disease wurde 1999 von LEVEY et al. zur Abschätzung der glomerulären Filtrationsrate entwickelt. Sie berechnet sich wie folgt:

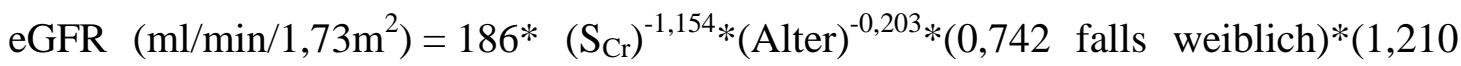
falls schwarze Hautfarbe). Der $\mathrm{S}_{\mathrm{Cr}}$ - Wert wurde dem tagesaktuellen Ausdruck des Zentrallabors der Universitätsklinik Göttingen entnommen. Aufgrund des retrospektiven Studiendesigns und der damit einhergehenden Limitierung konnte die Hautfarbe in der Approximation nicht berücksichtigt werden. 
- T3/T7/T14: stehen für die jeweils gemessenen Intervalle 72 Stunden=T3, 168 Stunden $=\mathrm{T} 7$ und 336 Stunden $=\mathrm{T} 14$ nach der kardiopulmonalen Reanimation. Diese Werte wurden nach den zuvor aufgeführten Rahmenbedingungen erhoben. Für den Fall, dass am entsprechenden Tag keine Laborparameter bestimmt wurden, musste auf einen direkt umliegenden Tag $( \pm 1$ Tag) ausgewichen werden. Dies geschah in wenigen Einzelfällen und wurde unter der Spalte „INFO“ vermerkt.

- Tx: letzter in der Patientenakte dokumentierten Behandlungstag. Dieser inkludiert den Zeitraum vom 15. Tag bis zum 65. Tag. Grund des Behandlungsendes und der Dokumentation können eine Verlegung auf eine andere Station oder in eine andere Klinik sowie die Entlassung nach Hause oder der Exitus letalis sein.

- hy. BI: Hypoxic Brain Injury spiegelt das neurologische Outcome des Patienten wider. Kodiert wurde auf der Grundlage des Abschlussberichtes in folgende Gruppen: kein signifikanter Hirnschaden $=0$, ein irreversibler Hirnschaden mit funktioneller Einschränkung = 1 und es konnte keine genaue Angabe dem Bericht entnommen werden $=3$. Bei einem Großteil der nicht dokumentierten Hirnfunktion kann davon ausgegangen werden, dass eine normale Hirnfunktion bestand. 


\subsection{Statistische Auswertung}

Für die deskriptive Auswertung wurde in Abhängigkeit vom Endpunkt die absolute und prozentuale Anzahl (z. B. Geschlechtsverteilung, Outcome, etc.) oder der arithmetische Mittelwert und der Standardfehler (z. B. Alter, APACHE-II-Score, etc.) bestimmt und angegeben.

Die statistische Auswertung wurde mittels Statistica 9.0, Microsoft ${ }^{\circledR}$ Excel und R-Studio durchgeführt. Histogramme und Kreisdiagramme geben jeweils die prozentuale oder relative Häufigkeit und deren Verteilung wieder. Die Box-Plots dienen der grafischen Darstellung kardinalskalierter Werte und geben den Mittelwert, Interquantilrange (Mittelwert \pm den Standardfehler) sowie unterer und oberer Whisker (Mittelwert \pm der zweifachen Standardabweichung) wieder.

Um Verteilungsunterschiede zwischen den Gruppen bei dichotomen Endpunkten (z. B. Nierenversagen: ja/nein, Outcome: Death, CKI, NFK) aufzeigen zu können, wurden die Daten mittels Chi-Quadrat-Test getestet. Für dichotome Endpunkte, die eine Stichprobengröße unter 60 Fälle aufwiesen, wurde eine Yates-Korrektur durchgeführt. Ordinalskalierte Endpunkte (Risikofaktorklassen) wurden mithilfe des Mann-Whitney-U-Test verglichen. Die Vergleichsanalyse der Mittelwerte zwischen den Gruppen erfolgte durch einen t-Test.

Für den Vergleich der GFR in den beiden Kollektiven über die vier Zeitpunkte (T0, T3, T7, T14) wurde eine Varianzanalyse für Messwiederholungen (ANOVA) angewandt. Dabei wurden als Ko-Variable die Baselinewerte T0 sowie der APACHE-II-Score mit in das Modell einbezogen. Als Hauptfaktoren sind die Gruppe und die Zeit zu betrachten. Eine Wechselwirkung zwischen Kollektiv und Zeit wurde mit modelliert. Um weitere Faktoren, wie z. B. die Risikofaktoren und die Erkrankung an einem DM berücksichtigen zu können, wurde das zuvor beschriebene Modell auf eine dreifaktorielle Varianzanalyse erweitert. Sämtliche Wechselwirkungen wurden mittels Varianzanalyse mithilfe der Software SAS (Version 9.1, SAS Institute) berechnet.

Das Signifikanzniveau wurde für alle statistischen Tests auf $5 \%(\mathrm{p} \leq 0,05)$ festgelegt. Für weiterführende Paarvergleiche wurde eine Bonferroni-Korrektur durchgeführt. 


\section{Ergebnisse}

\subsection{Deskriptive Auswertung}

\subsubsection{Demografische Verteilung der Kohorte}

Die Studie beinhaltete 437 Studienteilnehmer, welche die Einschlusskriterien erfüllten (s. Kap. 2.2). Aufgrund unvollständiger Datensätze mussten 91 Patienten exkludiert werden. Demgemäß ergab sich ein Studienkollektiv von 346 Patienten, welches in zwei Kollektive aufgeteilt wurde. Das milde Hypothermiekollektiv $(\mathrm{n}=202)$ inkludierte alle Patienten, die nach der kardiopulmonalen Reanimation eine Behandlung mittels mHT erhalten hatten. Es setzte sich aus 148 männlichen Patienten (73,3\%) und 54 weiblichen Patienten (26,7\%) zusammen.

Das Kontrollkollektiv, welches nach kardiopulmonaler Reanimation keine Behandlung mittels milder Hypothermie erhielt, umfasste 144 Patienten, von denen 84 männlich und 60 weiblich waren. Dies entsprach einer prozentualen Verteilung von 58,3\% männlicher Patienten und 41,7\% weiblicher Patienten. Das milde Hypothermiekollektiv beinhaltete signifikant mehr Männer als das Kontrollkollektiv ( $\mathrm{p}=0,0036)$.

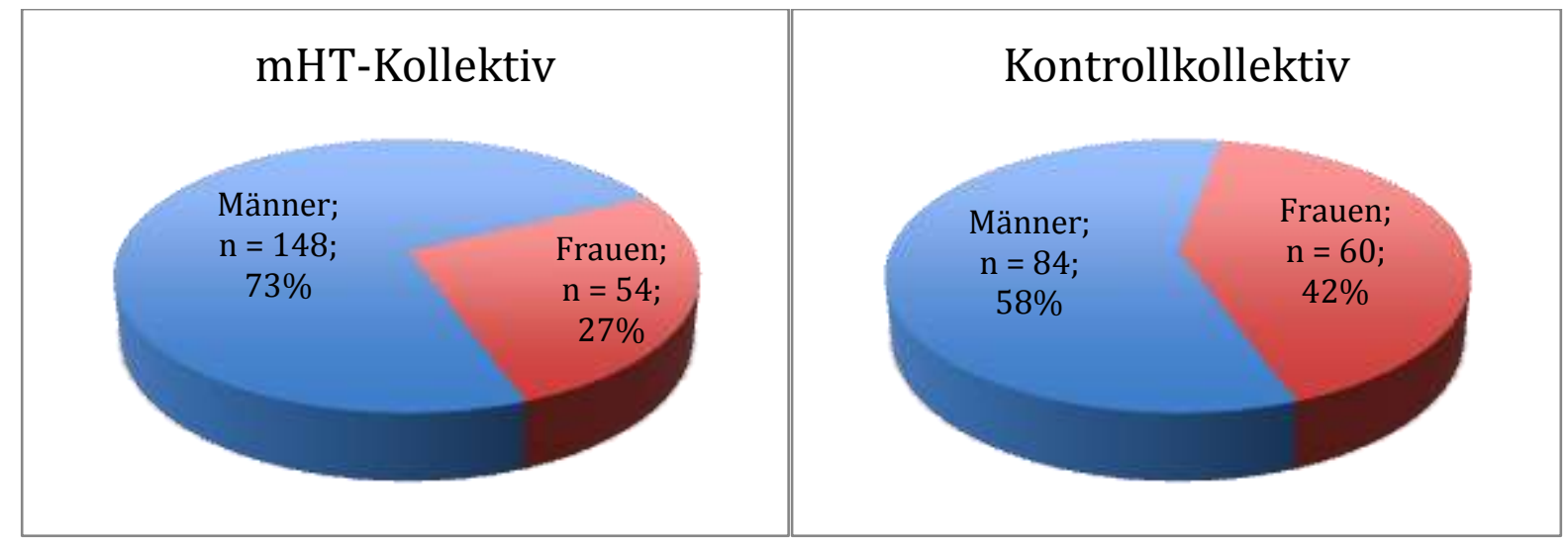

Abbildung 3: Absolute und prozentuale Verteilung des Geschlechtes innerhalb des Patienten- und des Kontrollkollektivs

Das durchschnittliche Lebensalter der beiden Kollektive visualisiert Abbildung 4. Im mHTKollektiv lag das mittlere Lebensalter zum Zeitpunkt der Aufnahme bei 67,0 Lebensjahren (SEM $\pm 0,9)$. In dem Kontrollkollektiv betrug das Durchschnittsalter 67,5 Lebensjahre $(\mathrm{SEM} \pm 1,0)$. Ein signifikanter Altersunterschied bestand bei globaler Betrachtung zwischen beiden Kollektiven demnach nicht $(p=0,6640)$. 


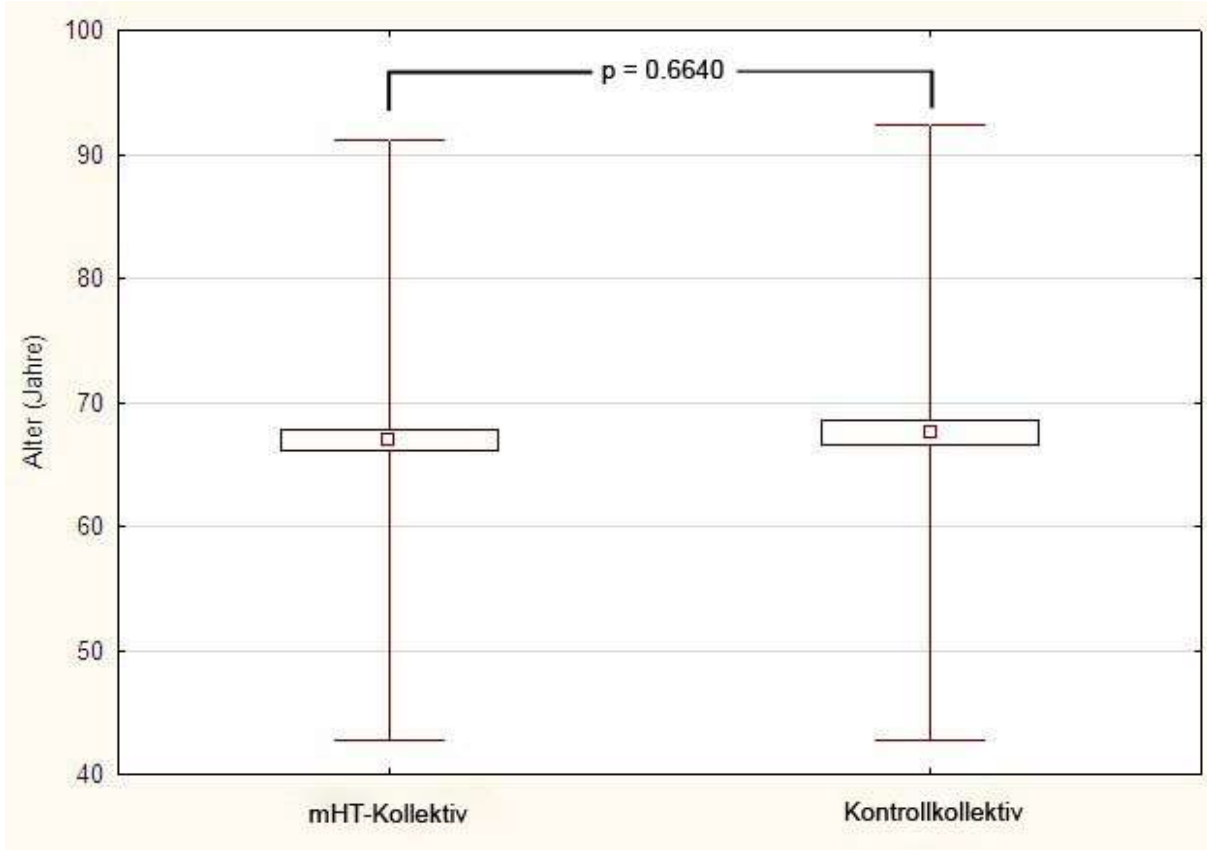

Abbildung 4: Durchschnittliches Lebensalter der Studienteilnehmer beider Kollektive

Abbildung 5 präsentiert die Verteilung des Durchschnittsalters des mHT- und Kontrollkollektivs unter Berücksichtigung des Geschlechtes. Das weibliche mHT-Kollektiv wies ein mittleres Lebensalter von 66,0 Jahren $(\mathrm{SEM} \pm 1,9)$ im Vergleich zu 71,5 Lebensjahren (SEM $\pm 1,4)$ im Kontrollkollektiv auf. Frauen, die nach kardiopulmonaler Reanimation mittels milder Hypothermie behandelt wurden, waren demnach im Durchschnitt 5,6 Jahre jünger als weibliche Studienteilnehmer des Kontrollkollektivs $(\mathrm{p}=0,0168)$. Unter den männlichen Studienteilnehmern bestand in der Altersverteilung kein signifikanter Unterschied zwischen beiden Kollektiven $(\mathrm{p}=0,1117)$. 


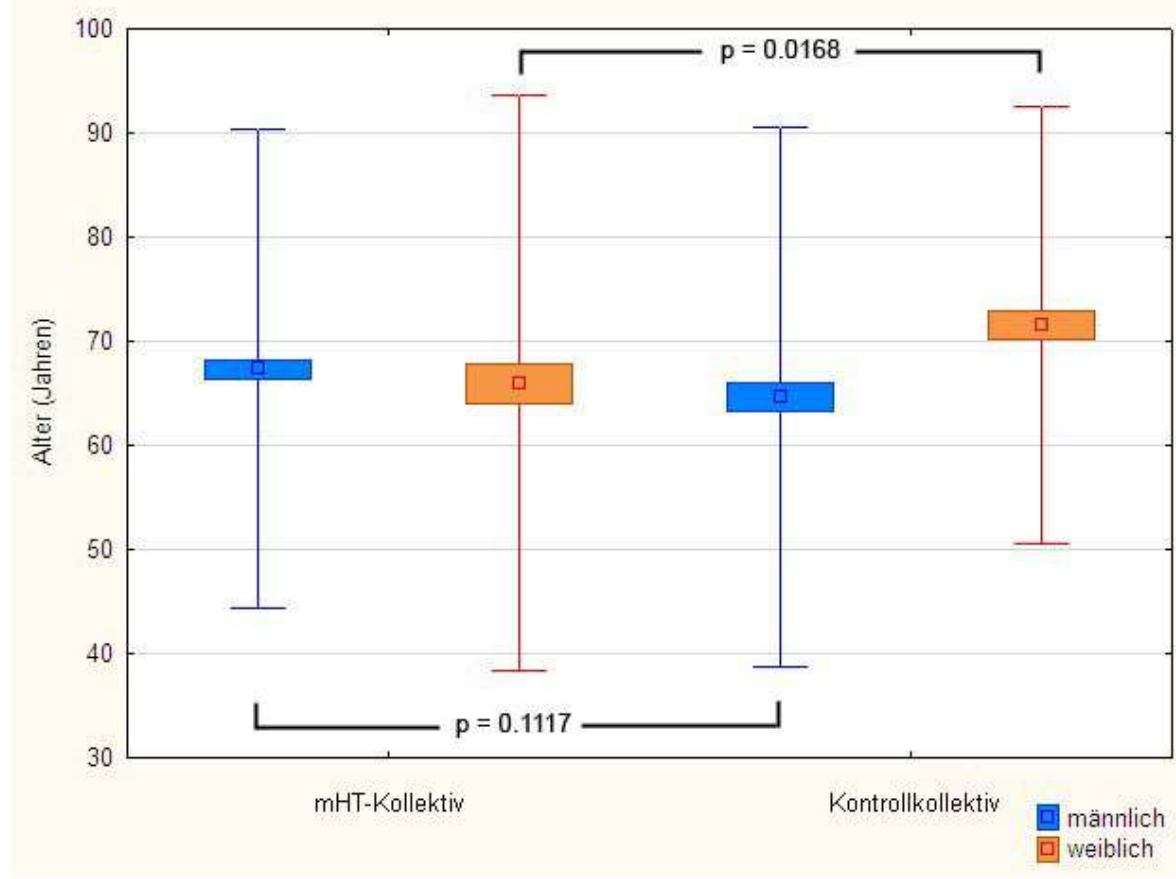

Abbildung 5: Durchschnittliches Lebensalter der Studienteilnehmer gruppiert nach Kollektiv und Geschlecht

\subsubsection{APACHE II-Scores}

Der zum Zeitpunkt der Aufnahme retrospektiv erhobene APACHE II-Scores betrug für das milde Hypothermiekollektiv im Mittel 28,4 Punkte (SEM \pm 0,4). Der Durchschnittswert des APACHE II-Scores in dem Kontrollkollektiv betrug zum Aufnahmezeitpunkt 25,2 Punkte $(\mathrm{SEM} \pm 0,6)$. Dies entsprach einem hochsignifikanten Unterschied zwischen den beiden Kollektiven, wobei das mHT-Kollektiv 3,2 Punkte höher lag und hiermit eine niedrigere Überlebenswahrscheinlichkeit als das Kontrollkollektiv aufwies. 


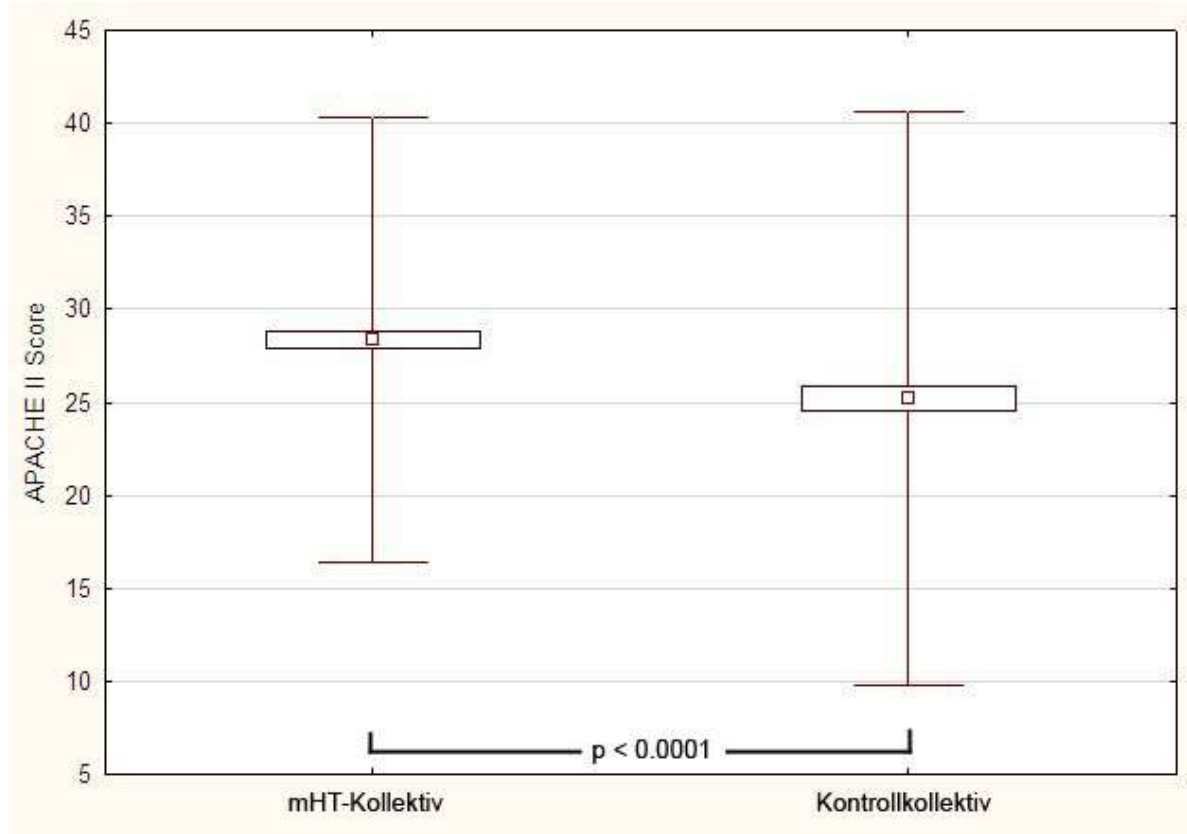

Abbildung 6: Häufigkeitsverteilung des APACHE II-Scores innerhalb der beiden Kollektive

Unter zusätzlicher Einbeziehung des Geschlechtes ergab sich die in Abbildung 7 dargestellte Verteilung des APACHE II-Scores.

Männliche Studienteilnehmer des milden Hypothermiekollektivs hatten einen mittleren APACHE II-Scores von 28,5 Punkte (SEM \pm 0,5). Das männliche Kontrollkollektiv lag im Durchschnitt bei 24,3 Punkten (SEM $\pm 0,9)$. Dieser Unterschied war hochsignifikant $(\mathrm{p}<$ 0,0001).

Für die weiblichen Patienten bestand kein signifikanter Unterschied zwischen den durchschnittlichen APACHE II-Scores beider Kollektive ( $p=0,1657)$. Das weibliche mHTKollektiv hatte einen mittleren Wert von 28,1 Punkten (SEM \pm 0,8) und das Kontrollkollektiv lediglich einen marginal niedrigeren Score von 26,41 Punkten (SEM $\pm 0,9)$. Innerhalb des milden Hypothermiekollektivs und des Kontrollkollektivs bestand ebenfalls kein signifikanter Unterschied zwischen Männern und Frauen und ihren durchschnittlichen APACHE II-Scores. 


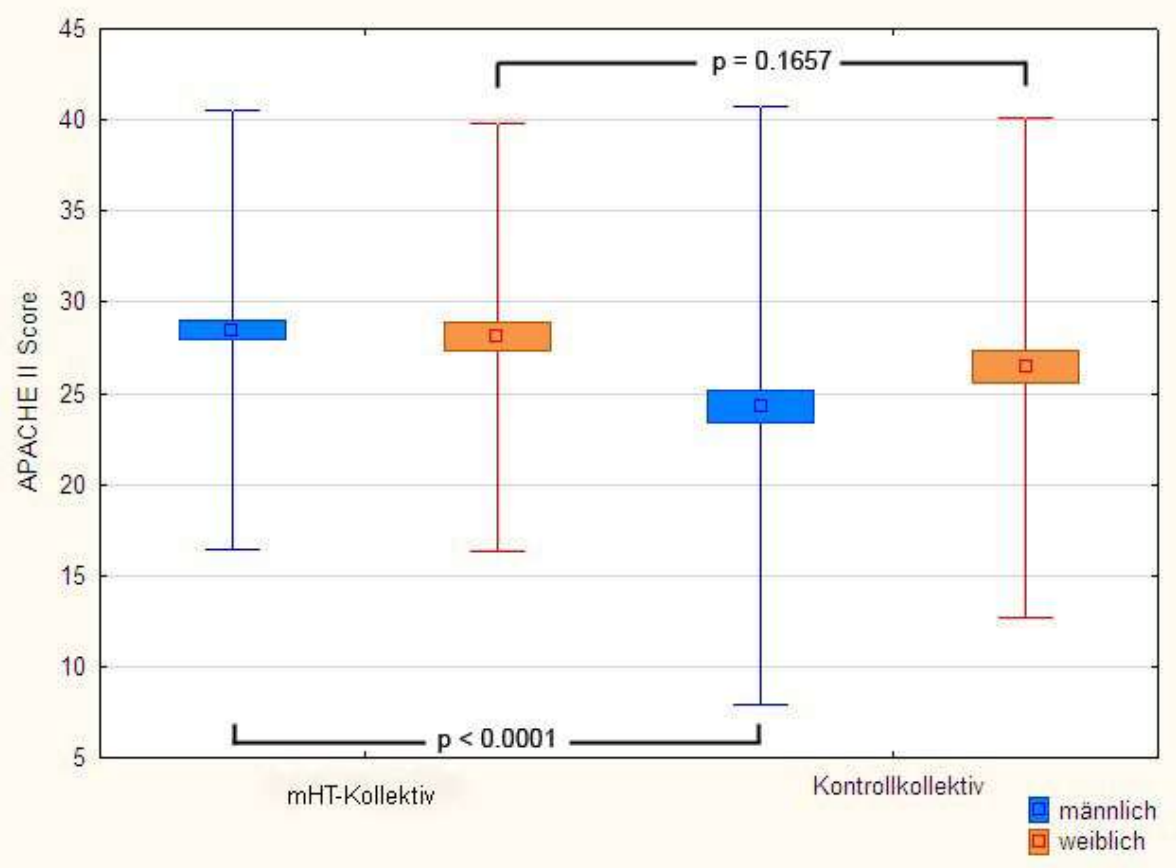

Abbildung 7: Häufigkeitsverteilung des APACHE II-Scores gruppiert nach dem Kollektiv und dem Geschlecht

\subsubsection{Häufigkeitsverteilung von Diabetes mellitus}

Abbildung 8 illustriert die Häufigkeitsverteilung von Patienten mit vorbekanntem DM innerhalb beider Kollektive. In dem milden Hypothermiekollektiv lag bei 15,8\% der Patienten $(n=32)$ ein vordiagnostizierter DM vor. Im Vergleich dazu waren $25,7 \%$ der Studienteilnehmer $(\mathrm{n}=37)$ des Kontrollkollektivs bereits vor der kardiopulmonalen Reanimation an einem DM erkrankt. Dieser Unterschied war signifikant ( $p=0,0238)$.

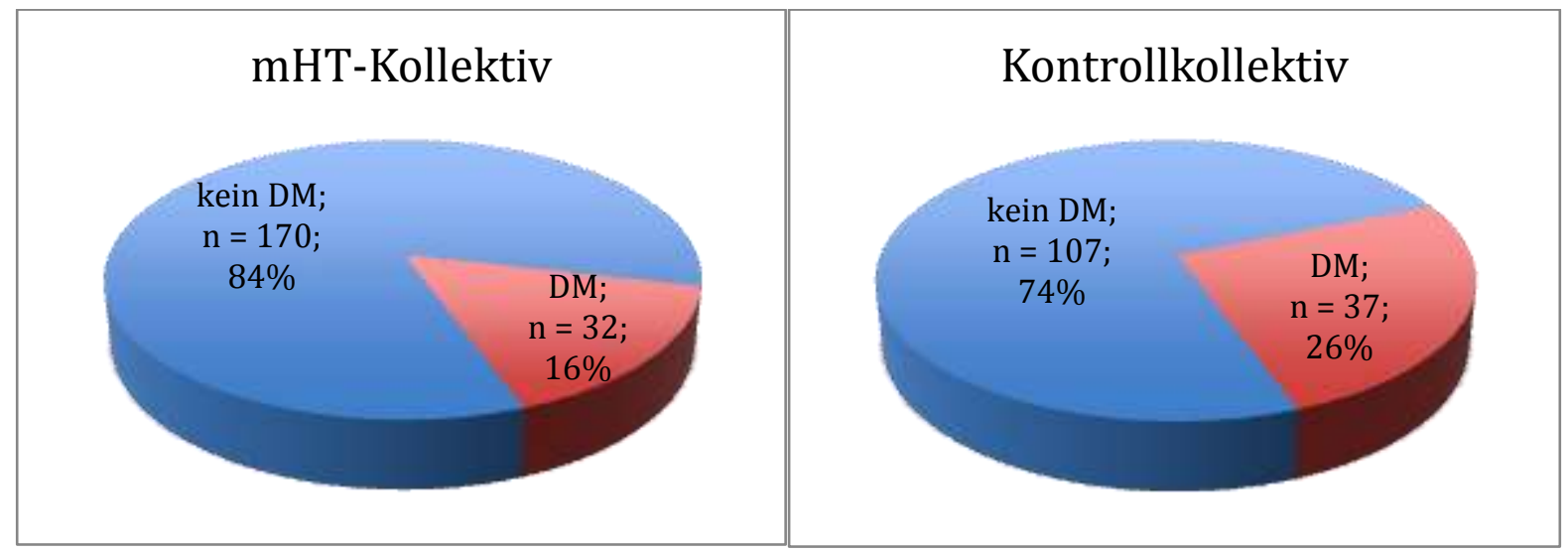

Abbildung 8: Absolute und prozentuale Häufigkeitsverteilung der vordiagnostizierten Diabetes-mellitusErkrankungen innerhalb beider Kollektive 


\subsubsection{Häufigkeitsverteilung der Risikofaktoren für eine chronische}

\section{Niereninsuffizienz}

Die Häufigkeitsverteilung der nach Kapitel 2.3 evaluierten Risikofaktoren für eine chronische Niereninsuffizienz (CKI), kategorisiert nach mHT- und Kontrollkollektiv, wird in Abbildung 9 dargestellt.

Keinen Risikofaktor für eine CKI wiesen $28,71 \%$ der Patienten $(n=58)$ des milden Hypothermiekollektivs und $32,6 \%$ der Patienten $(\mathrm{n}=47)$ in dem Kontrollkollektiv auf. $37,6 \%(n=76)$ des mHT-Kollektivs und 43,1 \% der Patienten $(n=62)$ des Kontrollkollektivs hatten einen Risikofaktor für eine CKI. Mehr als einen Risikofaktor hatten 33,7\% der Studienteilnehmer $(n=68)$ des mHT-Kollektivs und $24,3 \%$ der Patienten $(n=35)$ in dem Kontrollkollektiv. Das mHT-Kollektiv inkludierte somit 3,9\% weniger Patienten ohne Risikofaktoren und 9,4\% mehr Patienten mit mehr als einem Risikofaktor für die Entstehung einer CKI. Bei globaler Betrachtung ergab sich jedoch kein signifikanter Unterschied bezüglich der Risikofaktorverteilung zwischen den beiden Kollektiven ( $\mathrm{p}=0,1415)$.

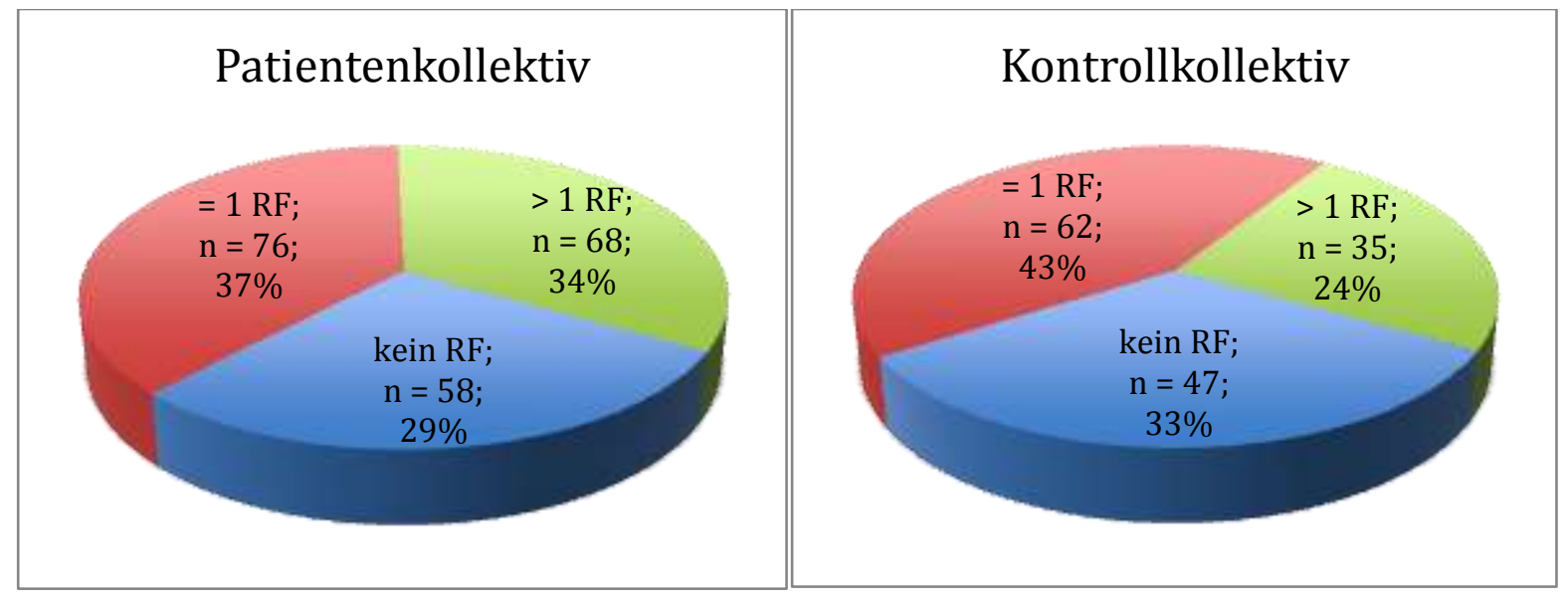

Abbildung 9: Absolute und prozentuale Häufigkeitsverteilung der Risikofaktoren für eine chronische Niereninsuffizienz

\subsubsection{Verweildauer auf der Intensivstation}

Die folgenden zwei Grafiken (Abb. $10 u$. 11) visualisieren die durchschnittliche Liegedauer der Studienteilnehmer auf der Intensivstation (ICU) der UMG. Die Angabe erfolgt in Tagen und stellt die absolute Verteilung sowie die prozentuale Verteilung, inklusive die Verteilungskurve, der beiden Kollektive dar. Im Mittel lagen die Patienten des milden Hypothermiekollektivs 11,8 Tage (SEM \pm 0,7) auf der ICU. Das Kontrollkollektiv erreichte 
eine durchschnittliche Liegezeit von 12,3 Tagen (SEM \pm 1,0). Ein signifikanter Unterschied bei der intensivmedizinischen Behandlungsdauer ergab sich zwischen beiden Kollektiven nicht $(\mathrm{p}=0,7072)$

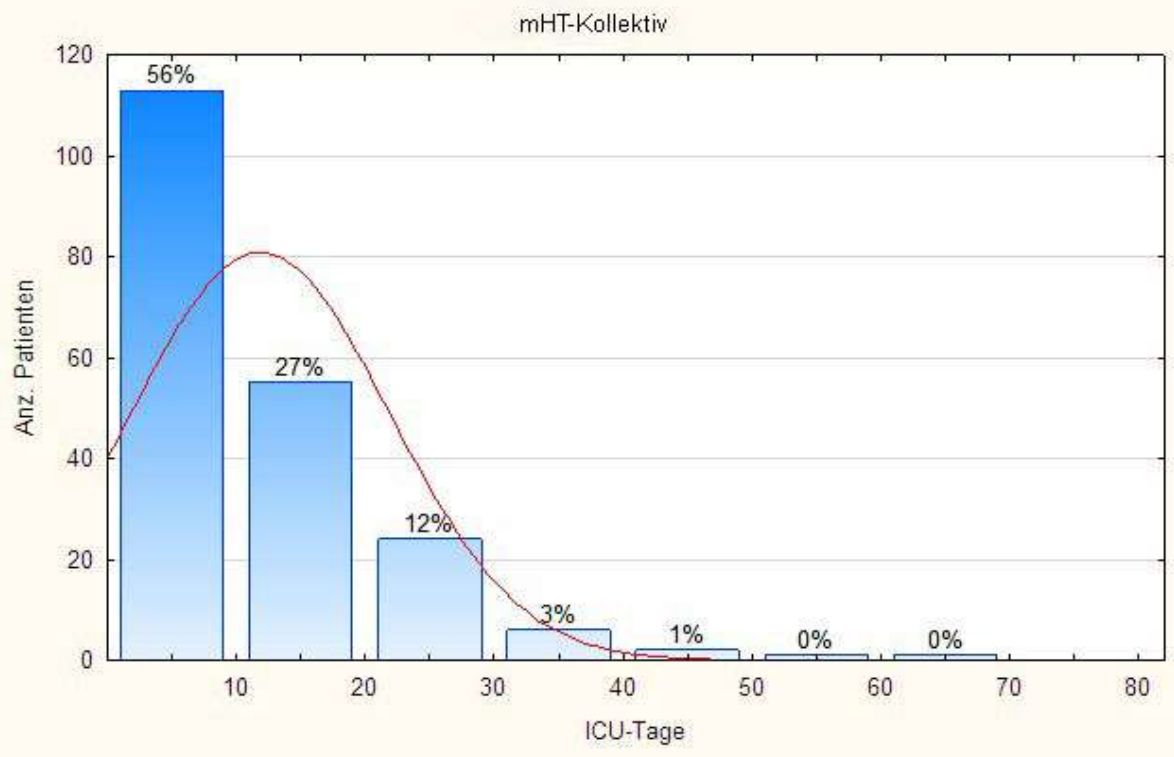

$n=202 ; M w=11.81$ Tage; SEM $+/-0.7$

Abbildung 10: Liegedauer des Patientenkollektivs auf der Intensivstation der Universitätsmedizin Göttingen in Tagen inklusive Verteilungskurve (rote Kurve), Mittelwert (Mw) und Standardfehler (SEM)

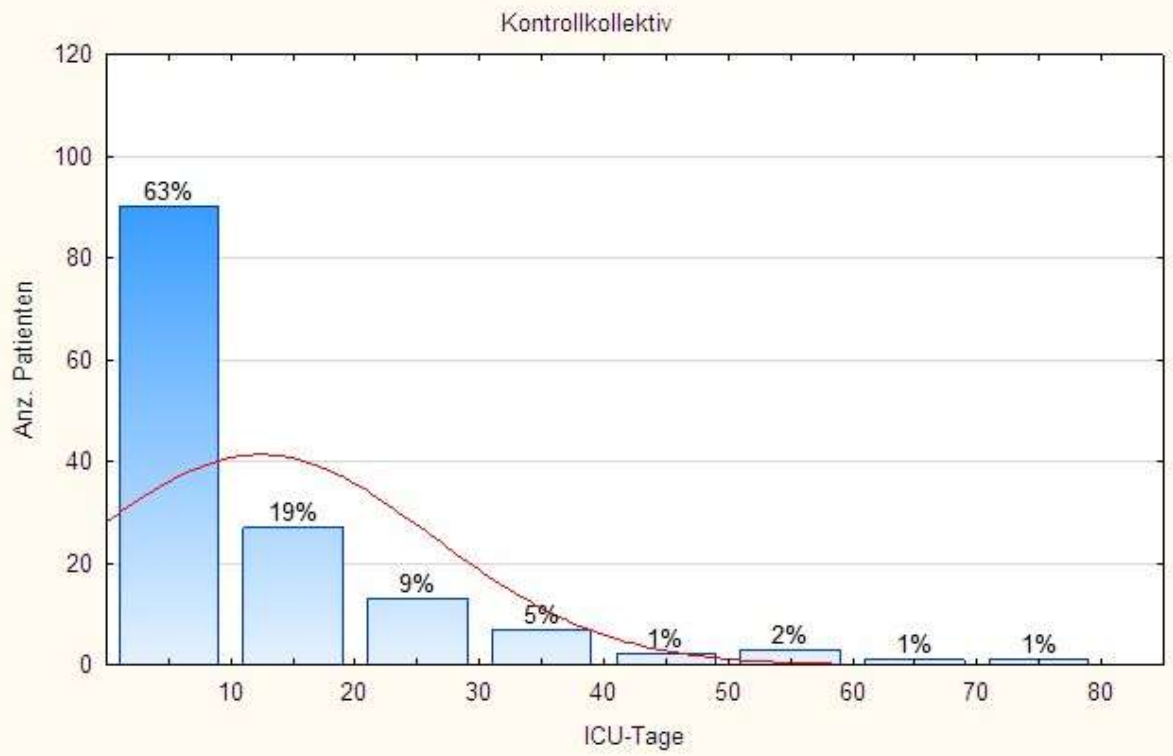

$n=144 ; M w=12.29 ; S E M+/-1.0$

Abbildung 11: Liegedauer des Kontrollkollektivs auf der Intensivstation der Universitätsmedizin Göttingen in Tagen inklusive Verteilungskurve (rote Kurve), Mittelwert (Mw) und Standardfehler (SEM) 


\subsection{Häufigkeitsverteilung des akuten Nierenversagens}

Im vorliegenden Abschnitt wird die Auftretenswahrscheinlichkeit des akuten Nierenversagens der einzelnen Studienteilnehmer während der Behandlung an der UMG untersucht. Es wurden drei Kategorien definiert und als abhängige Variable betrachtet.

Kein ANV:

ANV vor Aufnahme:
Der Patient erlitt während der stationären Behandlung an der UMG kein akutes Nierenversagen.

Es trat während der stationären Behandlung ein akutes Nierenversagen auf.

Es bestand bereits zum Zeitpunkt der Aufnahme ein akutes Nierenversagen.

Als unabhängige Variable wurde die Durchführung oder Nicht-Durchführung einer milden Hypothermie nach kardiopulmonaler Reanimation festgelegt.

Zusätzlich wurde die Auftretenswahrscheinlichkeit des akuten Nierenversagens unter Berücksichtigung der einzelnen Kofaktoren, Geschlecht, DM und weiterer Risikofaktoren evaluiert.

Für die durchgeführten Untersuchungen wurden alle Patienten $(n=346)$ in die Studie einbezogen. Eine Differenzierung bezüglich der Art und Weise der durchgeführten milden Hypothermie wurde nicht vorgenommen.

\subsubsection{Globale Häufigkeitsverteilung des akuten Nierenversagens}

Abbildung 12 zeigt die absolute sowie die prozentuale Häufigkeitsverteilung des akuten Nierenversagens, kategorisiert nach dem betrachteten Kollektiv. Unter globaler Betrachtung konnte ein hochsignifikanter Unterschied zwischen den beiden Kollektiven und der Auftretenswahrscheinlichkeit des akuten Nierenversagens gemessen werden $(p<0,0001)$. In dem milden Hypothermiekollektiv $(n=202)$ erlitten $67,8 \%(n=137)$ der Patienten kein akutes Nierenversagen während der Behandlung an der UMG. Im Vergleich dazu hatten lediglich 27,8\% $(n=40)$ der Patienten des Kontrollkollektivs $(n=144)$ eine durchgehend normwertige Nierenfunktion.

Ein akutes Nierenversagen trat bei $29,2 \%(\mathrm{n}=59)$ der Studienteilnehmer des mHTKollektivs auf. In dem zugehörigen Kontrollkollektiv erkrankten 45,8 \% $(n=66)$ an einer 
akuten Niereninsuffizienz. Dies entsprach einer relativen Risikoreduktion (RRR), bezogen auf die milde Hypothermie und das Risiko, an einem akuten Nierenversagen zu erkranken, von 36,3\%. Ein zum Zeitpunkt der Aufnahme vorbestehendes akutes Nierenversagen konnte bei $3,0 \%(n=6)$ des mHT-Kollektivs und bei 26,4\% $(n=38)$ der Patienten im Kontrollkollektiv eruiert werden.

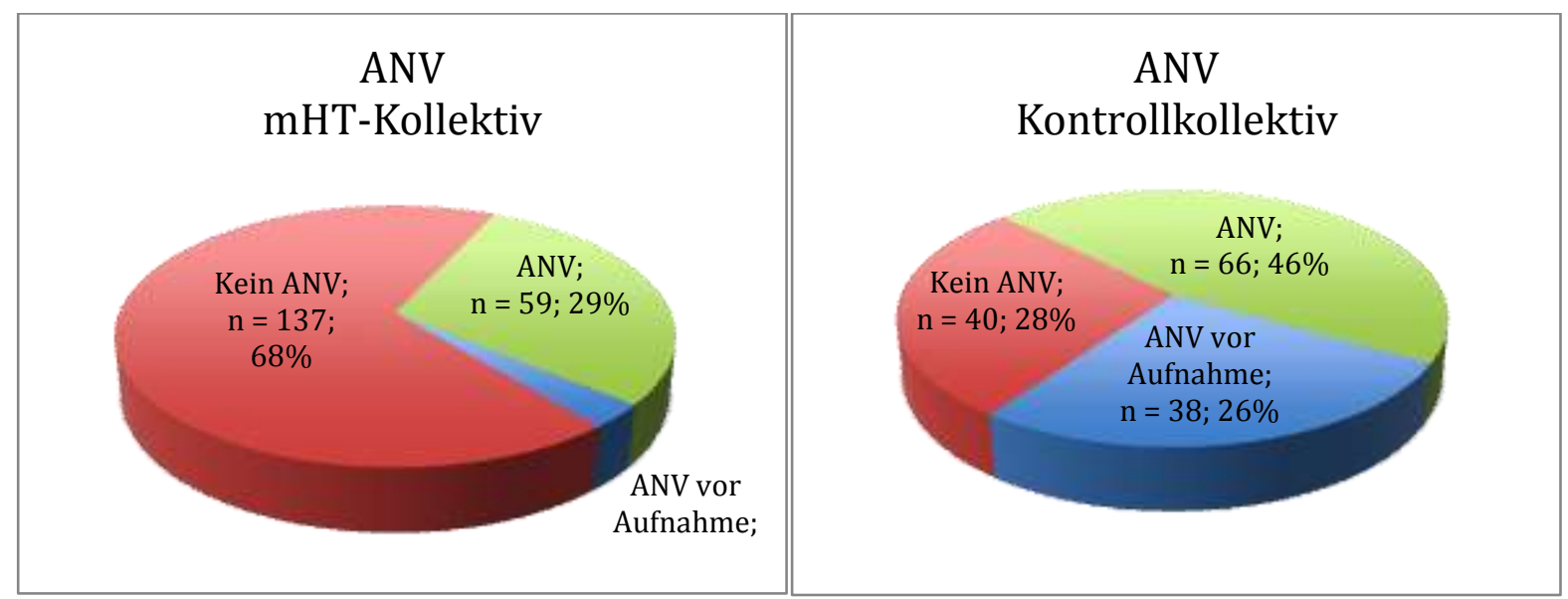

Abbildung 12: Absolute und prozentuale Häufigkeitsverteilung des akuten Nierenversagens des milden Hypothermie- und Kontrollkollektivs während der stationären Behandlung an der UMG

\begin{tabular}{|c|c|c|c|c|c|}
\hline Global & $\begin{array}{c}\text { mHT-Gruppe } \\
n=202(100 \%)\end{array}$ & $\begin{array}{l}\text { Kontrollgruppe } \\
\mathrm{n}=144(100 \%)\end{array}$ & RRR & ARR & p-Wert \\
\hline Kein ANV & $137 \quad(67,8 \%)$ & $40 \quad(27,8 \%)$ & $-144,2 \%$ & $-40,0 \%$ & $<0,0001$ \\
\hline ANV & $59 \quad(29,2 \%)$ & $66 \quad(45,8 \%)$ & $36,3 \%$ & $16,6 \%$ & 0,0015 \\
\hline $\begin{array}{l}\text { ANV vor } \\
\text { Aufnahme }\end{array}$ & $(3,0 \%)$ & $38 \quad(26,4 \%)$ & $88,7 \%$ & $23,4 \%$ & $<0,0001$ \\
\hline
\end{tabular}

Tabelle 8: Häufigkeitsverteilung des akuten Nierenversagens (ANV) unter globaler Betrachtung. Relative Risikoreduktion (RRR), absolute Risikoreduktion (ARR), Signifikanz (p-Wert)

Unter Ausschluss der Patienten, die bereits zum Zeitpunkt der Aufnahme ein akutes Nierenversagen hatten, erlitten 30,1\% $(n=59)$ des milden Hypothermiekollektivs $(n=196)$ und 62,3\% $(n=66)$ des Kontrollkollektivs $(n=106)$ ein akutes Nierenversagen während der stationären Behandlung. Der Unterschied bezüglich der Häufigkeitsverteilung des akuten Nierenversagens blieb in beiden Kollektiven mit einer Signifikanz von $p<0,0001$ konstant. 


\subsubsection{Häufigkeitsverteilung des akuten Nierenversagens unter}

\section{Berücksichtigung des Geschlechtes als Kofaktor}

Betrachtet wurde die Häufigkeitsverteilung des akuten Nierenversagens beider Kollektive während der stationären Behandlung gruppiert nach dem Geschlecht.

Es zeigte sich ein hochsignifikanter Unterscheid in der Häufigkeitsverteilung des ANV in der männlichen Subgruppe $(\mathrm{p}<$ 0,0001). In der milden Hypothermiegruppe lag die Wahrscheinlichkeit für Männer, an einem ANV zu erkranken, bei 32,4 \% (n = 48). Männliche Studienteilnehmer der Kontrollgruppe erkrankten mit einer Häufigkeit von 46,4 \% (n=39) an einem akuten Nierenversagen. Es ergab sich somit bei den Männern eine RRR in Bezug auf die Inzidenz eines akuten Nierenversagens von 30,2\%. Die absolute Risikoreduktion (ARR) lag bei $14,0 \%$.

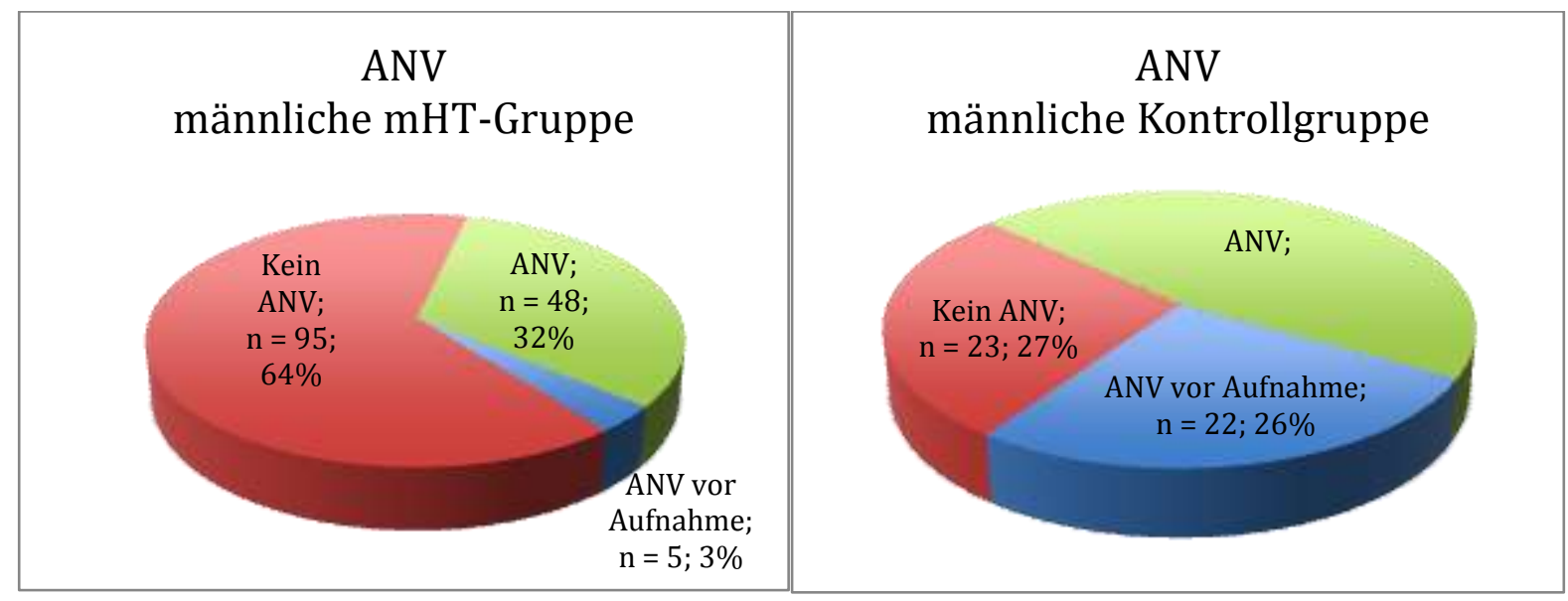

Abbildung 13: Absolute und prozentuale Häufigkeitsverteilung des akuten Nierenversagens der männlichen milden Hypothermie- und Kontrollgruppe während der stationären Behandlung

\begin{tabular}{|c|c|c|c|c|c|}
\hline Männer & $\begin{array}{c}\text { mHT-Gruppe } \\
\mathrm{n}=148(100 \%)\end{array}$ & $\begin{array}{l}\text { Kontrollgruppe } \\
\mathrm{n}=84(100 \%)\end{array}$ & RRR & ARR & p-Wert \\
\hline Kein ANV & $95 \quad(64,2 \%)$ & $23 \quad(27,4 \%)$ & $-134,4 \%$ & $-36,8 \%$ & $<0,0001$ \\
\hline ANV & $48 \quad(32,4 \%)$ & $39 \quad(46,4 \%)$ & $30,2 \%$ & $14,0 \%$ & 0,0343 \\
\hline $\begin{array}{l}\text { ANV vor } \\
\text { Aufnahme }\end{array}$ & $(3,4 \%)$ & $22 \quad(26,2 \%)$ & $87,1 \%$ & $22,8 \%$ & $<0,0001$ \\
\hline
\end{tabular}

Tabelle 9: Häufigkeitsverteilung des akuten Nierenversagens (ANV) in Abhängigkeit vom männlichen Geschlecht; relative Risikoreduktion (RRR), absolute Risikoreduktion (ARR), Signifikanz (p-Wert) 
Bei den weiblichen Studienteilnehmern zeigte sich eine ähnlich ausgeprägte Tendenz. In der mHT-Gruppe erkrankten lediglich 20,4\% $(\mathrm{n}=11)$ der Frauen an einem akuten Nierenversagen und mehr als das Doppelte der Frauen $(45,0 \%, n=27)$ in der Kontrollgruppe. Daraus ergab sich in der weiblichen Subgruppe eine RRR von $54,7 \%$ bei einer ARR von 24,6\%. In der Analyse ergab sich für Frauen ebenfalls ein hochsignifikanter Unterschied in der Häufigkeitsverteilung des akuten Nierenversagens zwischen der mHT- und Kontrollgruppe $(\mathrm{p}<0,0001)$.

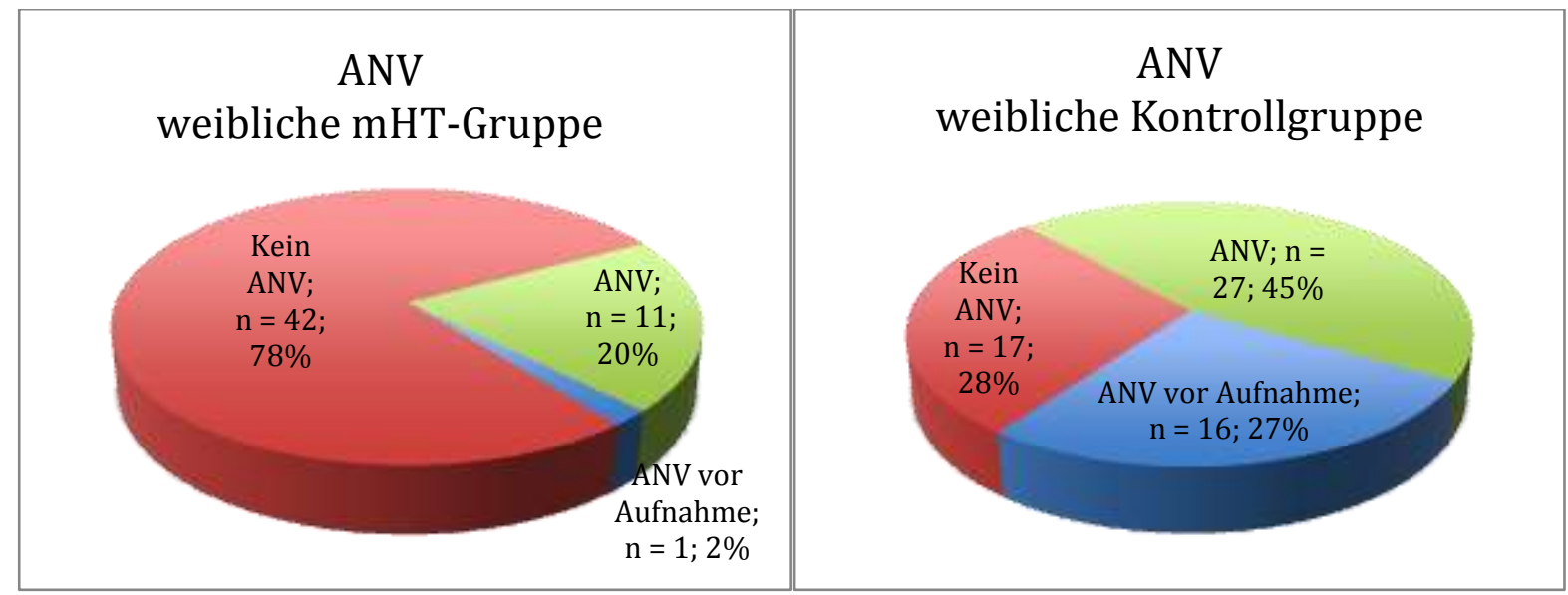

Abbildung 14: Absolute und prozentuale Häufigkeitsverteilung des akuten Nierenversagens der weiblichen milden Hypothermie- und Kontrollgruppe während der stationären Behandlung an der UMG

\begin{tabular}{|c|c|c|c|c|c|}
\hline Frauen & $\begin{array}{c}\text { mHT-Gruppe } \\
\mathrm{n}=54(100 \%)\end{array}$ & $\begin{array}{l}\text { Kontrollgruppe } \\
\mathrm{n}=60(100 \%)\end{array}$ & RRR & ARR & p-Wert \\
\hline Kein ANV & $42 \quad(77,8 \%)$ & $17 \quad(28,3 \%)$ & $-174,5 \%$ & $-49,4 \%$ & $<0,0001$ \\
\hline ANV & $11 \quad(20,4 \%)$ & $27 \quad(45,0 \%)$ & $54,7 \%$ & $24,6 \%$ & 0,0053 \\
\hline $\begin{array}{l}\text { ANV vor } \\
\text { Aufnahme }\end{array}$ & $(1,9 \%)$ & $16 \quad(26,7 \%)$ & $93,1 \%$ & $24,8 \%$ & 0,0002 \\
\hline
\end{tabular}

Tabelle 10: Häufigkeitsverteilung des akuten Nierenversagens (ANV) in Abhängigkeit vom weiblichen Geschlecht; relative Risikoreduktion (RRR), absolute Risikoreduktion (ARR), Signifikanz (p-Wert)

Die mHT führte bei Frauen $z u$ einer höheren Risikoreduktion in Bezug auf die Auftretenswahrscheinlichkeit des akuten Nierenversagens als bei Männern. Der Unterschied zwischen den beiden geschlechts-spezifischen mHT-Gruppen und der Häufigkeitsverteilung des ANVs war jedoch nicht signifikant $(\mathrm{p}=0,1865)$. 


\subsubsection{Häufigkeitsverteilung des akuten Nierenversagens unter}

\section{Berücksichtigung von Diabetes mellitus als Kofaktor}

Die Abbildungen 15 und 16 zeigen die Häufigkeitsverteilung des akuten Nierenversagens in Abhängigkeit des Kofaktors DM. Es bestand zwischen der milden Hypothermiegruppe und der Kontrollgruppe ein signifikanter Unterschied in der Auftretenswahrscheinlichkeit des akuten Nierenversagens. Der Unterschied war für Diabetiker mit $p=0,0029$ und für NichtDiabetikern mit $\mathrm{p}<0,0001$ signifikant.

Studienteilnehmer, die einer therapeutischen Hypothermie unterzogen wurden und nicht an DM vorerkrankt waren, erlitten mit einer Wahrscheinlichkeit von $28,2 \%(n=48)$ ein akutes Nierenversagen. In der Kontrollgruppe betrug das Risiko für ein ANV 45,8 \% ( $\mathrm{n}=49)$ und lag damit 17,6 \% höher als in der milden Hypothermiegruppe. Dies entsprach einer RRR von $38,3 \%$

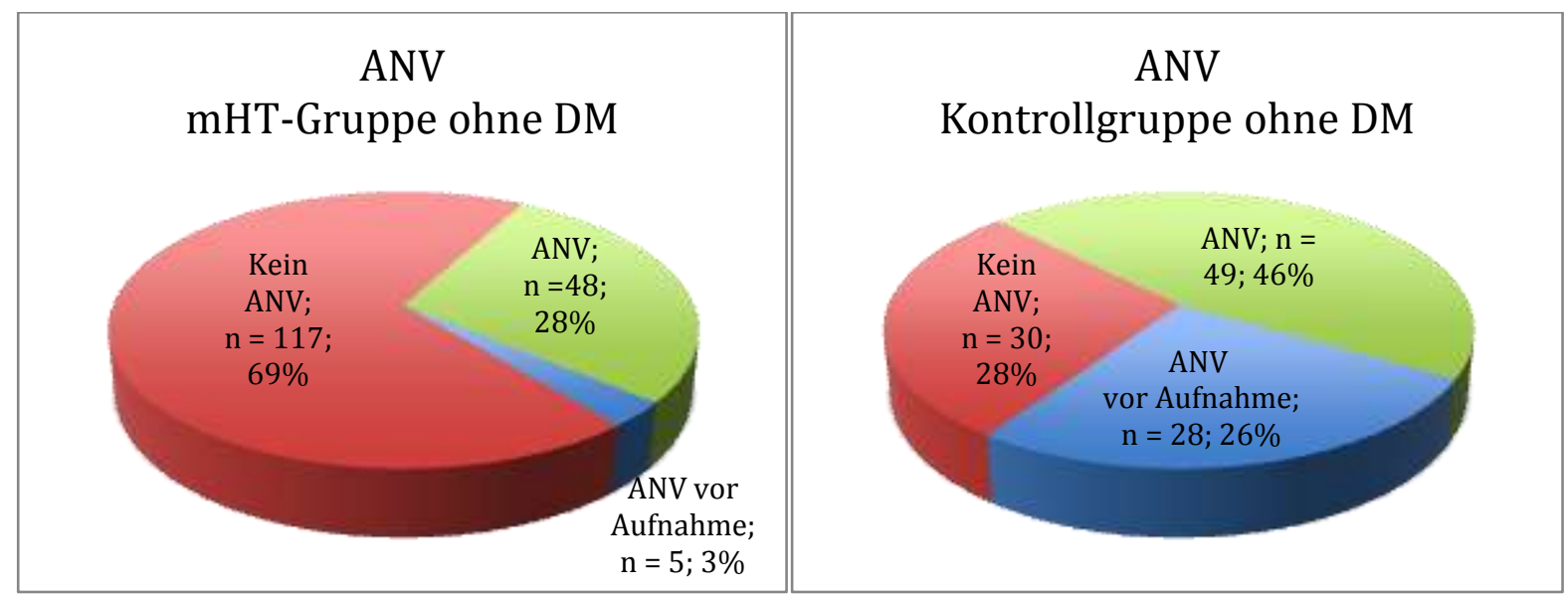

Abbildung 15: Absolute und prozentuale Häufigkeitsverteilung des akuten Nierenversagens bei NichtDiabetikern der milden Hypothermie- und Kontrollgruppe während der stationären Behandlung

\begin{tabular}{|c|c|c|c|c|c|}
\hline $\begin{array}{c}\text { Ohne } \\
\text { DM }\end{array}$ & $\begin{array}{c}\text { mHT-Gruppe } \\
\mathrm{n}=170(100 \%)\end{array}$ & $\begin{array}{l}\text { Kontrollgruppe } \\
\mathrm{n}=107(100 \%)\end{array}$ & RRR & ARR & p-Wert \\
\hline Kein ANV & $117 \quad(68,8 \%)$ & $30 \quad(28,0 \%)$ & $-145,5 \%$ & $-40,8 \%$ & $<0,0001$ \\
\hline ANV & $(28,2 \%)$ & $49 \quad(45,8 \%)$ & $38,3 \%$ & $17,6 \%$ & 0,0029 \\
\hline $\begin{array}{l}\text { ANV vor } \\
\text { Aufnahme }\end{array}$ & $(2,9 \%)$ & $28 \quad(26,2 \%)$ & $88,8 \%$ & $23,2 \%$ & $<0,0001$ \\
\hline
\end{tabular}

Tabelle 11: Häufigkeitsverteilung des akuten Nierenversagens (ANV) bei Nicht-Diabetikern; relative Risikoreduktion (RRR), absolute Risikoreduktion (ARR), Signifikanz (p-Wert) 
Ein vergleichbarer Trend zeigte sich bei den Diabetikern. In der mHT-Gruppe erkrankten $34,4 \%(\mathrm{n}=11)$ an einem akuten Nierenversagen. Diabetiker, die nicht mittels Hypothermie nach kardiopulmonaler Reanimation behandelt wurden, erkrankten mit einer Häufigkeit von 46,0 \% ( $\mathrm{n}=17)$ an einem ANV. Dies entsprach einer relativen Reduktion des Risikos durch die initiierte Therapie von $25,2 \%$.

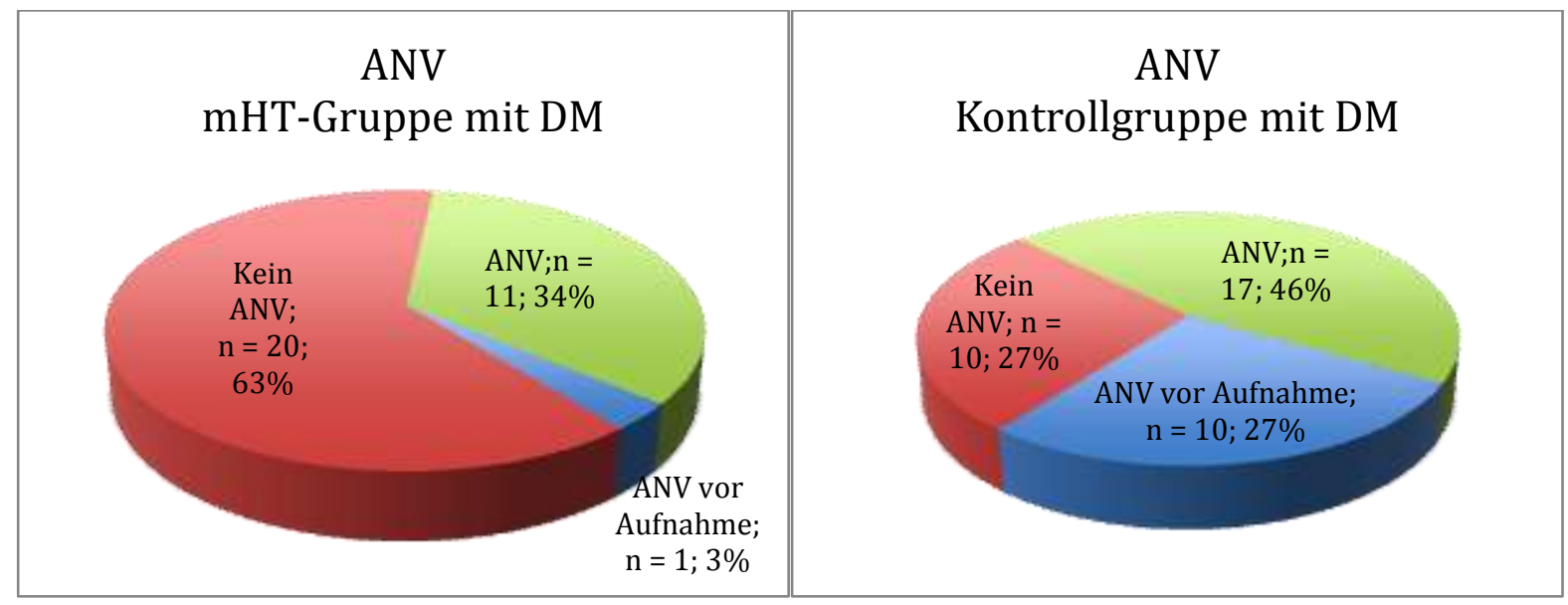

Abbildung 16: Absolute und prozentuale Häufigkeitsverteilung des akuten Nierenversagens von Diabetikern in der milden Hypothermie- und Kontrollgruppe während der stationären Behandlung

\begin{tabular}{|c|c|c|c|c|c|}
\hline $\begin{array}{l}\text { Diabetes } \\
\text { mellitus }\end{array}$ & $\begin{array}{c}\text { mHT-Gruppe } \\
\mathrm{n}=32(100 \%)\end{array}$ & $\begin{array}{l}\text { Kontrollgruppe } \\
\mathrm{n}=37(100 \%)\end{array}$ & RRR & ARR & p-Wert \\
\hline Kein ANV & $20 \quad(62,5 \%)$ & $10 \quad(27,0 \%)$ & $-131,3 \%$ & $-35,5 \%$ & 0,0065 \\
\hline ANV & $11 \quad(34,4 \%)$ & $17 \quad(45,9 \%)$ & $25,2 \%$ & $11,6 \%$ & 0,4652 \\
\hline $\begin{array}{l}\text { ANV vor } \\
\text { Aufnahme }\end{array}$ & $(3,1 \%)$ & $10 \quad(27,0 \%)$ & $88,4 \%$ & $23,9 \%$ & 0,0176 \\
\hline
\end{tabular}

Tabelle 12: Häufigkeitsverteilung des akuten Nierenversagens (ANV) in Abhängigkeit von einer Diabetesmellitus-Erkrankung; relative Risikoreduktion (RRR), absolute Risikoreduktion (ARR), Signifikanz (p-Wert)

In der Häufigkeitsverteilung des akuten Nierenversagens nach milder Hypothermie war zwischen Diabetikern und Nicht-Diabetikern kein signifikanter Unterschied ( $\mathrm{p}=0,7751)$ vorhanden. 


\subsubsection{Häufigkeitsverteilung des akuten Nierenversagens unter}

Berücksichtigung der Risikofaktoren für eine chronische Niereninsuffizienz als

\section{Kofaktor}

Betrachtet man die Häufigkeitsverteilung des akuten Nierenversagens der beiden Kollektive gruppiert nach den drei Risikofaktorklassen, ergeben sich folgende Verteilungen:

Patienten der milden Hypothermiegruppe, die keinen Risikofaktor für die Entstehung einer CKI hatten, erlitten mit einer Wahrscheinlichkeit von $24,1 \% \quad(\mathrm{n}=14)$ ein akutes Nierenversagen. Im Vergleich dazu erkrankten 51,1\% $(\mathrm{n}=24)$ der Kontrollgruppe an einem akuten Nierenversagen. Dies entsprach einer ARR von 26,9\% und einer RRR von 52,7 \%.

Es zeigte sich demnach ein hochsignifikanter Unterschied $(\mathrm{p}<0,0001)$ in Bezug auf die Inzidenz des ANV zwischen der mHT- bzw. Kontrollgruppe ohne additive Risikofaktoren.

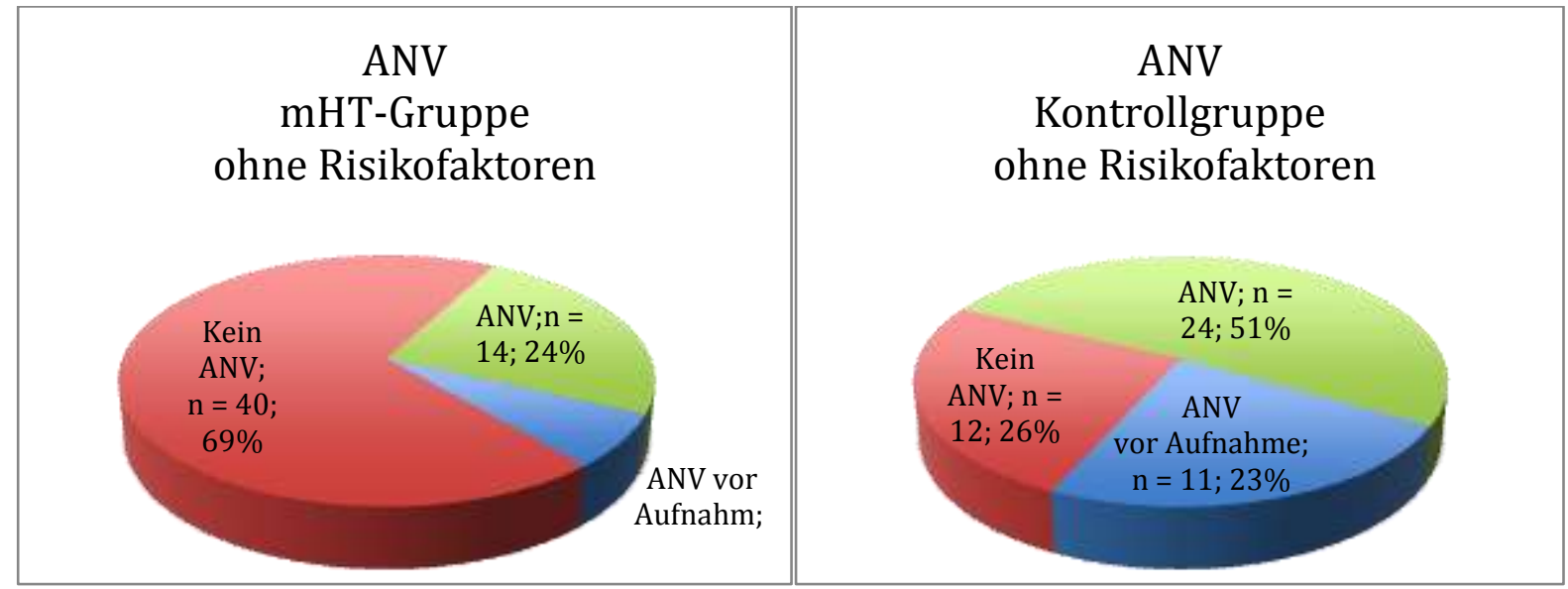

Abbildung 17: Absolute und prozentuale Häufigkeitsverteilung des akuten Nierenversagens in der milden Hypothermie- und Kontrollgruppe ohne additive Risikofaktoren während der stationären Behandlung

\begin{tabular}{|c|c|c|c|c|c|}
\hline $\begin{array}{c}\text { Ohne Risiko- } \\
\text { faktor }\end{array}$ & $\begin{array}{c}\text { mHT-Gruppe } \\
\mathrm{n}=58(100 \%)\end{array}$ & $\begin{array}{l}\text { Kontrollgruppe } \\
\mathrm{n}=47(100 \%)\end{array}$ & RRR & ARR & p-Wert \\
\hline Kein ANV & $40 \quad(69,0 \%)$ & $12(25,5 \%)$ & $-170,1 \%$ & $-43,4 \%$ & $<0,0001$ \\
\hline ANV & $14 \quad(24,1 \%)$ & $24 \quad(51,1 \%)$ & $52,7 \%$ & $26,9 \%$ & 0,0080 \\
\hline $\begin{array}{l}\text { ANV vor } \\
\text { Aufnahme }\end{array}$ & $(6,9 \%)$ & $11 \quad(23,4 \%)$ & $70,5 \%$ & $16,5 \%$ & 0,0337 \\
\hline
\end{tabular}

Tabelle 13: Häufigkeitsverteilung des akuten Nierenversagens (ANV) im Patienten- bzw. Kontrollkollektiv ohne additive Risikofaktoren; relative Risikoreduktion (RRR), absolute Risikoreduktion (ARR), Signifikanz (pWert) 
Bei Patienten, die einen Risikofaktor für die Entstehung einer CKI aufwiesen, verhielt sich die Tendenz annähernd gleich. In dieser Subgruppe konnte das relative Risiko für das akute Nierenversagen um 31,5\% reduziert werden. Dies entsprach einer Senkung der Häufigkeit von 40,3\% $(n=25)$ in der Kontrollgruppe auf 27,6\% $(n=21)$ in der mHT-Gruppe. Auch in dieser Subgruppe war ein hochsignifikanter Unterschied in der Häufigkeitsverteilung des ANV messbar $(\mathrm{p}<0,0001)$.

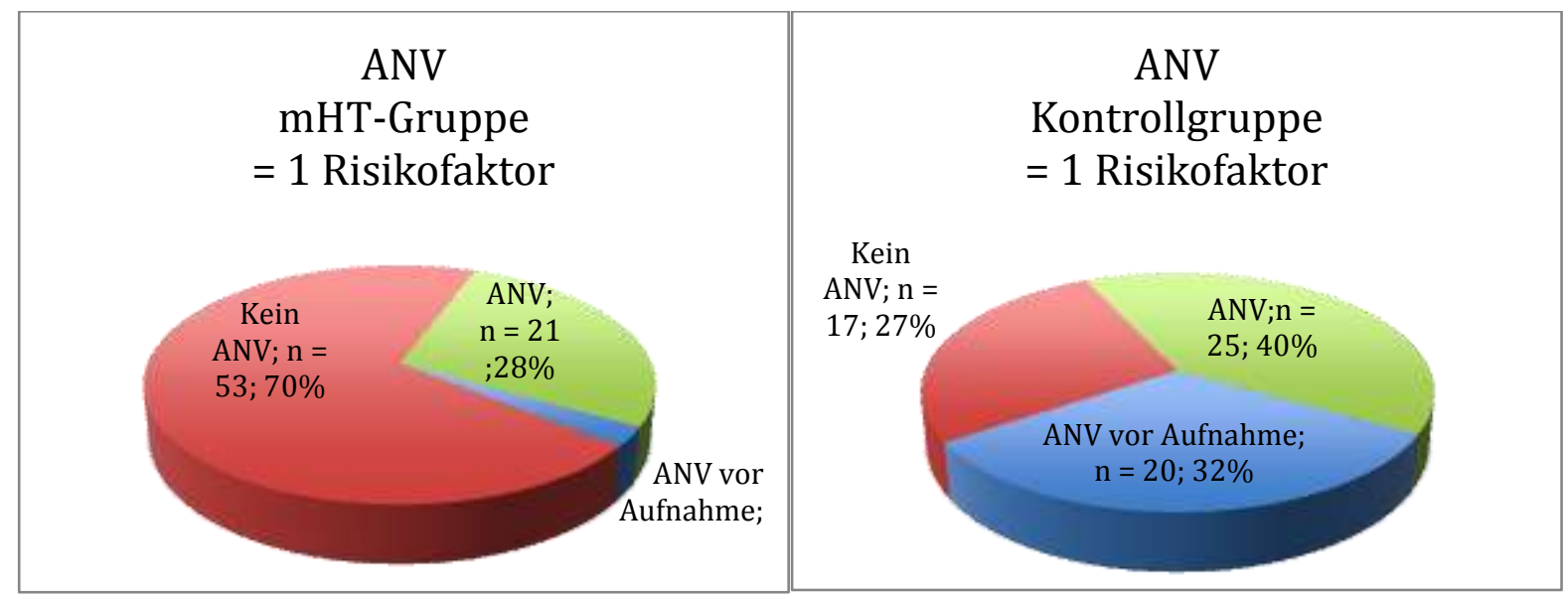

Abbildung 18: Absolute und prozentuale Häufigkeitsverteilung des akuten Nierenversagens der milden Hypothermie- und Kontrollgruppe mit einem Risikofaktor während der stationären Behandlung

\begin{tabular}{|c|c|c|c|c|c|}
\hline $\begin{array}{c}=1 \text { Risiko- } \\
\text { faktor }\end{array}$ & $\begin{array}{c}\text { mHT-Gruppe } \\
\mathrm{n}=76(100 \%)\end{array}$ & $\begin{array}{l}\text { Kontrollgruppe } \\
\mathrm{n}=62(100 \%)\end{array}$ & RRR & ARR & p-Wert \\
\hline Kein ANV & $53 \quad(69,7 \%)$ & $17 \quad(27,4 \%)$ & $-154,3 \%$ & $-42,3 \%$ & $<0,0001$ \\
\hline ANV & $21 \quad(27,6 \%)$ & $25 \quad(40,3 \%)$ & $31,5 \%$ & $12,7 \%$ & 0,0179 \\
\hline $\begin{array}{l}\text { ANV vor } \\
\text { Aufnahme }\end{array}$ & $(2,6 \%)$ & $20 \quad(32,3 \%)$ & $91,8 \%$ & $29,6 \%$ & $<0,0001$ \\
\hline
\end{tabular}

Tabelle 14: Häufigkeitsverteilung des akuten Nierenversagens (ANV) in Abhängigkeit von der Risikofaktorklasse (ein Risikofaktor); relative Risikoreduktion (RRR), absolute Risikoreduktion (ARR), Signifikanz (p-Wert)

In der Subgruppe, welche mehr als einen Risikofaktor für die Erkrankung an einer CKI hatte, bestand ebenso eine signifikant günstigere Verteilung der Auftretenswahrscheinlichkeit des ANV $(\mathrm{p}<0,0001)$.

In der mHT-Gruppe erlitten 35,3\% $(\mathrm{n}=24)$ der Studienteilnehmer mit mehr als einem Risikofaktor ein ANV. Die entsprechende Kontrollgruppe wies eine Erkrankungswahrscheinlichkeit von 48,6\% $(n=17)$ auf. Hiermit lag die Wahrscheinlichkeit 
für ein ANV in der milden Hypothermiegruppe um 13,3\% niedriger als in der Kontrollgruppe. Die relative Risikoreduktion, bezogen auf das ANV, betrug in dieser Subgruppe $27,3 \%$.

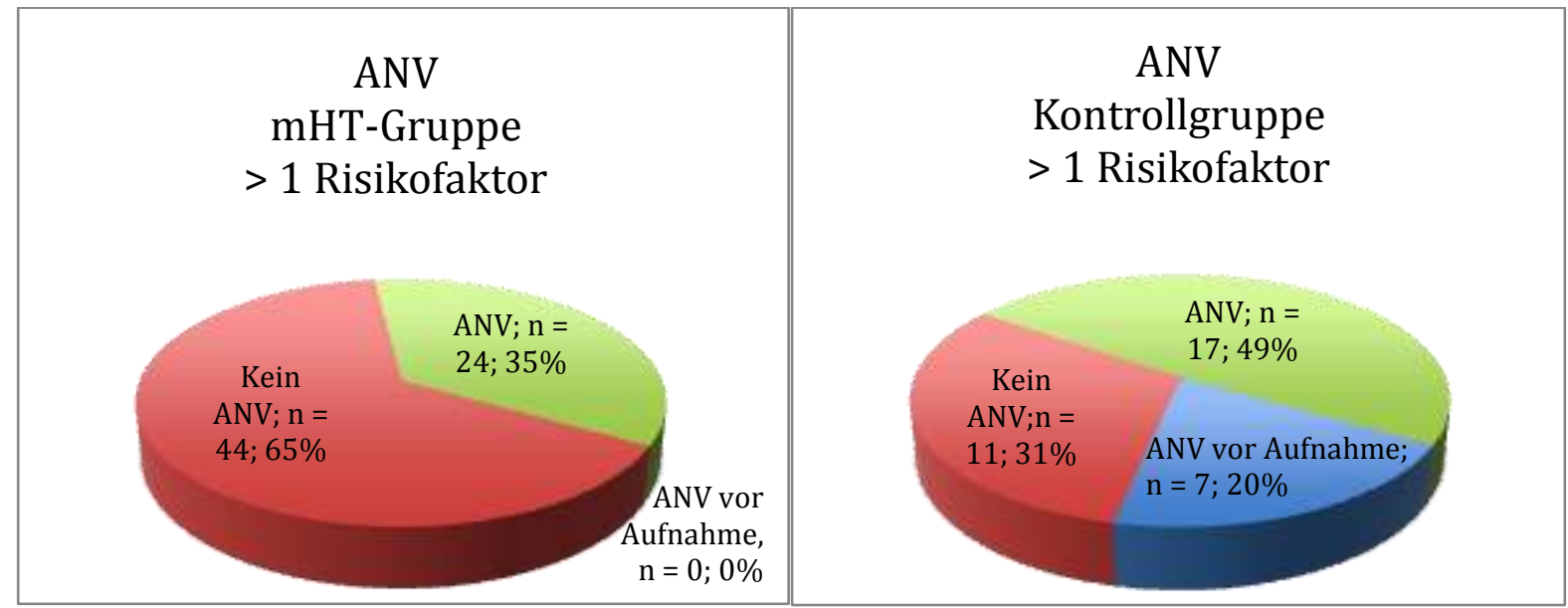

Abbildung 19: Absolute und prozentuale Häufigkeitsverteilung des akuten Nierenversagens der milden Hypothermie- und Kontrollgruppe mit mehr als einem Risikofaktor während der stationären Behandlung

\begin{tabular}{|c|c|c|c|c|c|}
\hline $\begin{array}{l}>1 \text { Risiko- } \\
\text { faktor }\end{array}$ & $\begin{array}{c}\text { mHT-Gruppe } \\
\mathrm{n}=68(100 \%)\end{array}$ & $\begin{array}{l}\text { Kontrollgruppe } \\
\mathrm{n}=35(100 \%)\end{array}$ & RRR & ARR & p-Wert \\
\hline Kein ANV & $44 \quad(64,7 \%)$ & $11 \quad(31,4 \%)$ & $-105,9 \%$ & $-33,3 \%$ & 0,0013 \\
\hline ANV & $24 \quad(35,3 \%)$ & $17 \quad(48,6 \%)$ & $27,3 \%$ & $13,3 \%$ & 0,1923 \\
\hline $\begin{array}{l}\text { ANV vor } \\
\text { Aufnahme }\end{array}$ & $0 \quad(0,0 \%)$ & $7 \quad(20,0 \%)$ & $100,0 \%$ & $20,0 \%$ & 0,0001 \\
\hline
\end{tabular}

Tabelle 15: Häufigkeitsverteilung des akuten Nierenversagens (ANV) in Abhängigkeit von der Risikofaktorklasse (mehr als ein Risikofaktor); relative Risikoreduktion (RRR), absolute Risikoreduktion (ARR), Signifikanz (p-Wert)

Betrachtet man die Häufigkeitsverteilung des akuten Nierenversagen exklusiv für die milde Hypothermie ergab sich kein signifikanter Unterschied $(\mathrm{p}=0,1558)$ zwischen den drei Risikofaktorklassen. Die drei Subgruppen verhielten sich somit annähernd gleich.

\subsubsection{Zeitpunkt des akuten Nierenversagens}

Betrachtet man die Patienten beider Kollektive, die ein akutes Nierenversagen erlitten, einzeln und vergleicht den Diagnosezeitpunkt, ergibt sich die Abbildung 20. Patienten, die gekühlt wurden und ein akutes Nierenversagen erlitten $(n=59)$, erkrankten durchschnittlich am 1,4 Tag $(\mathrm{SEM} \pm 0,2)$. In dem Kontrollkollektiv $(\mathrm{n}=66)$ lag der mittlere Erkrankungszeitpunkt bei 
1,8 Tagen $(\mathrm{SEM} \pm 0,5)$. Der Unterschied zwischen den Erkrankungszeitpunkten lag jedoch außerhalb des Signifikanzniveaus $(\mathrm{p}=0,4342)$.

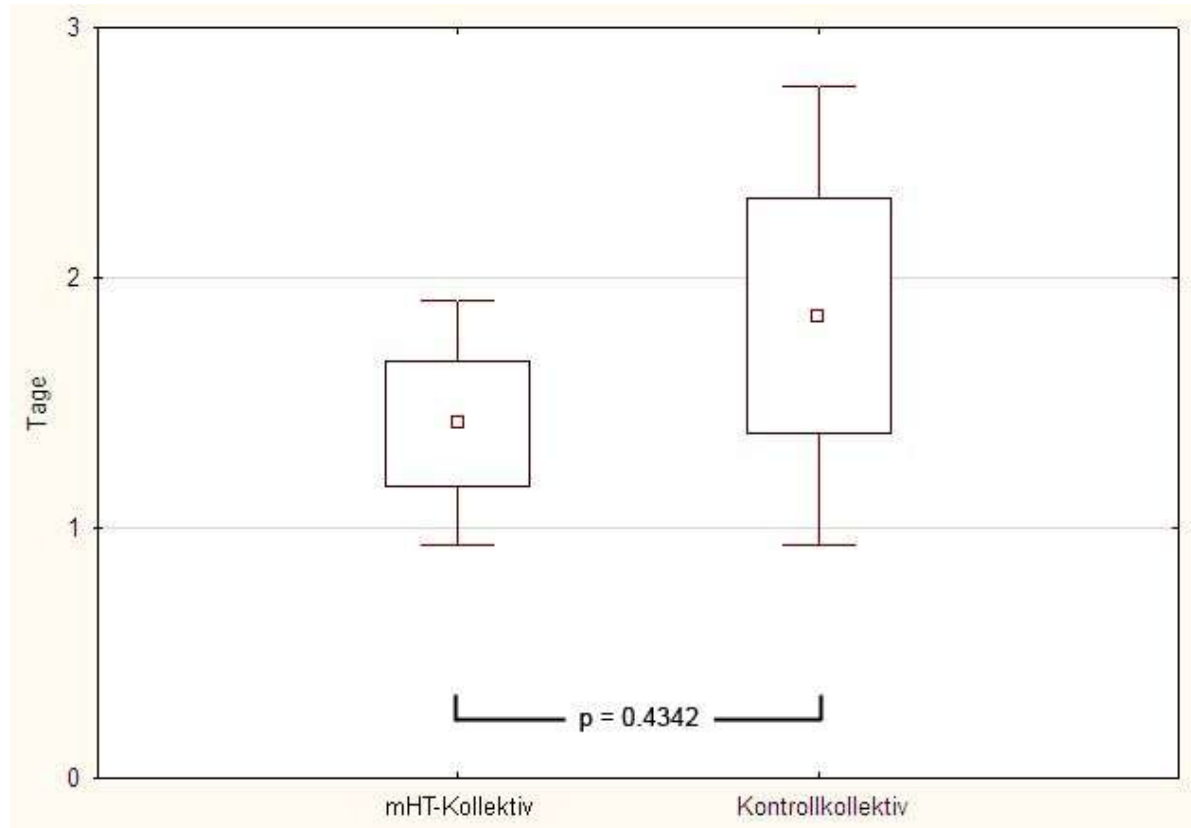

Abbildung 20: Der zeitliche Beginn (Tage) des akuten Nierenversagens des milden Hypothermie- und Kontrollkollektivs während der stationären Behandlung an der UMG; Mittelwert (Punkt), Mittelwert \pm SEM (Box), 95\%iges Konfidenzintervall (Whisker) 


\subsection{Zustand des Patienten zum Zeitpunkt der Entlassung}

Im folgenden Abschnitt wurde die Nierenfunktion der einzelnen Studienteilnehmer zum Zeitpunkt der Entlassung aus der UMG untersucht. Zum Endzeitpunkt konnten alle Patienten einer der drei definierten Kategorien zugeteilt und als abhängige Variable betrachtet werden.

Tod: Der Patient verstarb während der stationären Behandlung

CKI: $\quad$ Zum Zeitpunkt der Entlassung aus der UMG bestand eine aktenanamnestische chronische Niereninsuffizienz

NKF: Der Patient konnte mit einer uneingeschränkten Nierenfunktion entlassen werden.

Als unabhängige Variable wurde die Durchführung oder Nicht-Durchführung einer mHT nach kardiopulmonaler Reanimation festgelegt.

Zusätzlich wurde die Beeinflussung des Outcomes (Nierenfunktion) unter Berücksichtigung der einzelnen Kofaktoren - Geschlecht, DM und Risikofaktoren für eine CKI - evaluiert.

Für die durchgeführten Untersuchungen wurden alle Patienten $(n=346)$ mit in die Studie einbezogen. Eine Differenzierung bezüglich der Art und Weise der durchgeführten milden Hypothermie wurde für das gesamte Patientenkollektiv nicht vorgenommen.

\subsubsection{Globale Häufigkeitsverteilung des Outcomes}

Im Patientenkollektiv $(n=202)$ verstarben 45,5\% $(n=92)$ der Studienteilnehmer während der stationären Behandlung. Mit einer chronischen Niereninsuffizienz wurden 5,0 \% $(\mathrm{n}=10)$ der Patienten in die ambulante Weiterbehandlung entlassen und 49,5\% $(\mathrm{n}=100)$ der Patienten des milden Hypothermiekollektivs konnten die UMG mit einer uneingeschränkten Nierenfunktion verlassen.

In dem Kontrollkollektiv $(n=144)$ verstarben insgesamt $51,4 \%(n=74)$ der Patienten während der stationären Behandlung am UKG. 20,8 \% $(n=30)$ der Studienteilnehmer hatten zum Endzeitpunkt eine CKI und lediglich 27,8\% $(\mathrm{n}=40)$ konnten mit einer uneingeschränkten Nierenfunktion aus dem Klinikum entlassen werden.

Daraus ergab sich im Gesamtkollektiv ein hochsignifikanter Unterschied $(\mathrm{p}<0,0001)$ bezüglich der Nierenfunktion zum Endzeitpunkt der Behandlung. 


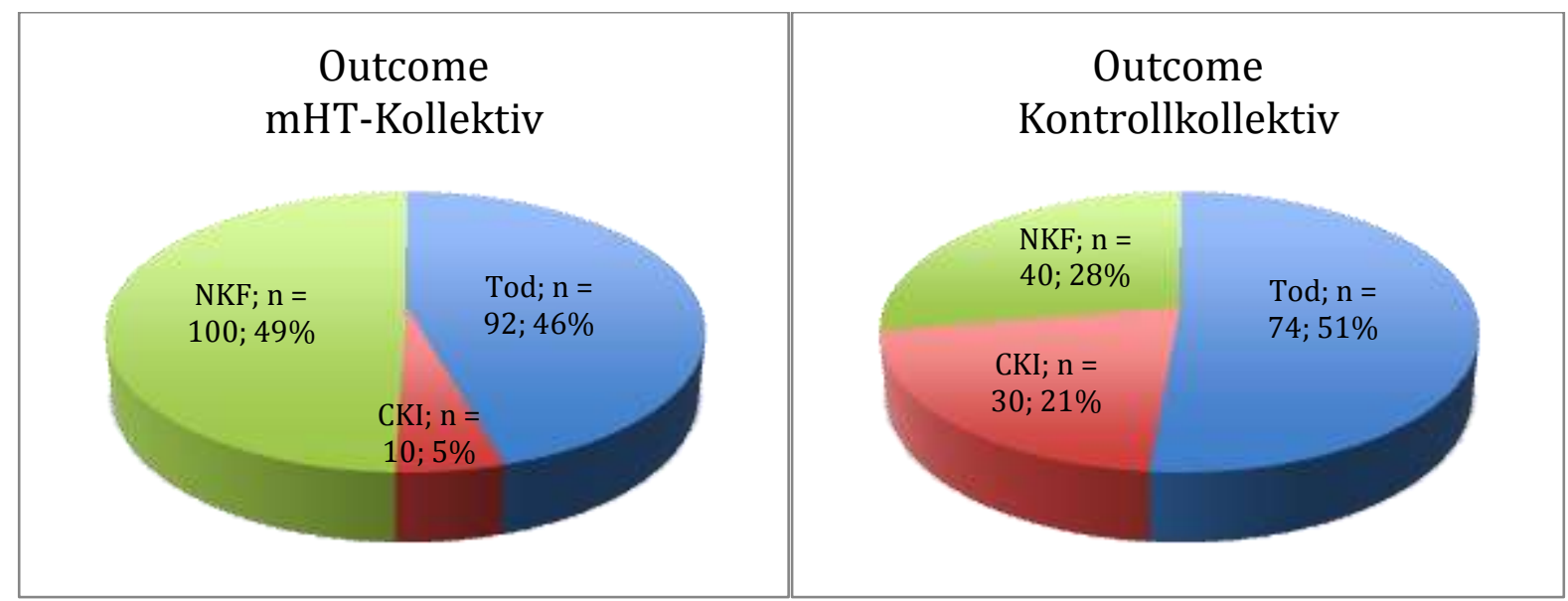

Abbildung 21: Absolute und prozentuale Häufigkeitsverteilung des Outcomes im milden Hypothermie- und Kontrollkollektiv zum Zeitpunkt der Entlassung aus der Universitätsmedizin Göttingen

\begin{tabular}{|c|c|c|c|c|c|}
\hline Global & $\begin{array}{l}\text { mHT-Kollektiv } \\
\mathrm{n}=202(100 \%)\end{array}$ & $\begin{array}{c}\text { Kontrollkollektiv } \\
\mathrm{n}=144(100 \%)\end{array}$ & RRR & ARR & $\mathrm{p}$-Wert \\
\hline Tod & $(45,5 \%)$ & $(51,4 \%)$ & $11,4 \%$ & $5,8 \%$ & 0,2835 \\
\hline CKI & $(5,0 \%)$ & $(20,8 \%)$ & $76,2 \%$ & $15,9 \%$ & $<0,0001$ \\
\hline $\mathrm{NKF}$ & $(49,5 \%)$ & $(27,8 \%)$ & $-78,2 \%$ & $-21,7 \%$ & $<0,0001$ \\
\hline
\end{tabular}

Tabelle 16: Häufigkeitsverteilung des Outcomes unter globaler Betrachtung; relative Risikoreduktion (RRR), absolute Risikoreduktion (ARR), Signifikanz (p-Wert)

Ferner zeigte sich, dass die milde Hypothermie zu einer RRR von 76,2 \% in Bezug auf die Auftretenswahrscheinlichkeit einer CKI zum Endzeitpunkt der Untersuchung führte. Die ARR lag bei $15,9 \%$.

Die Wahrscheinlichkeit für den Exitus letalis eines Patienten war in dem mHT-Kollektiv 5,8 \% niedriger im Vergleich zum Kontrollkollektiv. 


\subsubsection{Häufigkeitsverteilung des Outcomes unter Berücksichtigung des}

\section{Geschlechtes als Kofaktor}

Bezieht man das Geschlecht als Kofaktor mit in die Auswertung ein, zeigte sich eine ähnliche Tendenz in Bezug auf die Risikoreduktion wie unter der globalen Betrachtung.

In der männlichen milden Hypothermiegruppe, erlitten 4,7\% $(n=7)$ der Patienten ein chronisches Nierenversagen und 23,8 \% $(\mathrm{n}=20)$ der Männer der Kontrollgruppe. Daraus ergab sich eine RRR von $80,1 \%$.

Betrachtet man den Endpunkt Tod, verstarben in der männlichen mHT-Gruppe 41,2 \% $(n=61)$ der Männer und in der Kontrollgruppe 44,1\% $(n=37)$ der Patienten. Hieraus ergab sich eine lediglich geringe Reduktion des relativen Risikos von 6,4 \%.

Unter Einzelbetrachtung bestand weiterhin ein signifikanter Unterscheid zwischen den beiden männlichen Subgruppen und ihrem Outcome ( $<<0,0001)$.

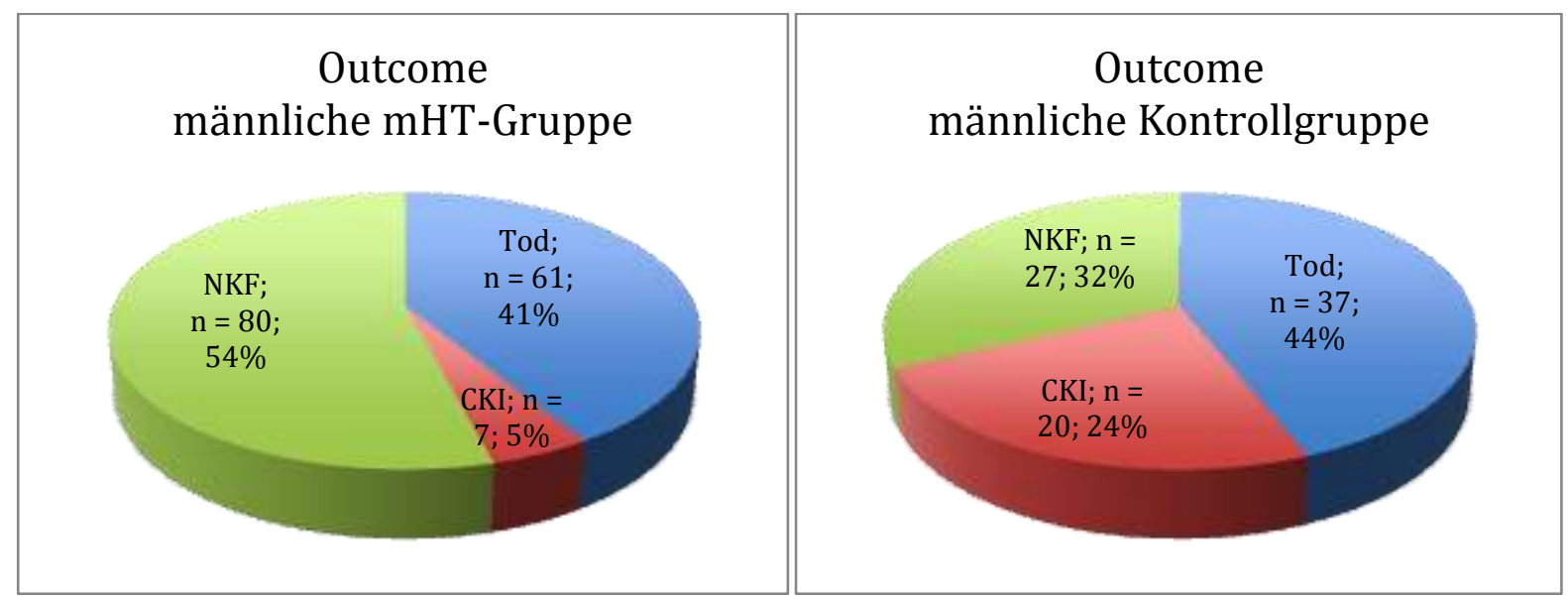

Abbildung 22: Absolute und prozentuale Häufigkeitsverteilung des Outcomes in der männlichen milden Hypothermie- und Kontrollgruppe zum Zeitpunkt der Entlassung

\begin{tabular}{|c|rr|rr|r|r|r|}
\hline \multirow{2}{*}{ Männer } & \multicolumn{2}{|c|}{ mHT-Gruppe } & \multicolumn{2}{|c|}{ Kontrollgruppe } & \multicolumn{2}{|c|}{ RRR } & \multicolumn{2}{|c|}{ ARR } & \multicolumn{1}{c|}{ p-Wert } \\
\hline Tod & 61 & $(41,2 \%)$ & 37 & $(44,1 \%)$ & $6,4 \%$ & $2,8 \%$ & 0,6748 \\
CKI & 7 & $(4,7 \%)$ & 20 & $(23,8 \%)$ & $80,1 \%$ & $19,1 \%$ & $<0,0001$ \\
NKF & 80 & $(54,1 \%)$ & 27 & $(32,1 \%)$ & $-68,2 \%$ & $-21,9 \%$ & 0,0013 \\
\hline
\end{tabular}

Tabelle 17: Häufigkeitsverteilung des Outcomes in Abhängigkeit vom männlichen Geschlecht; relative Risikoreduktion (RRR), absolute Risikoreduktion (ARR), Signifikanz (p-Wert) 
Frauen wiesen in der mHT-Gruppe eine Wahrscheinlichkeit von 5,6\% (n=3) auf, nach Klinikaufenthalt eine fortbestehende CKI zu erleiden. In der weiblichen Kontrollgruppe lag das Risiko bei $15,0 \%(n=9)$. Hieraus ergab sich eine ARR von 9,4\% und eine RRR von $63,0 \%$. Jedoch war der Unterschied zwischen den weiblichen Subgruppen und ihrem Outcome nicht signifikant $(\mathrm{p}=0,1174)$.

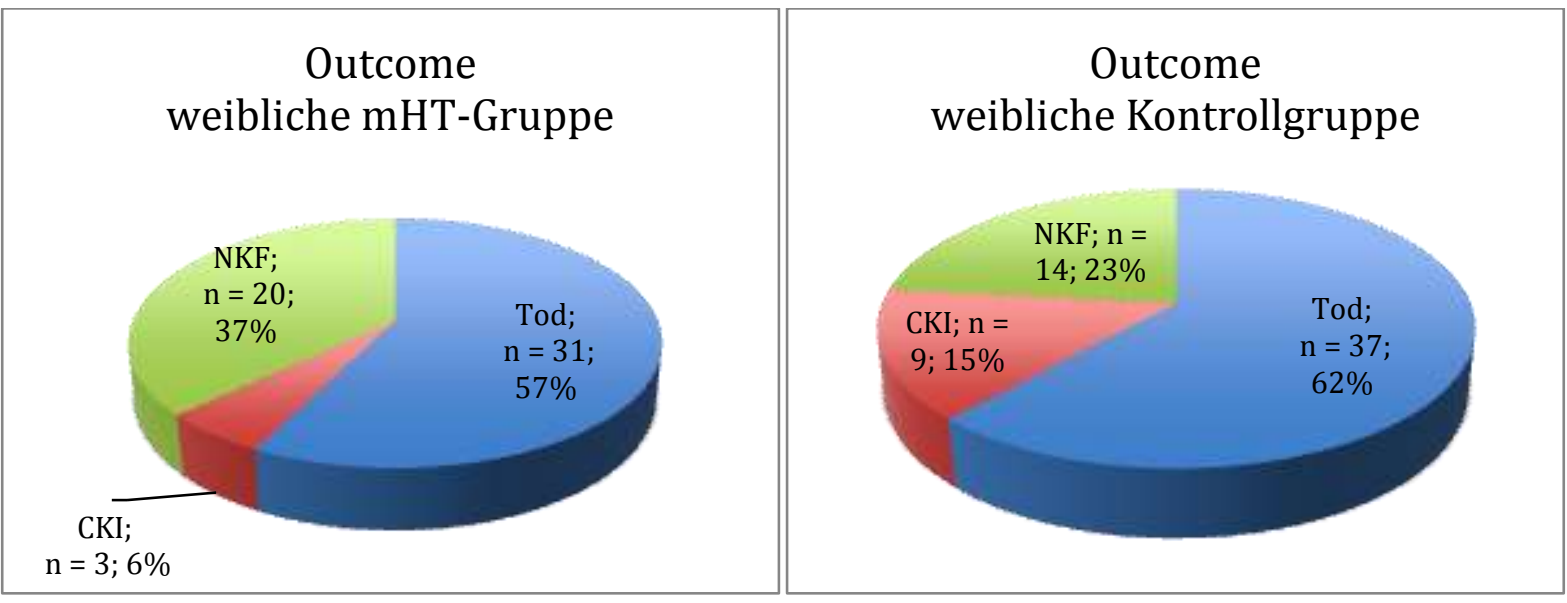

Abbildung 23: Absolute und prozentuale Häufigkeitsverteilung des Outcomes in der weiblichen milden Hypothermie- und Kontrollgruppe zum Zeitpunkt der Entlassung

\begin{tabular}{|c|rr|rr|r|r|r|}
\hline \multirow{2}{*}{ Frauen } & \multicolumn{2}{|c|}{ mHT-Gruppe } & \multicolumn{2}{|c|}{ Kontrollgruppe } & \multicolumn{1}{|c|}{ RRR } & \multicolumn{1}{c|}{ ARR } & \multicolumn{1}{c|}{-Wert } \\
\hline Tod & 31 & $(57,4 \%)$ & 37 & $(61,7 \%)$ & $6,9 \%$ & $4,3 \%$ & 0,6435 \\
CKI & 3 & $(5,6 \%)$ & 9 & $(15,0 \%)$ & $63,0 \%$ & $9,4 \%$ & 0,1009 \\
NKF & 20 & $(37,0 \%)$ & 14 & $(23,3 \%)$ & $-58,7 \%$ & $-13,7 \%$ & 0,1103 \\
\hline
\end{tabular}

Tabelle 18: Häufigkeitsverteilung des Outcomes in Abhängigkeit vom weiblichen Geschlecht; relative Risikoreduktion (RRR), absolute Risikoreduktion (ARR), Signifikanz (p-Wert)

Das männliche Geschlecht zeigte tendenziell eine höhere Wahrscheinlichkeit für eine normale Nierenfunktion bei Entlassung als das weibliche. Für die Auftretenswahrscheinlichkeit des Exitus letalis nach Durchführung der milden Hypothermie ergab sich eine geringere Wahrscheinlichkeit für Männer als für Frauen. Der Unterschied bezüglich des Outcomes zwischen männlicher und weiblicher milder Hypothermiegruppe war jedoch nicht signifikant $(p=0,0980)$. 


\subsubsection{Häufigkeitsverteilung des Outcomes unter Berücksichtigung von}

\section{Diabetes mellitus als Kofaktor}

Das Outcome der beiden Kollektive gruppiert über den Kofaktor DM visualisieren die im folgenden dargestellten Abbildungen (Abb. $24 u$ u. 25).

Studienteilnehmer, welche einen DM vor Aufnahme hatten, zeigten im Vergleich zu NichtDiabetikern einen knapp nicht signifikanten Unterschied in Bezug auf das Outcome und der Therapie mittels milder Hypothermie $(p=0,0542)$. Für Nicht-Diabetiker bestand ein hochsignifikanter Unterschied zwischen der mHT- und Kontrollgruppe bezogen auf das Outcome $(\mathrm{p}<0,0001)$.

In der Subgruppe der Nicht-Diabetiker lag die Auftretenswahrscheinlichkeit des chronischen Nierenversagens bei 5,9\% $(n=10)$ in der milden Hypothermiegruppe und bei 22,4 \% $(n=24)$ in der Kontrollgruppe. Dies entsprach einer RRR von 73,8 \% und einer ARR von 16,6 \% (p = 0,0006). Die Sterblichkeit lag in der Kontrollgruppe bei 46,7\% $(\mathrm{n}=50)$ im Vergleich zu $42,4 \%(n=72)$ in der mHT-Gruppe. Der Unterschied war nicht signifikant $(p=0,4750)$.

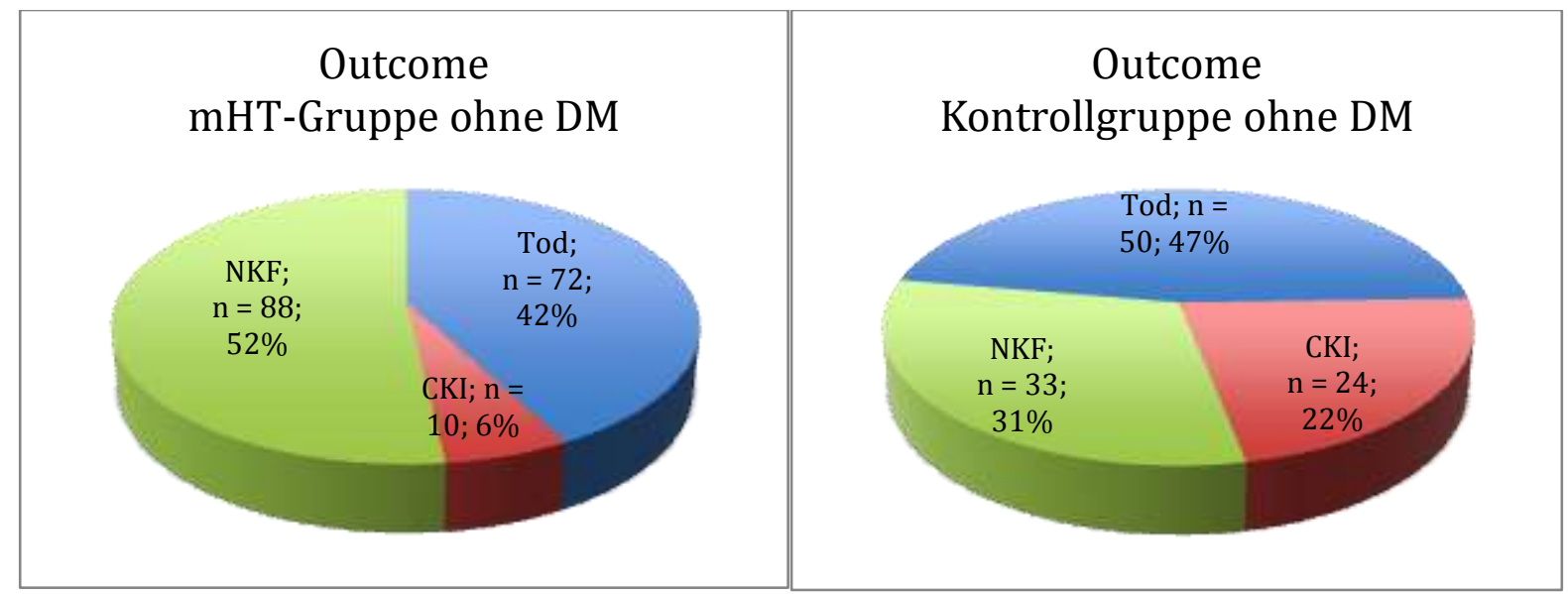

Abbildung 24: Absolute und prozentuale Häufigkeitsverteilung des Outcomes der Nicht-Diabetiker in der milden Hypothermie- und Kontrollgruppe zum Zeitpunkt der Entlassung

\begin{tabular}{|c|c|c|c|c|c|}
\hline $\begin{array}{c}\text { Ohne } \\
\text { DM }\end{array}$ & $\begin{array}{c}\text { mHT-Gruppe } \\
\mathrm{n}=170(100 \%)\end{array}$ & $\begin{array}{c}\text { Kontrollgruppe } \\
\mathrm{n}=107(100 \%)\end{array}$ & RRR & ARR & $\mathrm{p}$-Wert \\
\hline Tod & $72 \quad(42,4 \%)$ & $50 \quad(46,7 \%)$ & $9,4 \%$ & $4,4 \%$ & 0,4750 \\
\hline CKI & $(5,9 \%)$ & $(22,4 \%)$ & $73,8 \%$ & $16,6 \%$ & $<0,0001$ \\
\hline $\mathrm{NKF}$ & $(51,8 \%)$ & $(30,8 \%)$ & $-67,8 \%$ & $-21,0 \%$ & 0,0006 \\
\hline
\end{tabular}

Tabelle 19: Häufigkeitsverteilung des Outcomes bei Nicht-Diabetikern; relative Risikoreduktion (RRR), absolute Risikoreduktion (ARR), Signifikanz (p-Wert) 
In der mHT-Gruppe hatte zum Endzeitpunkt keiner der Diabetiker eine CKI und 37,5\% $(n=12)$ der Patienten konnten mit einer normwertigen Nierenfunktion aus der UMG entlassen werden. In dem entsprechenden Kontrollgruppe hatten 13,5\% $(n=5)$ der Diabetiker eine CKI und 21,6\% $(n=8)$ des Kollektivs konnten mit einer uneingeschränkten Nierenfunktion entlassen werden. Dies entsprach einer RRR bezogen auf die CKI bei Diabetikern und der Behandlung mittels milder Hypothermie von $100 \%$. Die ARR in dieser Gruppe betrug $13,5 \%$.

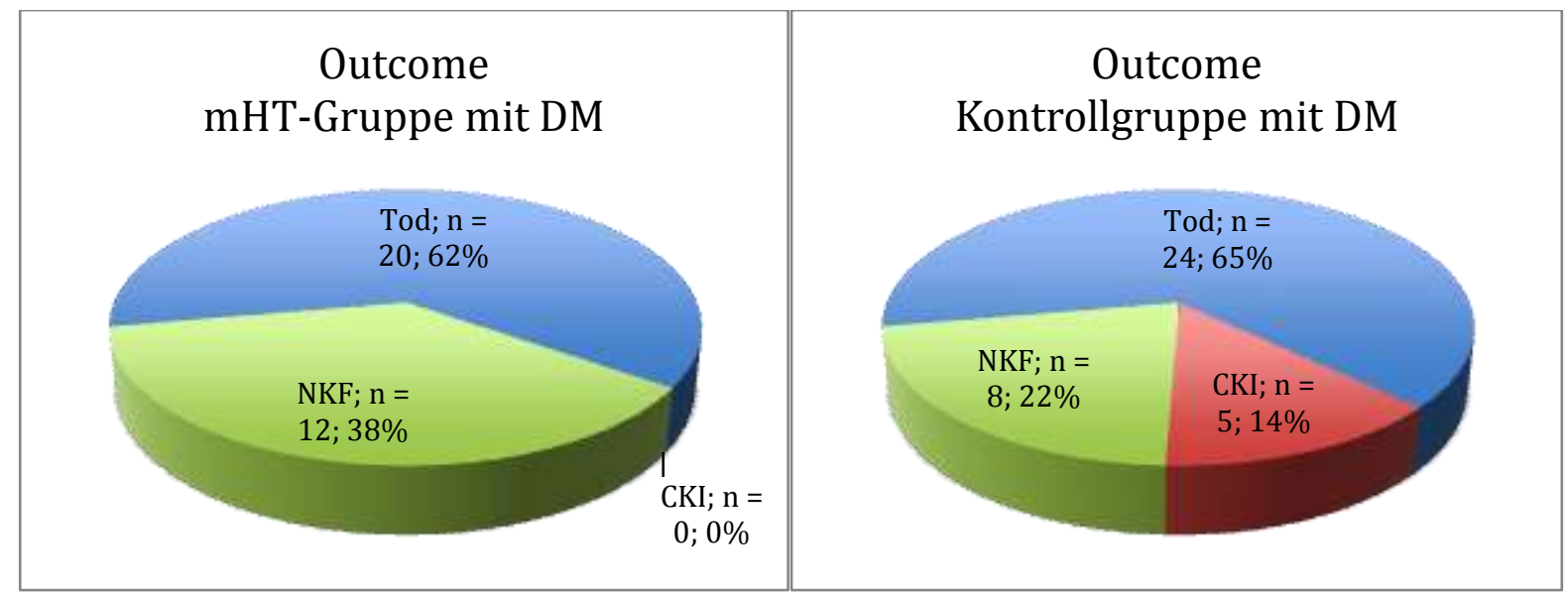

Abbildung 25: Absolute und prozentuale Häufigkeitsverteilung des Outcomes der Diabetiker in der milden Hypothermie- und Kontrollgruppe zum Zeitpunkt der Entlassung

\begin{tabular}{|c|c|c|c|c|c|}
\hline $\begin{array}{l}\text { Diabetes } \\
\text { mellitus }\end{array}$ & $\begin{array}{c}\text { mHT-Gruppe } \\
\mathrm{n}=32(100 \%)\end{array}$ & $\begin{array}{l}\text { Kontrollgruppe } \\
\mathrm{n}=37(100 \%)\end{array}$ & RRR & ARR & p-Wert \\
\hline Tod & $(62,5 \%)$ & $(64,9 \%)$ & $3,7 \%$ & $2,4 \%$ & 0,9623 \\
\hline CKI & $(0,0 \%)$ & $(13,5 \%)$ & $100,0 \%$ & $13,5 \%$ & 0,0903 \\
\hline $\mathrm{NKF}$ & $(37,5 \%)$ & $(21,6 \%)$ & $-73,4 \%$ & $-15,9 \%$ & 0,2365 \\
\hline
\end{tabular}

Tabelle 20: Häufigkeitsverteilung des Outcomes in Abhängigkeit von einer Diabetes-mellitus-Erkrankung; relative Risikoreduktion (RRR), absolute Risikoreduktion (ARR), Signifikanz (p-Wert)

Zwischen Diabetikern und Nicht-Diabetikern ergab sich für die Durchführung der milden Hypothermie ein annähernd signifikanter Unterschied bezüglich des Outcomes $(p=0,0676)$. In beiden mHT-Gruppen sank jedoch das Risiko für eine chronische Niereninsuffizienz. 


\subsubsection{Häufigkeitsverteilung des Outcomes unter Berücksichtigung der}

\section{Risikofaktorklassen als Kofaktor}

Betrachtet man den Gesundheitszustand der Studienteilnehmer unter Berücksichtigung der einzelnen Risikofaktorklassen als Kofaktor, zeigten sich die in den Abbildungen 26 bis 28 dargestellten Häufigkeitsverteilungen. Die statistische Auswertung ergab für alle drei Modelle einen signifikanten Unterschied für das Outcome zwischen den einzelnen Hypothermie- und Kontrollgruppen.

Den höchsten Benefit erzielten Patienten, die keinen Risikofaktor für die Entstehung einer CKI hatten. In dieser Subgruppe wiesen lediglich $1,7 \%(n=1)$ der mHT-Gruppe zum Zeitpunkt der Entlassung eine CKI auf. Die Auftretenswahrscheinlichkeit für eine CKI in der Kontrollgruppe lag zur Entlassung aus der UMG bei 19,1\% $(\mathrm{n}=9)$. Dies entsprach einer ARR von 17,4\%, bei einer RRR von 91,0\%. Die Sterblichkeit in dieser Subgruppe blieb annähernd konstant bei ca. $50 \%$.

Der Unterschied zwischen dem Outcome der milde Hypothermie- und der Kontrollgruppe war für Patienten mit keinem Risikofaktor signifikant ( $\mathrm{p}=0,0052)$.

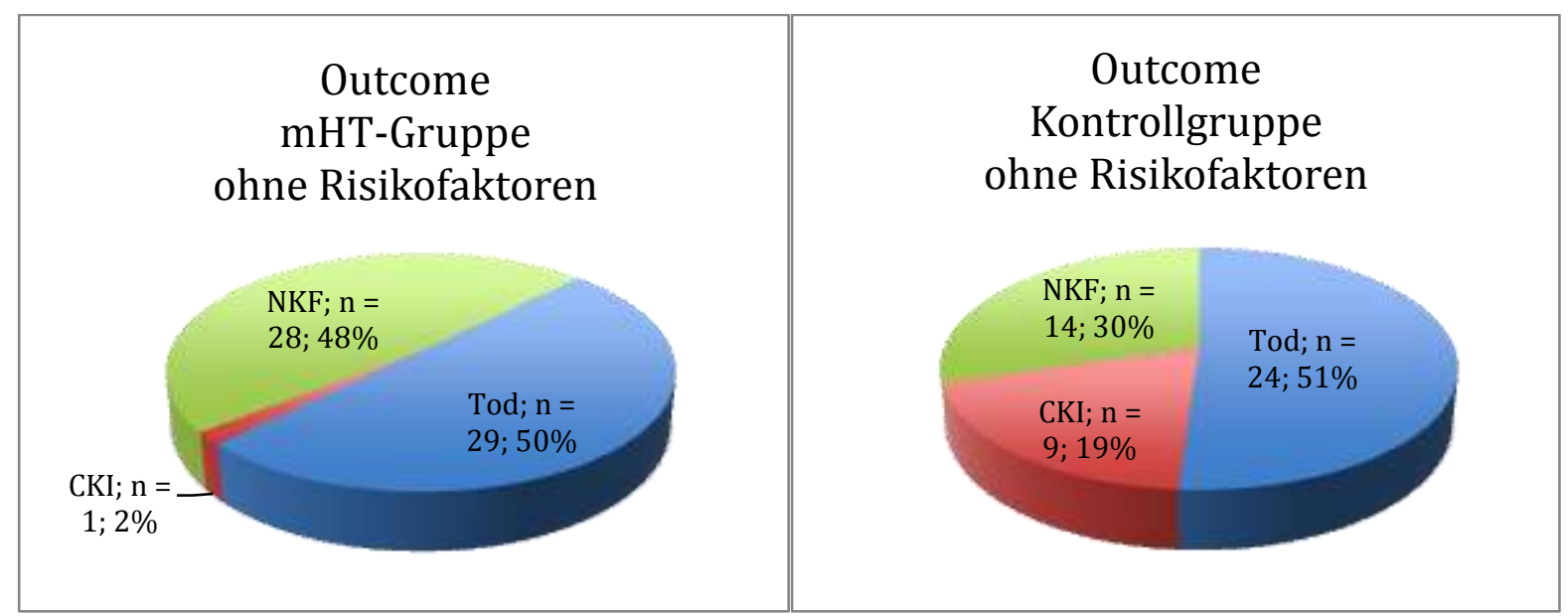

Abbildung 26: Absolute und prozentuale Häufigkeitsverteilung des Outcomes in der milden Hypothermie- und Kontrollgruppe ohne additive Risikofaktoren für eine CKI zum Zeitpunkt der Entlassung

\begin{tabular}{|c|c|c|c|c|c|c|c|}
\hline $\begin{array}{l}\text { Ohne Risiko- } \\
\text { faktor }\end{array}$ & \multicolumn{2}{|c|}{$\begin{array}{c}\text { mHT-Gruppe } \\
\mathrm{n}=58(100 \%)\end{array}$} & \multicolumn{2}{|c|}{$\begin{array}{l}\text { Kontrollgruppe } \\
\mathrm{n}=47(100 \%)\end{array}$} & RRR & ARR & p-Wert \\
\hline Tod & 29 & $(50,0 \%)$ & 24 & $(51,1 \%)$ & $2,1 \%$ & $1,1 \%$ & 0,9300 \\
\hline CKI & 1 & $(1,7 \%)$ & 9 & $(19,1 \%)$ & $91,0 \%$ & $17,4 \%$ & 0,0071 \\
\hline NKF & 28 & $(48,3 \%)$ & 14 & $(29,8 \%)$ & $-62,1 \%$ & $-18,5 \%$ & 0,0850 \\
\hline
\end{tabular}

Tabelle 21: Häufigkeitsverteilung des Outcomes in Abhängigkeit von der Risikofaktorklasse (kein Risikofaktor); relative Risikoreduktion (RRR), absolute Risikoreduktion (ARR), Signifikanz (p-Wert) 
In der milden Hypothermiegruppe, die einen Risikofaktor aufwiesen, erkrankten 9,2\% (n=7) an einen CKI. Dies entsprach einer Reduktion des absoluten Risikos von 11,8 \% im Vergleich zu der Kontrollgruppe $(21,0 \%, \mathrm{n}=13)$ und einer RRR von $56,1 \%$. Für Patienten mit einem Risikofaktor sank die Sterblichkeit in der mHT-Gruppe um 10,8\% auf 40,8\%. Es bestand ebenfalls ein signifikanter Unterschied innerhalb dieser Subgruppe $(p=0,0143)$.

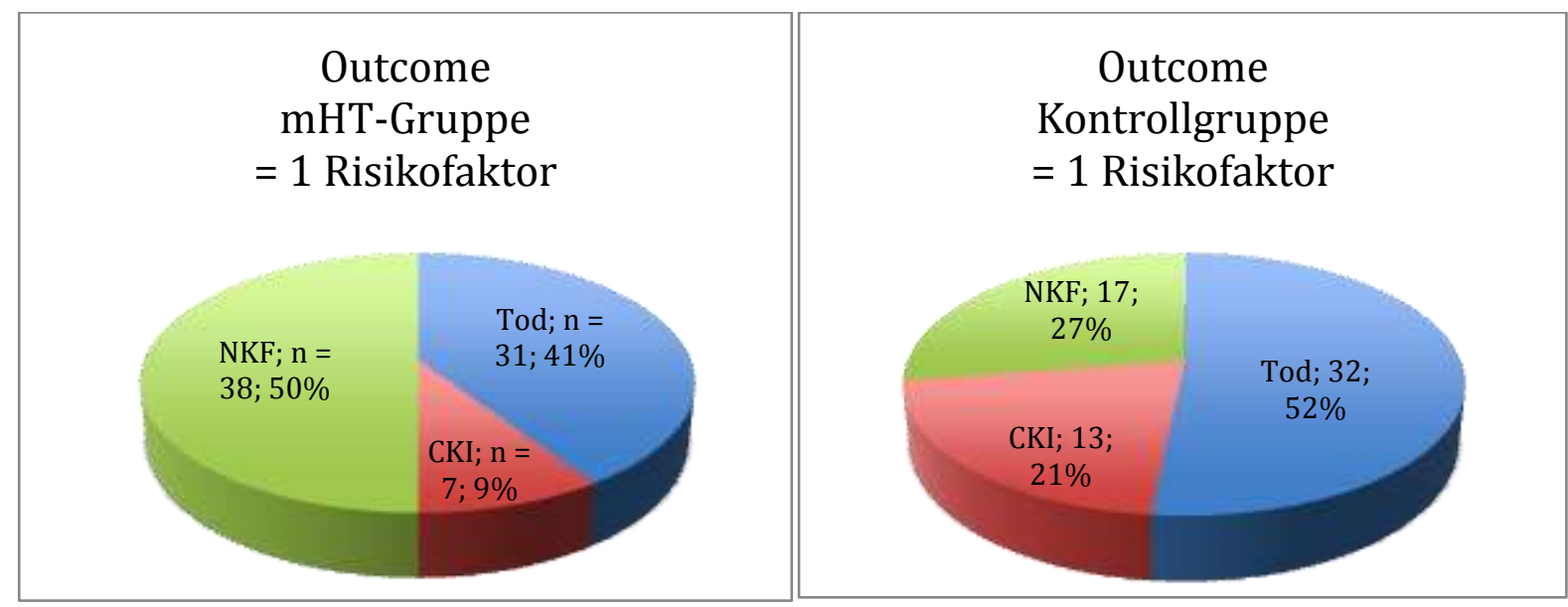

Abbildung 27: Absolute und prozentuale Häufigkeitsverteilung des Outcomes in der milden Hypothermie- und Kontrollgruppe mit einem Risikofaktor für eine chronische Niereninsuffizienz zum Zeitpunkt der Entlassung

\begin{tabular}{|c|c|c|c|c|c|c|c|}
\hline $\begin{aligned} &= 1 \text { Risiko- } \\
& \text { faktor }\end{aligned}$ & \multicolumn{2}{|c|}{$\begin{array}{c}\text { mHT-Gruppe } \\
\mathrm{n}=76(100 \%)\end{array}$} & \multicolumn{2}{|c|}{$\begin{array}{l}\text { Kontrollgruppe } \\
\mathrm{n}=62(100 \%)\end{array}$} & RRR & ARR & $\mathrm{p}$-Wert \\
\hline Tod & 31 & $(40,8 \%)$ & 32 & $(51,6 \%)$ & $21,0 \%$ & $10,8 \%$ & 0,2722 \\
\hline CKI & 7 & $(9,2 \%)$ & 13 & $(21,0 \%)$ & $56,1 \%$ & $11,8 \%$ & 0,0875 \\
\hline $\mathrm{NKF}$ & 38 & $(50,0 \%)$ & 17 & $(27,4 \%)$ & $-82,4 \%$ & $-22,6 \%$ & 0,0117 \\
\hline
\end{tabular}

Tabelle 22: Häufigkeitsverteilung des Outcomes in Abhängigkeit von der Risikofaktorklasse (ein Risikofaktor); relative Risikoreduktion (RRR), absolute Risikoreduktion (ARR), Signifikanz (p-Wert)

Für Studienteilnehmer, die mehr als einen Risikofaktor für die Entstehung einer CKI aufwiesen, ergab sich ein Erkrankungswahrscheinlichkeit von 2,9\% $(\mathrm{n}=2)$ in der mHTGruppe und 20,0\% $(\mathrm{n}=7)$ in der Kontrollgruppe. Daraus ergab sich für die milde Hypothermie eine ARR von $17,1 \%$ und eine RRR von $85,3 \%$ für das chronische Nierenversagen nach kardiopulmonaler Reanimation. Die Mortalität während der stationären Behandlung sank in der mHT-Gruppe um 4,4\%.

Das Outcome der Studienteilnehmer mit mehr als einem Risikofaktor stellte sich zwischen den beiden Gruppen weiterhin als signifikant unterschiedlich dar $(p=0,0059)$. 


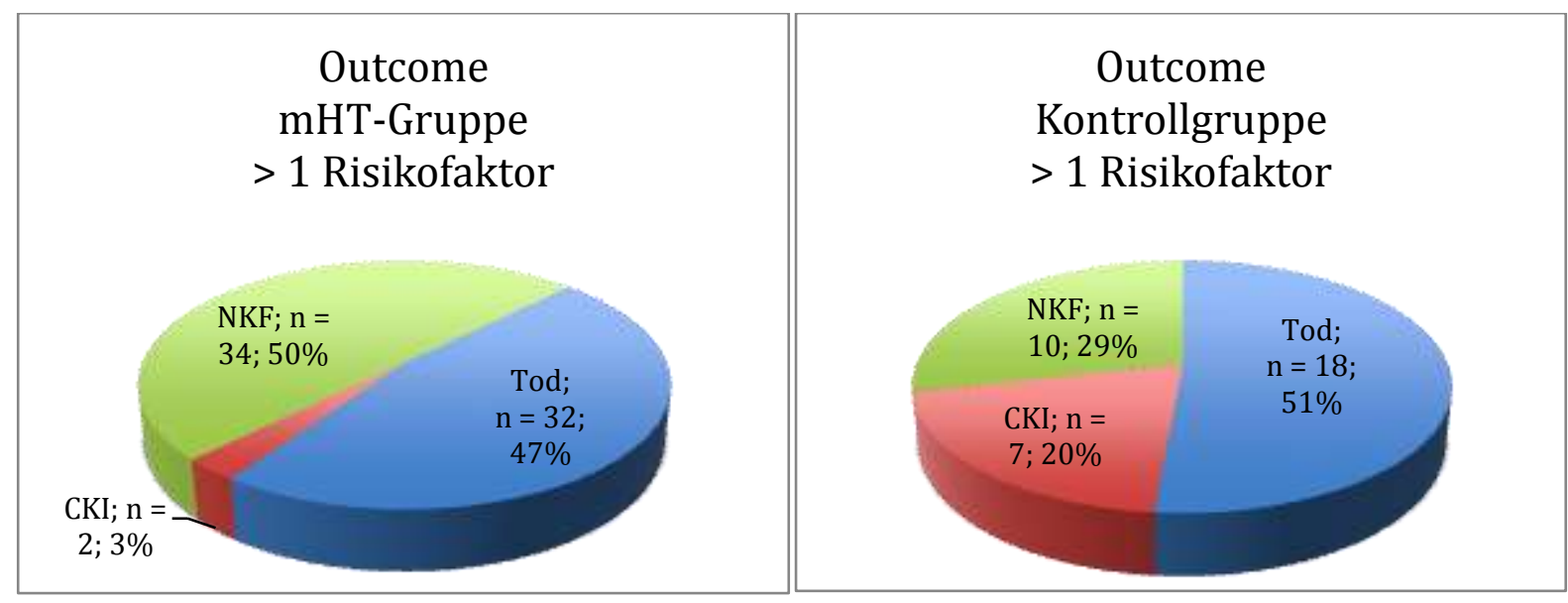

Abbildung 28: Absolute und prozentuale Häufigkeitsverteilung des Outcomes in der milden Hypothermie- und Kontrollgruppe mit mehr als einem Risikofaktor für eine chronische Niereninsuffizienz zum Zeitpunkt der Entlassung

\begin{tabular}{|c|c|c|c|c|c|c|c|}
\hline $\begin{array}{l}>1 \text { Risiko- } \\
\text { faktor }\end{array}$ & \multicolumn{2}{|c|}{$\begin{array}{c}\text { mHT-Gruppe } \\
\mathrm{n}=68(100 \%)\end{array}$} & \multicolumn{2}{|c|}{$\begin{array}{l}\text { Kontrollgruppe } \\
\mathrm{n}=35(100 \%)\end{array}$} & RRR & ARR & p-Wert \\
\hline Tod & 32 & $(47,1 \%)$ & 18 & $(51,4 \%)$ & $8,5 \%$ & $4,4 \%$ & 0,8320 \\
\hline CKI & 2 & $(2,9 \%)$ & 7 & $(20,0 \%)$ & $85,3 \%$ & $17,1 \%$ & 0,0112 \\
\hline $\mathrm{NKF}$ & 34 & $(50,0 \%)$ & 10 & $(28,6 \%)$ & $-75,0 \%$ & $-21,4 \%$ & 0,0612 \\
\hline
\end{tabular}

Tabelle 23: Häufigkeitsverteilung des Outcomes in Abhängigkeit von der Risikofaktorklasse (mehr als ein Risikofaktor); relative Risikoreduktion (RRR), absolute Risikoreduktion (ARR), Signifikanz (p-Wert)

Die drei mHT-Subgruppen verhielten sich bezüglich ihres Outcomes tendenziell gleich. Zwischen allen drei Risikofaktorklassen bestand nach der Durchführung der milden Hypothermie kein signifikanter Unterschied ( $p=0,2627)$ bezüglich des Outcomes. 


\subsection{Verlauf der glomerulären Filtrationsrate}

Im vorliegenden Abschnitt werden die errechneten MDRD-Werte $(\mathrm{ml} / \mathrm{min})$ in Abhängigkeit von dem Kollektiv und der Zeit (Tage) grafisch dargestellt.

Die MDRD-Werte wurden mittels Varianzanalyse für Messwiederholungen (ANOVA) errechnet und über die y-Achse aufgetragen. Sie bildete die abhängige Variable. Die Punkte geben den Mittelwert an. Die vertikalen Linien stellen das 95 \%ige Konfidenzintervall dar.

Die x-Achse gibt den zeitlichen Verlauf in Tagen wieder und ist in vier Zeitpunkte untergliedert (0. Tag = Aufnahmezeitpunkt, 3. Tag, 7. Tag, 14. Tag). Die MDRD-Messwertpunkte der beiden Kollektive wurden zur bildhaften Veranschaulichung mithilfe einer Graden verbunden. Diese gibt einen möglichen, nicht aber den gemessenen Verlauf wieder. Als unabhängige Variable wurde die Durchführung oder Nicht-Durchführung der milden Hypothermie festgelegt. Der Baselinewert sowie der APACHE II-Scores wurden als Kovariable mit in das Modell einbezogen. Alle angegebenen p-Werte wurden mittels Bonferroni-Methode adjustiert.

In den Kapiteln 3.4.2 bis 3.4.4 wird das zuvor beschriebene Modell unter Berücksichtigung des Geschlechtes, einer DM-Erkrankung oder der Anzahl der Risikofaktoren auf eine dreifaktorielle Varianzanalyse erweitert.

\subsubsection{Verlauf der glomerulären Filtrationsrate über die Zeit}

Die Abbildung 29 visualisiert den globalen Verlauf der MDRD-Werte (ml/min) der beiden Kollektive über den zeitlichen Verlauf (Tage). Zwischen der Gruppe und der Zeit konnte ein signifikanter Unterschied bezüglich der geschätzten glomerulären Filtrationsrate gemessen werden $(p=0,0406)$. Unter Betrachtung der Einzelmesszeitpunkte ergaben sich folgende Ergebnisse:

Zum Zeitpunkt der stationären Aufnahme betrug der mittlere MDRD-Wert in dem milden Hypothermiekollektiv 66,14 $\mathrm{ml} / \mathrm{min}(\mathrm{SEM} \pm 4,3)$ und in dem Kontrollkollektiv im Mittel 62,42 (SEM $\pm 6,3)$. Es bestand zum Beginn der Beobachtung kein signifikanter Unterschied $(\mathrm{p}=0,614)$ zwischen den beiden Kollektiven .

Am 3. Tag stieg das mHT-Kollektiv auf eine durchschnittliche glomeruläre Filtrationsrate (GFR) von $68,40 \mathrm{ml} / \mathrm{min}(\mathrm{SEM} \pm 2,7)$ an. Das Kontrollkollektiv fiel zunächst auf einen Wert von 52,55 ml/min (SEM $\pm 3,9)$. Diese gegenläufige Tendenz der Filtration beider Kollektive zeigte einen messbaren signifikanten Unterschied $(\mathrm{p}=0,0174)$. 
Nach 7 Tagen lag der mittlere MDRD-Wert des mHT-Kollektivs bei 81,05 $\mathrm{ml} / \mathrm{min}$ (SEM \pm 2,9) und in dem Kontrollkollektiv im Mittel bei 57,31 ml/min (SEM $\pm 4,0)$. Der Unterschied zwischen beiden Kohorten vergrößerte sich auf ein Signifikanzniveau von $p<0,0001$.

Zum Endzeitpunkt der Messung betrug der Mittelwert im milden mHT-Kollektiv 88,56 $\mathrm{ml} / \mathrm{min}(\mathrm{SEM} \pm 3,2)$. Das Kontrollkollektiv erreichte einen mittleren MDRD-Wert von 64,06 $\mathrm{ml} / \mathrm{min}$ (SEM \pm 4,2). Hiermit erwies sich die milde Hypothermie bezogen auf den Endzeitpunkt als ein hochsignifikanter Faktor im Bezug auf die glomeruläre Filtrationsrate $(\mathrm{p}<0,0001)$.

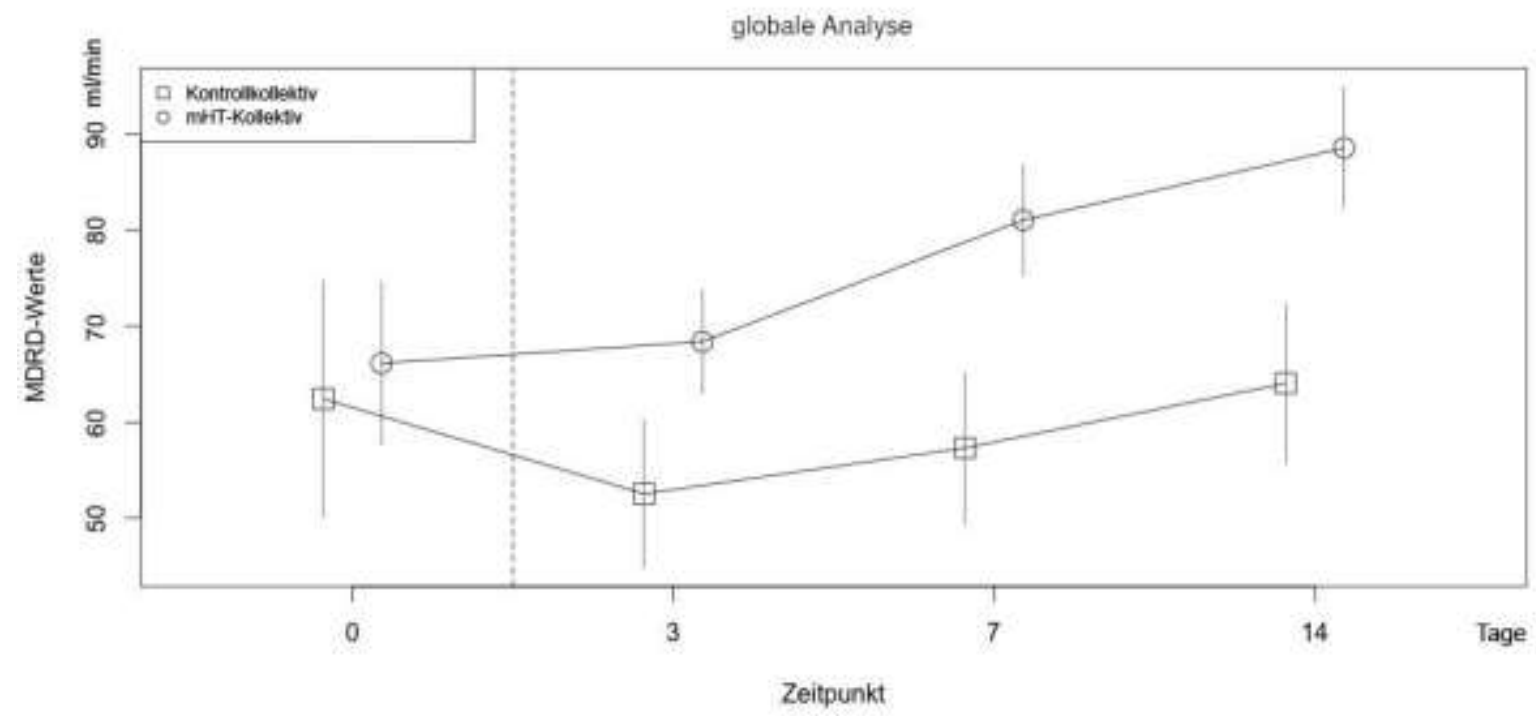

Abbildung 29: Verlaufskurve der approximierten MDRD-Werte (ml/min) über die Messzeitpunkte (Tage) in dem milden Hypothermie- und Kontrollkollektiv

\subsubsection{Verlauf der glomerulären Filtrationsrate über die Zeit und in}

\section{Abhängigkeit vom Geschlecht}

Berücksichtigt man das Geschlecht als Kofaktor, ergeben sich die in Abbildung 30 dargestellten Verläufe.

Unter Einzelbetrachtung starteten männliche Studienteilnehmer in der milden Hypothermiegruppe mit einer mittleren GFR von $62,43 \mathrm{ml} / \mathrm{min}(\mathrm{SEM} \pm 2,0)$ und in der Kontrollgruppe mit einem Mittelwert von 62,44 ml/min (SEM \pm 4,4). Zum Zeitpunkt der Aufnahme lag die durchschnittliche glomeruläre Filtrationsrate der Männer annähernd auf demselben Niveau ( $\mathrm{p}=0,9994)$. Im weiteren Verlauf konnte ein kontinuierlicher Anstieg der MDRD-Werte in der mHT-Gruppe gemessen werden. Am 3. Tag betrug der Durchschnittswert 67,70 ml/min 
$(\mathrm{SEM} \pm 3,2)$, am 7 . Tag 79,34 $\mathrm{ml} / \mathrm{min}(\mathrm{SEM} \pm 3,4)$ und nach 14 . Tagen ergab er im Mittel $88,49 \mathrm{ml} / \mathrm{min}(\mathrm{SEM} \pm 3,7)$.

In der männlichen Kontrollgruppe zeigte sich am 3. Tag ein geringer Abfall der GFR auf $59,16 \mathrm{ml} / \mathrm{min}(\mathrm{SEM} \pm 5,1)$. Zum Zeitpunkt T7 stieg der MDRD-Wert auf 65,07 $\mathrm{ml} / \mathrm{min}$ (SEM $\pm 5,2)$ und am Endzeitpunkt T14 weiter auf 70,63 $\mathrm{ml} / \mathrm{min}(\mathrm{SEM} \pm 5,4)$ an.

Nach Ablauf der Beobachtung bestand kein signifikanter Unterschied in der glomerulären

Filtrationsrate zwischen männlichen Studienteilnehmern der mHT-Gruppe und der Kontrollgruppe $(\mathrm{p}=0,491)$.
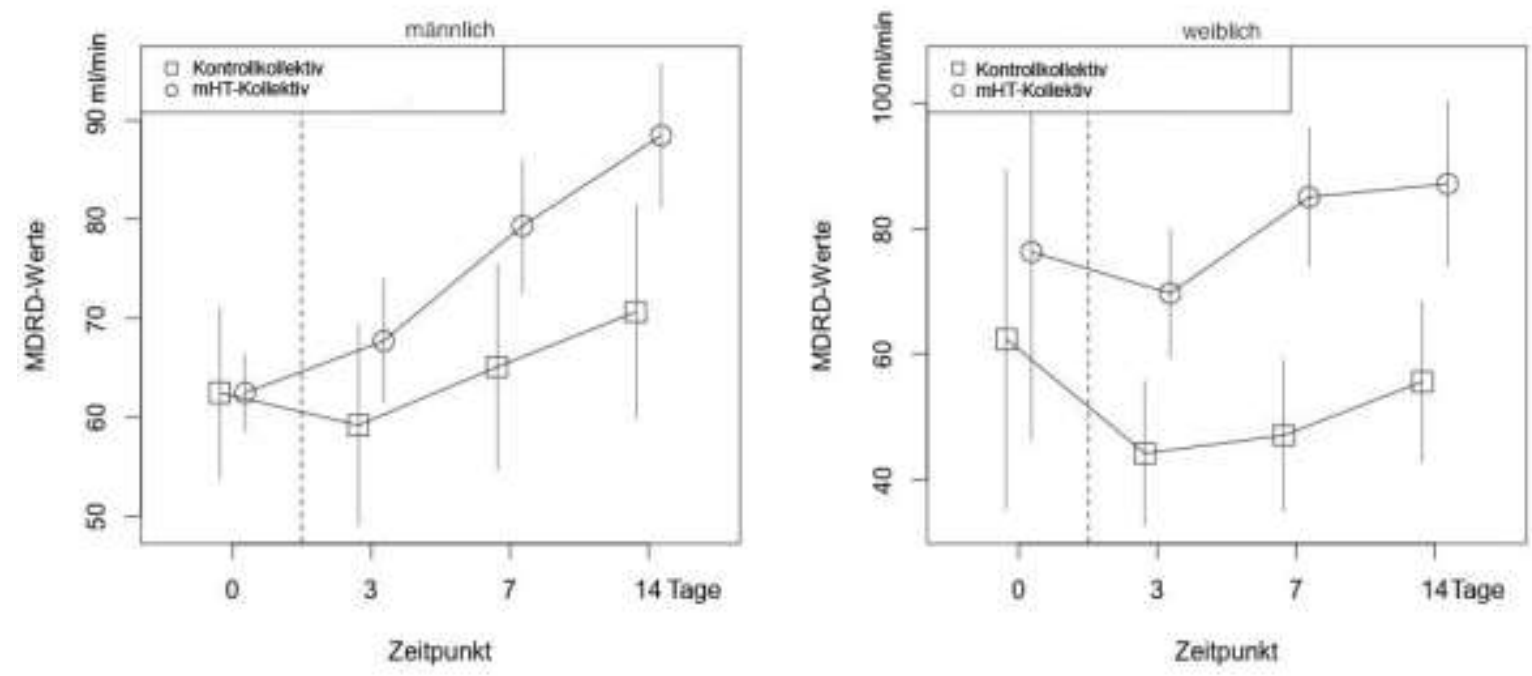

Abbildung 30: Verlaufskurve der approximierten MDRD-Werte ( $\mathrm{ml} / \mathrm{min})$ über die Messzeitpunkte (Tage) in Abhängigkeit vom Geschlecht bei der milden Hypothermie- und der Kontrollgruppe

\begin{tabular}{|c|cc|cc|r|}
\hline \multicolumn{7}{|c|}{ Männliche Studienteilnehmer } \\
\hline \multirow{2}{*}{ Messzeitpunkt } & \multicolumn{2}{|c|}{ mHT-Gruppe } & \multicolumn{2}{c|}{ Kontrollgruppe } & \\
& MDRD-Wert & SEM & MDRD-Wert & SEM \\
ml/min & \pm & ml/min & \pm & p-Wert \\
\hline 0. Tag & 62,43 & 2,02 & 62,44 & 4,41 & 0,9994 \\
3. Tag & 67,70 & 3,19 & 59,16 & 5,14 & $\approx 1$ \\
7. Tag & 79,34 & 3,40 & 65,07 & 5,27 & $\approx 1$ \\
14. Tag & 88,49 & 3,65 & 70,63 & 5,43 & 0,4907 \\
\hline
\end{tabular}

Tabelle 24: Approximierte MDRD-Werte (ml/min) der männlichen Studienteilnehmer inklusive Standardfehler (SEM), zeitlicher Verlauf (Tage) und Signifikanz (p-Wert)

Weibliche Studienteilnehmer hatten zum Startzeitpunkt in milden Hypothermiegruppe einen durchschnittlichen MDRD-Wert von 76,30 ml/min (SEM $\pm 15,3$ ) und in der entsprechenden Kontrollgruppe einen Mittelwert von 62,40 ml/min (SEM $\pm 13,8)$. Eine signifikante Differenz 
bestand zwischen beiden Gruppen zum Beobachtungsbeginn nicht $(\mathrm{p}=0,4996)$. Im Verlauf ergaben sich für die weibliche mHT-Gruppe folgende mittlere MDRD-Werte: Zum Zeitpunkt T3 fiel der Wert auf 69,69 ml/min (SEM $\pm 5,2)$ ab, konnte dann jedoch im Verlauf einen stetigen Anstieg auf 85,05 ml/min (SEM $\pm 5,6)$ am 7. Tag und zum Endzeitpunkt auf 87,18 $\mathrm{ml} / \mathrm{min}(\mathrm{SEM} \pm 6,7)$ erzielen. In der Kontrollgruppe war ebenfalls am 3. Tag ein Abfall der GFR auf einen Durchschnittswert von 44,15 ml/min (SEM $\pm 5,8)$ zu verzeichnen. Im weiteren Verlauf ergab sich jedoch auch hier ein kontinuierlicher Anstieg der GFR auf 47,02 ml/min $(\mathrm{SEM} \pm 6,1)$ an Tag 7 und auf 55,59ml/min (SEM \pm 6,5) am Endzeitpunkt (T14) der Beobachtung.

Vergleicht man die Endzeitpunkte der weiblichen Studienteilnehmer, zeigte sich, dass Frauen, die mittels milder Hypothermie behandelt wurden, eine gering signifikant bessere GFR aufwiesen als die weibliche Kontrollgruppe $(p=0,0484)$.

\begin{tabular}{|c|c|c|c|c|c|}
\hline \multicolumn{6}{|c|}{ Weibliche Studienteilnehmerinnen } \\
\hline \multirow[b]{2}{*}{ Messzeitpunkt } & \multicolumn{2}{|c|}{ mHT-Gruppe } & \multicolumn{2}{|c|}{ Kontrollgruppe } & \multirow[b]{2}{*}{ p-Wert } \\
\hline & $\begin{array}{l}\text { MDRD-Wert } \\
\mathrm{ml} / \mathrm{min}\end{array}$ & $\begin{array}{l}\text { SEM } \\
\pm\end{array}$ & $\begin{array}{l}\text { MDRD-Wert } \\
\mathrm{ml} / \mathrm{min}\end{array}$ & $\begin{array}{l}\text { SEM } \\
\pm\end{array}$ & \\
\hline 0. Tag & 76,30 & 15,26 & 62,40 & 13,80 & 0,4996 \\
\hline 3. Tag & 69,69 & 5,24 & 44,15 & 5,81 & 0,0793 \\
\hline 7. Tag & 85,05 & 5,63 & 47,02 & 6,11 & 0,0004 \\
\hline 14. Tag & 87,19 & 6,67 & 55,59 & 6,45 & 0,0484 \\
\hline
\end{tabular}

Tabelle 25: Approximierte MDRD-Werte ( $\mathrm{ml} / \mathrm{min})$ der weiblichen Studienteilnehmerinnen inklusive Standardfehler (SEM), zeitlicher Verlauf (Tage) und Signifikanz (p-Wert)

\subsubsection{Verlauf der glomerulären Filtrationsrate über die Zeit und in} Abhängigkeit von Diabetes mellitus

Betrachtet man die GFR in Abhängigkeit von einer DM, ergeben sich die im Folgenden beschriebenen Verläufe ( $A b b .31)$.

Patienten, die keinen vordiagnostizierten DM hatten und mittels milder therapeutischer Hypothermie nach kardiopulmonaler Reanimation behandelt wurden, hatten zum Aufnahmezeitpunkt einen mittleren MDRD-Wert von 63,79 ml/min (SEM $\pm 2,0$ ). Die entsprechende Kontrollgruppe lag zum Zeitpunkt der Aufnahme bei einer durchschnittlichen GFR von 67,62 $\mathrm{ml} / \mathrm{min}$ (SEM \pm 8,2). Zwischen den beiden Gruppen bestand zum Startzeitpunkt kein signifikanter Unterschied in Bezug auf die durchschnittlichen MDRD-Werte $(p=0,5845)$. 
In der milden Hypothermiegruppe konnte ein stetiger Anstieg der GFR gemessen werden. Am 3. Tag lag der durchschnittliche MDRD-Wert bei 70,72 $\mathrm{ml} / \mathrm{min}(\mathrm{SEM} \pm 2,9)$, am 7 . Tag bei $83,47 \mathrm{ml} / \mathrm{min}(\mathrm{SEM} \pm 3,1)$ und zum Ende des Beobachtungszeitraumes bei $91,56 \mathrm{ml} / \mathrm{min}$ (SEM $\pm 3,4)$. Die Kontrollgruppe zeigte zunächst einen Abfall der GFR an Tag 3 auf einen Mittelwert von 54,97 ml/min $(\mathrm{SEM} \pm 4,6)$. Am 7. Tag erholten sich die Werte und stiegen auf $58,97 \mathrm{ml} / \mathrm{min}(\mathrm{SEM} \pm 4,7)$ und am 14. Tag weiter auf $64,35 \mathrm{ml} / \mathrm{min}(\mathrm{SEM} \pm 4,9)$ an. Zum Endzeitpunkt der Beobachtung wiesen Nicht-Diabetiker der mHT-Gruppe eine signifikant bessere GFR auf als Nicht-Diabetiker ihrer Kontrollgruppe ( $p=0,0005)$.
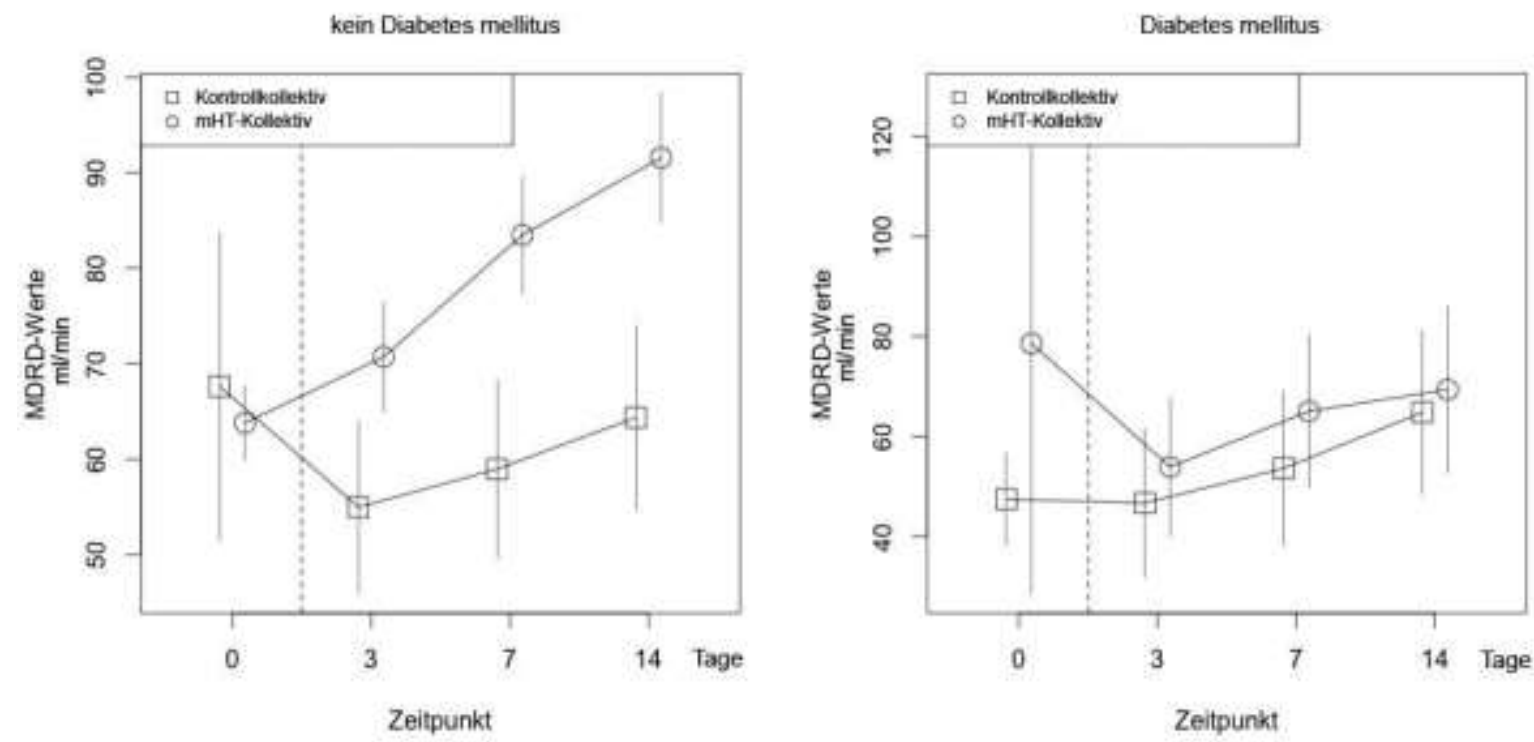

Abbildung 31: Verlaufskurve der approximierten MDRD-Werte (ml/min) über die Messzeitpunkte (Tage) in Abhängigkeit von einer Diabetes-mellitus-Erkrankung in der milden Hypothermie- und Kontrollgruppe

\begin{tabular}{|c|cc|cc|r|}
\hline \multicolumn{7}{|c|}{ Kein Diabetes mellitus } \\
\hline & \multicolumn{2}{|c|}{ mHT-Gruppe } & \multicolumn{2}{c|}{ Kontrollgruppe } & \\
Messzeitpunkt & $\begin{array}{c}\text { MDRD-Wert } \\
\text { ml/min }\end{array}$ & $\begin{array}{c}\text { SEM } \\
\pm\end{array}$ & MDRD-Wert & SEM & m-Wert \\
& 63,79 & 1,97 & 67,62 & 8,23 & 0,5845 \\
\hline 0. Tag & 70,72 & 2,91 & 54,97 & 4,57 & 0,2841 \\
3. Tag & 83,47 & 3,10 & 58,97 & 4,71 & 0,0015 \\
7. Tag & 91,56 & 3,41 & 64,35 & 4,88 & 0,0005 \\
14. Tag & & & & & \\
\hline
\end{tabular}

Tabelle 26: Approximierte MDRD-Werte ( $\mathrm{ml} / \mathrm{min})$ der Nicht-Diabetiker inklusive Standardfehler (SEM), zeitlicher Verlauf (Tage) und Signifikanz (p-Wert) 
Diabetiker, welche nach der kardiopulmonalen Reanimation mittels milder Hypothermie behandelt wurden, zeigten zum Aufnahmezeitpunkt eine durchschnittliche GFR von 78,61 $\mathrm{ml} / \mathrm{min}(\mathrm{SEM} \pm 25,5)$. Die zugehörige Kontrollgruppe hatte zum Vergleichszeitpunkt eine mittlere GFR von 47,39 ml/min (SEM $\pm 4,7$ ). Hieraus ergab sich kein signifikanter Unterschied bezüglich der durchschnittlichen Filtrationsrate zum Aufnahmezeitpunkt $(p=0,2020)$. Am 3. Tag kam es zu einer Abnahme der mittleren GFR in der mHT-Gruppe auf 53,87 $\mathrm{ml} / \mathrm{min}(\mathrm{SEM} \pm 7,0)$. Im weiteren Verlauf stagnierte die Abnahme und zum dritten Messzeitpunkt (T7) lag der mittlere MDRD-Wert bei 65,02 ml/min (SEM \pm 7,8). 14 Tage nach der Reanimation betrug die durchschnittliche GFR in dieser Gruppe 69,35 ml/min (SEM $\pm 8,4$ ). Die Kontrollgruppe wies im Vergleich zur Vormessung am 3. Tag einen annähernd konstanten MDRD-Wert von 46,64 ml/min (SEM \pm 7,6) auf. Im weiteren Beobachtungszeitraum stieg der MDRD-Wert auf 53,61 ml/min $(S E M \pm 7,9)$ an, um am 14. Tag weiter auf 64,80 $\mathrm{ml} / \mathrm{min}(\mathrm{SEM} \pm 8,3)$ anzusteigen.

Vergleicht man die durchschnittliche GFR von Diabetikern zum Beobachtungsende miteinander, ergab sich kein signifikanter Unterscheid bezüglich der Nierenfunktion zwischen der milden Hypothermie- und der Kontrollgruppe $(\mathrm{p} \approx 1)$.

\begin{tabular}{|c|cc|cc|r|}
\hline \multicolumn{7}{|c|}{ Diabetes mellitus } \\
\hline & \multicolumn{7}{|c|}{ mHT-Gruppe } & \multicolumn{2}{c|}{ Kontrollgruppe } & \\
Messzeitpunkt & $\begin{array}{c}\text { MDRD-Wert } \\
\text { ml/min }\end{array}$ & $\begin{array}{c}\text { SEM } \\
\pm\end{array}$ & $\begin{array}{c}\text { MDRD-Wert } \\
\text { ml/min }\end{array}$ & $\begin{array}{c}\text { SEM } \\
\pm\end{array}$ & p-Wert \\
\hline 0. Tag & 78,61 & 25,51 & 47,39 & 4,70 & 0,2020 \\
3. Tag & 53,87 & 6,99 & 46,64 & 7,56 & $\approx 1$ \\
7. Tag & 65,02 & 7,76 & 53,61 & 7,86 & $\approx 1$ \\
14. Tag & 69,35 & 8,39 & 64,80 & 8,27 & $\approx 1$ \\
\hline
\end{tabular}

Tabelle 27: Approximierte MDRD-Werte (ml/min) der Diabetiker inklusive Standardfehler (SEM), zeitlicher Verlauf (Tage) und Signifikanz (p-Wert) 


\subsubsection{Verlauf der glomerulären Filtrationsrate über die Zeit und in}

\section{Abhängigkeit von Risikofaktorklassen für eine chronische Niereninsuffizienz}

Abbildung 32 veranschaulicht die durchschnittliche GFR der beiden Gruppen über den zeitlichen Verlauf unter Berücksichtigung der in Kapitel 2.3 beschriebenen Risikofaktorklassen für ein chronisches Nierenversagen.

Für Patienten, die keinen Risikofaktor für die Entstehung einer CKI hatten, zeigte sich zum Anfang der Beobachtung kein signifikanter Unterschied in der glomerulären Filtrationsrate zwischen der milden Hypothermiegruppe und der Kontrollgruppe $(\mathrm{p}=0,2968)$. In der mHTGruppe lag die mittlere GFR zum Zeitpunkt der Aufnahme bei 61,07 ml/min (SEM $\pm 3,0)$ und in der entsprechenden Kontrollgruppe bei 77,66 ml/min (SEM $\pm 17,21)$. Während des Verlaufes kam es in der mHT-Gruppe zu einem kontinuierlichen Anstieg der MDRD-Wert bis hoch auf 93,74 ml/min zum Endzeitpunkt der Beobachtung. Die Kontrollgruppe verhielt sich entgegengesetzt ihrer Vergleichsgruppe und fiel kontinuierlich auf einen Endwert von 50,99 $\mathrm{ml} / \mathrm{min}(\mathrm{SEM} \pm 7,5) \mathrm{ab}$. Hieraus resultiert für den Endzeitpunkt der Beobachtung eine signifikant bessere GFR in der milden Hypothermiegruppe $(\mathrm{p}=0,0017)$.

\begin{tabular}{|c|cc|cc|r|}
\hline \multicolumn{7}{|c|}{ Keine Risikofaktoren } \\
\hline \multirow{3}{*}{ Messzeitpunkt } & \multicolumn{2}{|c|}{ mHT-Gruppe } & \multicolumn{2}{c|}{ Kontrollgruppe } & \\
& $\begin{array}{c}\text { MDRD-Wert } \\
\text { ml/min }\end{array}$ & $\begin{array}{c}\text { SEM } \\
\pm\end{array}$ & MDRD-Wert & SEM & ml/min \\
\hline 0. Tag & 61,07 & 2,99 & 77,66 & 17,21 & 0,2968 \\
3. Tag & 68,03 & 4,85 & 42,25 & 6,79 & 0,3311 \\
7. Tag & 83,98 & 5,42 & 47,89 & 7,2 & 0,0117 \\
14. Tag & 93,74 & 6 & 50,99 & 7,47 & 0,0017 \\
\hline
\end{tabular}

Tabelle 28: Approximierte MDRD-Werte $(\mathrm{ml} / \mathrm{min})$ der Studienteilnehmer ohne Risikofaktoren inklusive Standardfehler (SEM), zeitlicher Verlauf (Tage) und Signifikanz (p-Wert)

Für Studienteilnehmer, welche einen Risikofaktor für das Erleiden einer CKI aufwiesen, zeigte sich, dass die milde Hypothermie kein signifikanter Faktor für eine veränderte GFR war. Beide starteten mit einem annähernd gleichen Durchschnittswert. Am 14. Tag lag die milde Hypothermiegruppe bei einer mittleren GFR von 77,31 $\mathrm{ml} / \mathrm{min}(\mathrm{SEM} \pm 5,5)$ und die entsprechende Kontrollgruppe bei $60,35 \mathrm{ml} / \mathrm{min}$ (SEM $\pm 8,2$ ). Es bestand kein signifikanter Unterschied innerhalb dieser Subgruppe und ihrer GFR zum Endzeitpunkt der Studie $(p \approx 1)$. 


\begin{tabular}{|c|cc|cc|r|}
\hline \multicolumn{7}{|c|}{ = 1 Risikofaktor } \\
\hline \multirow{2}{*}{ Messzeitpunkt } & \multicolumn{2}{|c|}{ mHT-Gruppe } & \multicolumn{2}{c|}{ Kontrollgruppe } & \\
& $\begin{array}{c}\text { MDRD-Wert } \\
\text { ml/min }\end{array}$ & $\begin{array}{c}\text { SEM } \\
\pm\end{array}$ & MDRD-Wert & SEM & ml/min \\
\pm & 76,78 & 10,95 & 53,67 & 5,51 & 0,0803 \\
0. Tag & 72,86 & 4,51 & 59,02 & 5,98 & $\approx 1$ \\
3. Tag & 83,42 & 4,62 & 65,21 & 6,14 & $\approx 1$ \\
7. Tag & 95,24 & 5,15 & 75,52 & 6,37 & $\approx 1$ \\
14. Tag & &
\end{tabular}

Tabelle 29: Approximierte MDRD-Werte ( $\mathrm{ml} / \mathrm{min})$ der Studienteilnehmer mit einem Risikofaktor inklusive Standardfehler (SEM), zeitlicher Verlauf (Tage) und Signifikanz (p-Wert)

Patienten, die mehr als einen Risikofaktor für die Entstehung einer chronischeren Niereninsuffizienz aufwiesen, zeigten die gleiche Tendenz wie Studienteilnehmer mit einem Risikofaktor. Beide Gruppen starteten mit der annähernd gleichen durchschnittlichen GFR von ca. 58,00 $\mathrm{ml} / \mathrm{min}(\mathrm{p}=0,8423)$. Die mHT-Gruppe erreichte lediglich einen marginal höheren mittleren MDRD-Wert von 77,31 ml/min (SEM \pm 5.5$)$ im Vergleich zu 60,35 ml/min $(\mathrm{SEM} \pm 8,2)$ in der Kontrollgruppe. Es ergab sich somit für diese Subgruppe ebenfalls kein signifikanter Unterschied in Bezug auf die GFR zum Endzeitpunkt der Beobachtung $(\mathrm{p} \approx 1)$.

\begin{tabular}{|c|cc|cc|r|}
\hline \multicolumn{7}{|c|}{$>$ 1 Risikofaktor } \\
\hline & \multicolumn{2}{|c|}{ mHT-Gruppe } & \multicolumn{2}{c|}{ Kontrollgruppe } & \\
Messzeitpunkt & $\begin{array}{c}\text { MDRD-Wert } \\
\text { ml/min }\end{array}$ & $\begin{array}{c}\text { SEM } \\
\pm\end{array}$ & $\begin{array}{c}\text { MDRD-Wert } \\
\text { ml/min }\end{array}$ & $\begin{array}{c}\text { SEM } \\
\pm\end{array}$ & p-Wert \\
\hline 0. Tag & 58,58 & 2,8 & 57,45 & 5,68 & 0,8423 \\
3. Tag & 64,07 & 4,69 & 55,45 & 7,49 & $\approx 1$ \\
7. Tag & 76,34 & 5,08 & 56,9 & 7,6 & $\approx 1$ \\
14. Tag & 77,31 & 5,48 & 60,35 & 8,15 & $\approx 1$ \\
\hline
\end{tabular}

Tabelle 30: Approximierte MDRD-Werte ( $\mathrm{ml} / \mathrm{min})$ der Studienteilnehmer mit mehr als einem Risikofaktor inklusive Standardfehler (SEM), zeitlicher Verlauf (Tage) und Signifikanz (p-Wert) 

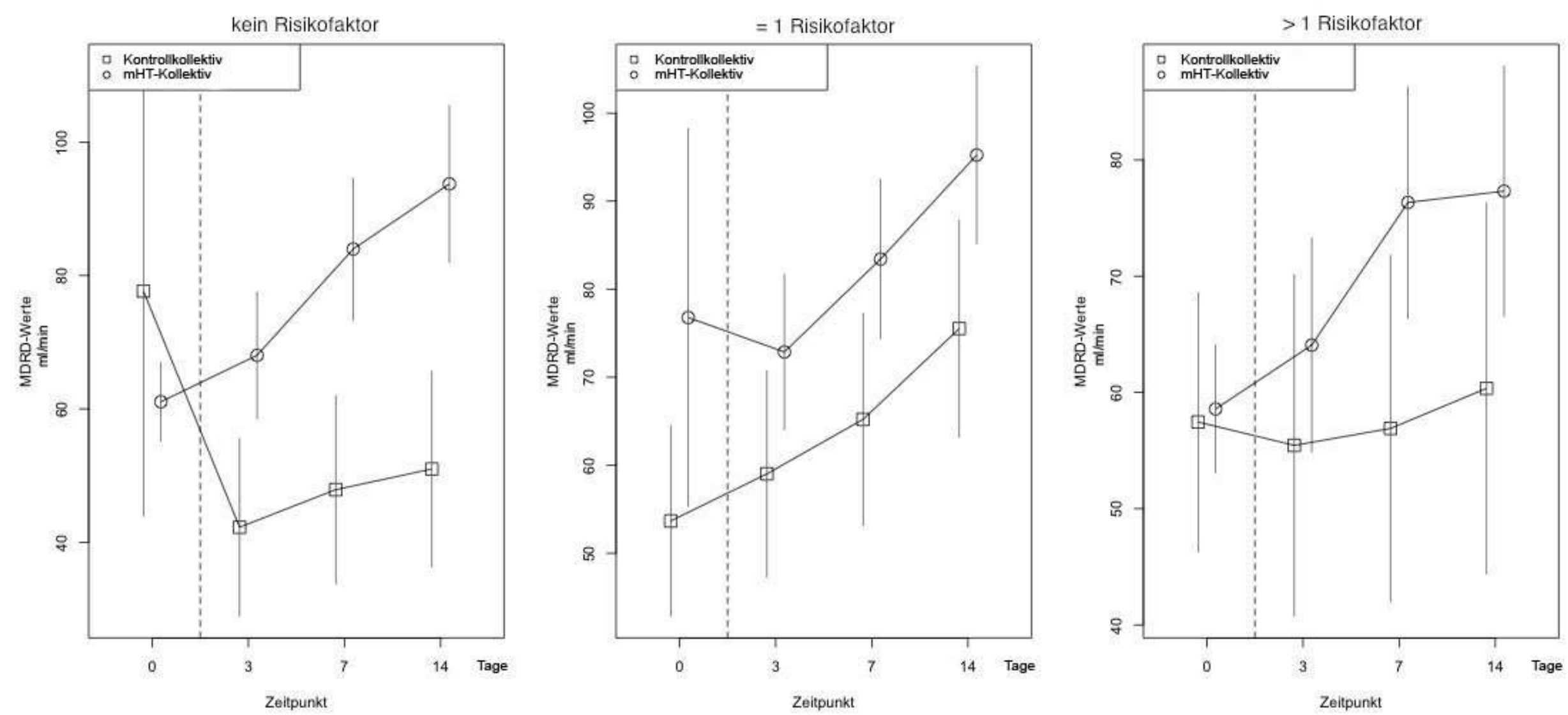

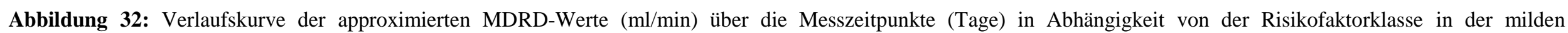
Hypothermie- und Kontrollgruppe 


\section{Diskussion}

Der Anlass für die vorliegende Untersuchung resultierte aus dem klinischen Eindruck, dass sich eine nach Standard Operating Procedure (SOP) durchgeführte milde therapeutische Hypothermie prognostisch günstig auf die Auftretenswahrscheinlichkeit eines akuten Nierenversagens nach ROSC auswirkt. Das Kernziel der vorliegenden Arbeit bestand demnach darin zu evaluieren, inwieweit die mHT nach kardiopulmonaler Reanimation eine protektive Wirkung auf die Nierenfunktion ausübt. Zu diesem Zweck sollen in dem vorliegenden Kapitel die eingangs gestellten Fragen beantwortet und die Ergebnisse mit anderen Studien verglichen und diskutiert werden.

\subsection{Einfluss der milden therapeutischen Hypothermie auf die Inzidenz des akuten Nierenversagens}

In dem milden Hypothermiekollektiv (mHT-Kollektiv) lag die Auftretenswahrscheinlichkeit des akuten Nierenversagens (ANV) signifikant niedriger $(\mathrm{p}=0,0015)$. Erkrankten 45,8 \% (66 / 144) der Patienten im Kontrollkollektiv, sank das Risiko in dem mHT-Kollektiv auf 29,2\% (59/202). Vergleicht man die Patienten, die kein ANV während der stationären Behandlung erlitten, miteinander, ergab sich für das milde Hypothermiekollektiv ein Zuwachs von 40,0 \% ( $<$ < 0,0001). Der Anteil an Patienten, die bereits vor der Einweisung in die UMG an einer Nierenfunktionsstörung litten und massiv erhöhte Kreatininwerte aufwiesen, lag im mHT-Kollektiv bei 3,0\% und war 23,4\% niedriger als in dem Kontrollkollektiv (26,4\%). Der durchschnittliche Erkrankungszeitpunkt des akuten Nierenversagens lag innerhalb der beiden Kollektive zwischen dem ersten und zweiten Tag und wies keinen signifikanten Unterschied auf ( $\mathrm{p}=0,4342)$.

Da es sich bei dem Herz-Kreislaufstillstand um ein plötzliches, akutes Ereignis handelt und sich die Mehrzahl der Patienten nicht in Vorbehandlung an der UMG befanden, waren für den überwiegenden Teil der Patienten keine Vorbefunde vorhanden. Patienten, die zum Aufnahmezeitpunkt bereits eine massive Erhöhung des Serum-Kreatininspiegels aufwiesen, wurden mit dem Verdacht auf ein vorbestehendes akutes Nierenversagen der Gruppe ,ANV vor Aufnahme‘ zugeteilt. Hier wäre es für die exaktere Zuteilung wünschenswert gewesen, über aktuelle Befunde oder Laborberichte zur Auswertung zu verfügen. Unsicherheiten in der Auswertung könnten daraus entstanden sein, dass Patienten, welche bereits vor dem HerzKreislaufstillstand ein akutes Nierenversagen erlitten, oder bei denen das ANV mit 
konsekutiver Hyperkaliämie die Ursache der Reanimationspflichtigkeit war (Holzer 2005). Schließt man die Patienten aus der Studie aus, die bereits vor der Aufnahme in der UMG ein akutes Nierenversagen aufwiesen, verstärkt sich der positive Effekt der milden Hypothermie auf das mHT-Kollektiv. Erkrankten in dieser Kohorte 62,3\% des Kontrollkollektivs an einem ANV, lag die Auftretenswahrscheinlichkeit in dem mHT-Kollektiv lediglich bei 30,1\% (p < $0,0001)$.

Bei der retrospektiven Erhebung und Klassifikation kann es ebenfalls zu einer Abweichung in der exakten Ermittlung des Zeitpunktes des ANV gekommen sein. Die in Kapitel 2.3 beschriebene AKI-Klassifikation ermöglichte die Diagnosestellung des akuten Nierenversagens sowohl anhand eines Serum-Kreatinin-Anstieges als auch anhand einer Oligo- oder Anurie. Der Anstieg des Serum-Kreatinins bei einem akuten Nierenversagen zeigt sich jedoch meist erst im Verlauf von zwei Tagen (Thomas und Thomas 2009). Für Patienten, welche eine abrupte Erhöhung des Serum-Kreatinins und eine Oligo- oder Anurie aufwiesen, wurde der früheste Diagnosezeitpunkt notiert. Bei einem isolierten Anstieg des Serum-Kreatinins kann es zu einer verzögerten Diagnose und folglich zu Unsicherheiten innerhalb der Daten kommen. Ebenfalls eine zeitliche Diskrepanz kann bei Patienten auftreten, die vor Aufnahme auf der Intensivstation eine Herzkatheteruntersuchung erhielten. Sie wurden im Vergleich zu Patienten ohne Koronarangiografie erst später auf der Intensivstation aufgenommen und daher könnte eine akute Niereninsuffizienz fälschlicherweise erst einige Stunden später diagnostiziert worden sein.

Trotz dieser genannten Limitationen ist für die vorliegende Untersuchung anzunehmen, dass die mHT zu einer Reduzierung der Erkrankungswahrscheinlichkeit des akuten Nierenversagens führte.

$\mathrm{Zu}$ einem ähnlichen Ergebnis kamen bereits zwei tierexperimentelle Studien. ZAGER et al. zeigten in ihrer 1989 publizierten Studie auf, dass durch die milde Hypothermie $\left(32-33{ }^{\circ} \mathrm{C}\right)$ die Funktion und zelluläre Integrität während sowie nach renaler Ischämie aufrechterhalten werden kann und ein geringeres Reperfusionstrauma entsteht. Der größte positive Effekt konnte erreicht werden, indem die Kühlung bereits während der Ischämiephase begonnen wurde. Eine verzögerte Absenkung der Körperkerntemperatur führte zu einer rapiden Abschwächung des Effektes.

In einer aktuelleren Studie konnten Zagers Ergebnisse erneut bestätigt werden. Das tierexperimentelle Modell setzte Ratten einer 45-minütigen renalen Ischämie aus und analysierte das Verhalten der Nierenfunktion unter Berücksichtigung einer Hyperthermie $\left(39,67^{\circ} \mathrm{C}\right)$, einer Hypothermie $\left(32,6^{\circ} \mathrm{C}\right)$ sowie der Normothermie $\left(36,5-37^{\circ} \mathrm{C}\right)$. Auch ihre 
Studie gelangte $\mathrm{zu}$ dem Ergebnis, dass die milde Hypothermie zu einer Minimierung des Reperfusionstraumas führte. Zusätzlich lagen die Serum-Kreatininwerte am dritten Tag in der Normothermiegruppe im durchschnitt 300 \% höher als in ihrer Hypothermiegruppe.

Diese Ergebnisse bestätigen somit die Annahme der protektiven Wirkung der mHT auf das Nierenparenchym im tierexperimentellen Modell. Es besteht der begründete Verdacht, dass die mHT auch für die signifikant geringere Auftretenswahrscheinlichkeit des akuten Nierenversagens in der vorliegenden Studie verantwortlich ist.

Vorangegangene klinische Studien konnten den positiven Effekt der mHT auf die Nierenfunktion bis jetzt jedoch noch nicht eindeutig nachweisen. In der von der Arbeitsgemeinschaft „The Hypothermia after Cardiac Arrest Study Group“ (HACA) veröffentlichten Studie zeigte sich kein signifikanter Unterscheid in der Inzidenz des akuten Nierenversagens. In beiden Studiengruppen trat mit einer prozentualen Wahrscheinlichkeit von $10 \%$ ein ANV als Komplikation in den ersten sieben Tagen der Postreanimationsphase auf (HACA 2002).

Vergleicht man die HACA-Studie mit der vorliegenden Studie, muss beachtet werden, dass in die HACA-Studie lediglich Patienten mit initialem Kammerflimmern inkludiert wurden. Da die Asystolie oder elektromechanische Entkopplung im Vergleich zum Kammerflimmern mit einer deutlich schlechteren Prognose behaftet ist, könnte dieser Unterschied ursächlich für die geringe Auftretenswahrscheinlichkeit des akuten Nierenversagens in der HACA-Studie sein. Das Erkrankungsrisiko für ein akutes Nierenversagen nach reanimationspflichtigem Kammerflimmern liegt bei $12 \%$ (Domanovits et al. 2001). Bezieht man alle vier Arten des Herz-Kreislaufstillstandes (Asystolie, pulslose elektrische Aktivität, pulslose ventrikuläre Tachykardie und Kammerflimmern) mit in die Auswertung ein, ergibt sich eine Inzidenz von circa $50 \%$ (Hasper et al. 2009, Chua et al. 2012).

Ein weiterer Nachteil der HACA-Studie besteht darin, dass kein genauer Rückschluss auf die Definition des akuten Nierenversagens möglich gewesen ist. Es ist lediglich eine Aussage über die Erkrankungshäufigkeit des akuten Nierenversagens getroffen worden, nicht jedoch über den Grad der Insuffizienz und des verwendeten Klassifikationssystems.

ZEINER et al. nahmen sich 2004 der Daten der HACA-Studie an und führten retrospektiv eine Auswertung mit der Fragestellung der Einflussnahme der mHT auf die Nierenfunktion durch. Sie gelangten zu dem Ergebnis, dass in der Hypothermiegruppe innerhalb der ersten 24 Stunden mehr Patienten die Kriterien des akuten Nierenversagens (Abnahme der SerumKreatinin-Clearance $\geq 25 \%$ im Vergleich zum Initialwert) erfüllten als in der Normothermiegruppe. Innerhalb der Studiendauer von 28 Tagen erlitten 9,4 \% (3/32) der Patienten in der Hypothermiegruppe und 14,3\% (4/28) der Patienten der Normothermiegruppe ein 
akutes Nierenversagen. Definiert war das ANV für den Endzeitpunkt ihrer Studie als ein Anstieg des Serum-Kreatinins von $\geq 0,5 \mathrm{mg} / \mathrm{dl}$ oder eine notwendige Dialyse.

Vergleicht man die Daten mit dieser Studie, ist anzumerken, dass weiterhin eine Diskrepanz innerhalb der Häufigkeitsverteilung des akuten Nierenversagens besteht. Dies kann zum einen durch die bereits angeführte Differenz in den Einschlusskriterien der Kollektive begründet sein. Ein wesentlich wichtigerer Faktor besteht jedoch in der wesentlich restriktiveren Definition des akuten Nierenversagens. Sprachen ZEINER et al. (2004) erst ab einem Stadium III nach der AKIN-Klassifikation von einem akuten Nierenversagen, besteht in dieser Studie bereits im Stadium I der begründete Verdacht auf ein akutes Nierenversagen. Die daraus resultierende geringe Inzidenz des ANV steht weiterhin im Kontrast zu den Ergebnissen der vorliegenden Studie und der bereits zuvor angeführten Studien von HASPER et al. (2009) und CHUA et al. (2012) und bedarf weiteren wissenschaftlichen Klärung.

Ein weiterer wesentlicher anzumerkender Faktor dieser Arbeit, der einen Einfluss auf die Inzidenz des ANV ausgeübt haben könnte, besteht in der uneinheitlichen Geschlechterverteilung innerhalb der beiden Kollektive $(\mathrm{p}=0,0036)$. Das milde Hypothermiekollektiv umfasste mit 26,7 \% (54/202) fast $15 \%$ weniger Frauen als das Kontrollkollektiv (41,7\%, 60/144). In der Literatur wird die Prozessrelevanz des Geschlechtes - bezogen auf die Auftretenswahrscheinlichkeit des akuten Nierenversagens - wie folgt bewertet:

In mehreren tierexperimentellen Studien konnte nachgewiesen werden, dass das Geschlecht einen besonderen Einfluss auf die Entstehung des akuten Nierenversagens ausübt. In der von MÜLLER et al. (2002) veröffentlichen Studie zeigte sich, dass männliche Ratten eine höhere Vulnerabilität für die Entstehung eines postischämischen Nierenversagens auswiesen als weibliche Ratten. Als Hauptfaktoren sahen die Autoren die Einflussnahme von Sexualhormonen und eine signifikant höhere Expression von Pre-Pro-Endothelin in männlichen Ratten.

Des Weiteren vermutet man, dass das weibliche Geschlecht eine höhere Resistenz gegenüber dem ischämischen akuten Nierenversagen aufweist (Wie et al. 2005). Insbesondere für Estradiol konnte im Mausmodell gezeigt werden, dass es einen protektiven Effekt auf die Niere nach kardiopulmonaler Reanimation ausübt (Hutchens et al. 2010).

Für die vorliegende Untersuchung bedeutet dies konkludierend, dass in dem Kontrollkollektiv, in welchem ein signifikant höherer Anteil an Frauen zu konstatieren war, ein geringeres Risiko für die Entstehung eines akuten Nierenversagens nach CPR herrschte als in dem mHT-Kollektiv. Berücksichtigt man diese Studienergebnisse, müsste die milde 
Hypothermie bei gleichmäßiger Geschlechterverteilung einen noch höheren positiven Effekt als in dieser Studie beschrieben auf das mHT-Kollektiv ausüben.

Führt man die Analyse unter Berücksichtigung des Geschlechtes als Kofaktor weiter aus, bestätigt sich der beschriebene Effekt. Weibliche Studienteilnehmer profitierten mit einer ARR von 24,6\%, bezogen auf die Inzidenz des ANV nach milder Hypothermie, in besonderen Maße von der Therapie. Männer erreichten durch die mHT eine ARR von 14,0 \%. Als Ursache für diesen positiven Therapieeffekt kann eine Verstärkung des bereits zuvor beschriebenen weiblichen hormonellen Schutzmechanismus und die damit einhergehende erhöhte Resistenz gegenüber dem akuten Nierenversagen vermutet werden. Ein signifikanter Unterschied $(p=0,1865)$ zwischen der männlichen und weiblichen milden Hypothermiegruppe bestand jedoch nicht.

Ebenfalls besonders erwähnenswert scheint die Einflussnahme der milden Hypothermie auf die Erkrankungswahrscheinlichkeit des akuten Nierenversagens in Abhängigkeit von den Risikofaktoren der CKI. Für die Subgruppe, welche keinen Risikofaktor für die Entstehung einer CKI aufwies, ergab sich durch die mHT eine ARR bezogen auf die Inzidenz des ANV von $26,9 \%$. Das Risiko für Patienten mit einem Risikofaktor reduzierte sich um $12,7 \%$ und für Patienten mit mehr als einem Risikofaktor konnte das Risiko um 13,3\% minimiert werden. Hieraus ergibt sich, dass in der mHT-Gruppe ohne einen Risikofaktor der höchste therapeutische Effekt erzielt werden konnte und zusätzlich die Erkrankungswahrscheinlichkeit mit 24,1\% am niedrigsten lag $(1 \mathrm{RF}=27,6 \%,>1 \mathrm{RF}=35,3 \%)$. Den größten prozentualen Anteil an den Risikofaktoren zeigen der DM und eine arterielle Hypertonie (aHT). Für einen vorbestehenden DM ergibt sich eine unklare Studienlage. In zwei Studien konnte kein signifikant häufigeres Auftreten des akuten Nierenversagens unter DM beobachtet werden (Domanovits et al. 2001, Chua et al. 2012). Eine ältere Studie kommt jedoch zu der Annahme, dass Diabetiker eine höhere Empfindlichkeit für die Entstehung eines chronischen sowie akuten Nierenversagens aufweisen. Für das gehäufte Auftreten des akuten Nierenversagens bei Diabetikern macht GRENFELL (1986) die hohe Anfälligkeit für ein hyperglykämisches hyperosmolares Koma, eine diabetische Ketoazidose sowie eine erhöhte Empfindlichkeit gegenüber radiologischem Kontrastmittel und der renalen Papillennekrose verantwortlich.

Für einen vorbestehenden arteriellen Hypertonus ist eine ähnliche wissenschaftliche Problematik existent. CHUA et al. (2012) zeigten keinen Zusammenhang zwischen der Inzidenz des akuten Nierenversagens nach CPR und einer arteriellen Hypertension auf $(\mathrm{p}=0,298)$. DOMANOVITS et al. beschrieben jedoch bereits 2001 einen hochsignifikanten 
Unterschied in der Erkrankungshäufigkeit zwischen Hypertonikern und dem ANV $(\mathrm{p}=0,001)$.

Somit ist keine einheitliche Aussage bezüglich der Korrelation der Risikofaktoren und der Auftretenswahrscheinlichkeit des akuten Nierenversagens nach kardiopulmonaler Reanimation $\mathrm{zu}$ treffen. Es scheint jedoch einen Zusammenhang zwischen der Anzahl der Risikofaktoren und der Wahrscheinlichkeit eines ANV zu bestehen. Ein signifikanter Unterschied bezüglich der Häufigkeitsverteilung des ANVs zwischen den mHT-Gruppen konnte in Abhängigkeit von der Risikofaktorklasse nicht bestätigt werden $(\mathrm{p}=0,1558)$.

Betrachtet man die protektive Wirkung der milden Hypothermie unter Berücksichtigung der positiven Ergebnisse tierexperimenteller Studien, einer frühzeitigeren Diagnosestellung des akuten Nierenversagens sowie die ungleichen Studienkollektive mit zu kleinen Gesamtpopulationen in der klinischen Forschung, bleibt der in dieser Studie gezeigte hoch signifikante Vorteil für die Auftretenswahrscheinlichkeit des akuten Nierenversagens unter mHT bestehen. Eine Meta-Analyse von SUSANTITAPHONG et al. aus dem Jahr $2012 \mathrm{kam}$ zu einem nicht eindeutigen Ergebnis. Sie werteten retrospektiv zehn randomisierte Kontrollstudien auf die präventive Wirkung der milden Hypothermie nach präklinischer kardiopulmonaler Reanimation oder Bypass-Operation aus. Zunächst konnte sie keinen signifikanten Unterscheid in der Erkrankungswahrscheinlichkeit des akuten Nierenversagen konstatieren. Nach zusätzlicher Meta-Regression zeigte sich jedoch eine Korrelation zwischen der Temperatur und der Häufigkeit des ANV.

Für eine endgültige Klärung der Sachlage und anschließende Einführung in die klinische Praxis wird jedoch die Datenlage und Qualität derzeit für unzureichend befunden. Die meisten Arbeiten konzentrierten sich bis dato ausschließlich auf das neurologische Outcome und die Beeinflussung der Mortalität. Für eine retrospektive Bewertung des akuten Nierenversagens waren die Erkrankungshäufigkeiten zu gering und die Studienkohorten zu klein gewählt, um eine fundierte Aussage treffen zu können (Moore et al. 2011).

Es ist zu hoffen, dass der durch diese Studie aufgezeigte positive Effekt der mHT auf die Inzidenz des akuten Nierenversagens durch die aktuell in Australien und Neuseeland erfolgende POLAR-AKI Studie bestätigt werden kann. Bei diesem durch die Intensive Care Foundation unterstützten Forschungsprojekt handelt es sich um eine Substudie der randomisierten, verblindeten Kontrollstudie „Prophylactic Hypothermia to Lessen traumatic brain injury“ (POLAR). Sie soll prospektiv die prophylaktische Wirkung der milden Hypothermie auf die Entwicklung des akuten Nierenversagens und die Nützlichkeit renaler 
Biomarker untersuchen (Moore et al. 2011). Das Studienende wird voraussichtlich Mitte 2017 sein. 


\subsection{Einfluss der milden therapeutischen Hypothermie auf das Outcome}

In der vorliegenden Studie lag die Erkrankungswahrscheinlichkeit des chronischen Nierenversagens zum Zeitpunkt der Entlassung in dem milden Hypothermiekollektiv hochsignifikant niedriger als im Kontrollkollektiv ( $<$ 0,0001). Unter globaler Betrachtung ergab sich für die CKI in dem mHT-Kollektiv eine absolute Risikoreduktion von 15,9\% auf 5,0 \% (10/202). Mit einer normalen Nierenfunktion konnte nahezu die Hälfte der Patienten $(49,5 \%, 100 / 202)$ des mHT-Kollektivs entlassen werden. Dies entsprach einem Zuwachs von $21,7 \%$ und war ebenfalls hochsignifikant $(\mathrm{p}<0,0001)$. Die Überlebenswahrscheinlichkeit lag im mHT-Kollektiv bei 45,5\% (92/202) und im Kontrollkollektiv bei 51,4 \% (74/144). Dies entsprach einer ARR von 5,8\% und war nicht signifikant niedriger als im Kontrollkollektiv. $\mathrm{Zu}$ berücksichtigen ist bei den Ergebnissen, dass die milde Hypothermie im Gesamtkollektiv zwar zu einer Senkung der Mortalität beitrug, diese jedoch nicht signifikant war. Führte die mHT in vorangegangenen Studien meist zu einer signifikanten Reduktion der Mortalität, stellt das Ergebnis der vorliegenden Studie eine Ausnahme dar und muss berücksichtigt werden (van der Wal et al. 2011, Reinikainen et al. 2012). Lediglich eine Studie konnte keinen signifikanten Unterschied in der Mortalität zwischen $33{ }^{\circ} \mathrm{C}$ - und $36{ }^{\circ} \mathrm{C}$-gekühlten Patienten nachweisen. Eine aktive Kontrolle und Steuerung der Körpertemperatur sowie eine Fieberprävention erhielten in dieser Studie jedoch auch die Patienten der $36^{\circ} \mathrm{C}$-Gruppe (Nielsen et al. 2013). Dies macht eine Vergleichbarkeit zur Normothermie fragwürdig. Grund für den marginalen Überlebensvorteil des mHT-Kollektivs in der vorliegenden Untersuchung könnte der signifikant höhere APACHE II-Scores und die damit verbundene höhere Mortalitätswahrscheinlichkeit sein. Lag das mHT-Kollektiv bei einem durchschnittlichen Score von 28,4 Punkten, wies das Kontrollkollektiv lediglich 26,0 Punkte auf ( $<<0,0001$ ). Ein weiterer Grund für die Diskrepanz könnte in der ungleichen Geschlechterverteilung beider Kollektive bestehen. Der Einfluss des Geschlechtes auf die Mortalität wird kontrovers diskutiert. Einige Studien zeigten, dass es keinen signifikanten Unterschied bezüglich des Geschlechtes und der Mortalität bis zur Entlassung aus dem Krankenhaus nach Wiederbelebung gab (Perers er al. 1999, Herlitz et al. 2004, Bunch et al. 2005, Arrich et al. 2006, Herlitz et al. 2008). Aktuellere Untersuchungen sprachen jedoch dem weiblichen Geschlecht eine bessere Überlebenswahrscheinlichkeit nach kardiopulmonaler Reanimation zu (Adielsson et al. 2011, Teodorescu et al. 2012). 
Schlussfolgernd könnten der höhere APACHE II-Scores und der höhere Anteil an Männern in dem mHT-Kollektiv ursächlich für den nicht signifikant besseren Überlebensvorteil dieses Kollektivs sein.

Betrachtet man die Inzidenz des chronischen Nierenversagens unter milder Hypothermie, zeigt sich eine hochsignifikant geringere Erkrankungswahrscheinlichkeit und beinahe doppelt so viele Studienteilnehmer konnten nach Durchführung einer mHT das Krankenhaus mit einer normalen Nierenfunktion verlassen. Nimmt man an, dass das chronische Nierenversagen eine Langzeitkomplikation der akuten Nierenschädigung ist, lässt sich die niedrigere Inzidenz mit der signifikant geringeren Erkrankungshäufigkeit des akuten Nierenversagens in dem milden Hypothermiekollektiv konnektieren (Reichel 2014). Untersuchungen über die Genese des chronischen Nierenversagens konnten ein bis zu 28-fach höheres Erkrankungsrisiko nach aufgetretenem ANV nachweisen. Das Risiko für die CKI steigt mit dem Ausmaß der vorangegangenen Schädigung (Lo et al. 2009). Die vollständige Regeneration eines akuten Nierenversagens hängt dabei signifikant von der Pathogenese ab. Für eine akute tubuläre Schädigung liegt das Risiko einer chronischen Dialysepflichtigkeit bei $11 \%$ und somit im unteren Risikobereich (Bonomini et al. 1984). In einer Langzeituntersuchung konnte bei $41 \%$ der Patienten, die eine akute tubuläre Schädigung erlitten, eine moderate bis schwere Einschränkung der GFR nachgewiesen werden und $10 \%$ der Patienten wurden dialysepflichtig (Morgera et al. 2002).

Tierexperimentelle Studien konnten aufzeigen, dass eine Ischämie über bereits vorgeschädigtem Nierenparenchym (z. B. diabetische Nephropathie) zu einer interstitiellen Fibrose mit konsekutiver Rarefizierung der Nephrone führt. Diese Umbauprozesse bewirkten eine Regression der Nierenfunktion bis hin zur CKI (Kelly et al. 2009).

Auf der Grundlage der angeführten Untersuchungen ist davon auszugehen, dass es nach einem akuten Nierenversagen nicht zur vollständigen Regeneration kommt und das Risiko für die Entstehung einer CKI erhöht bleibt. Schlussfolgernd könnte dies auch die Begründung für die geringere Auftretenswahrscheinlichkeit der CKI in dem mHT-Kollektiv sein. Geht man von der Annahme aus, dass die mHT nach kardiopulmonaler Reanimation die Inzidenz des akuten Nierenversagens verringert, folgt konsekutiv auch eine verringerte Erkrankungswahrscheinlichkeit für die CKI.

Fokussiert man das Outcome der Studienteilnehmer unter Berücksichtigung der Kofaktoren Geschlecht, DM und Risikofaktorklasse, zeigt sich die gleiche Tendenz. Alle Subgruppen profitierten von der milden Hypothermie durch eine Risikoreduktion der Mortalität sowie 
bezüglich der Auftretenswahrscheinlichkeit des chronischen Nierenversagens. Im Rückschluss nimmt der Patientenanteil mit einer unauffälligen Nierenfunktion zu. Ein signifikanter Unterschied zwischen den Subgruppen innerhalb des Hypothermiekollektivs bestand nicht. Einen überdurchschnittlich großen Vorteil erzielten jedoch männliche Studienteilnehmer durch die Therapie. In dieser Subgruppe konnte durch die mHT das absolute Risiko für eine CKI um 19,1\% gesenkt werden ( $p<0,0001)$. Weibliche Studienteilnehmer lagen mit einer ARR von lediglich 9,4\% unter dem Erwartungswert $(p=0,1009)$, führte doch die milde Hypothermie gemäß der Ergebnisse der vorliegenden Studie insbesondere in dem weiblichen Kollektiv zu einer deutlichen Senkung der Inzidenz des akuten Nierenversagens (s. Kap 3.3.2). Der Unterschied zwischen der weiblichen und der männlichen mHT-Gruppe und dem Outcome war jedoch nicht signifikant $(p=0,1865)$. Dieses Ergebnis bedarf einer weiteren wissenschaftlichen Analyse durch prospektive Studien.

Des Weiteren ergab sich für Diabetiker und Studienteilnehmer ohne vordiagnostizierten DM ebenfalls eine Senkung des Erkrankungsrisikos für die CKI. Profitierten Nicht-Diabetiker mit einer ARR von 16,6\% hochsignifikant von der milden Hypothermie ( $p<0,0001)$, lag die ARR für Diabetiker bei $13,5 \%(p=0,0903)$. Die Mortalität konnte in der DiabetikerSubgruppe um lediglich $2,4 \%$ gesenkt werden und dies lag ebenfalls unter dem Erwartungswert. Eine mögliche Erklärung für dieses Ergebnis wäre die generell schlechtere Überlebenswahrscheinlichkeit von Diabetikern nach erfolgreicher Wiederherstellung eines spontanen Kreislaufes. Studien sprachen dieser Gruppe ein 12 \%iges höheres Mortalitätsrisiko nach präklinischer Reanimation zu (Larsson et al. 2005). Für den innerklinischen HerzKreislaufstillstand lag die Überlebenswahrscheinlichkeit bis zur stationären Entlassung bei Diabetikern sogar bis zu $30 \%$ höher als bei nicht an DM vorerkrankten Patienten (Petursson et al. 2008).

CUENI-VILLOZ et al. (2011) konnten in ihrer prospektiven Untersuchung eine durch die milde Hypothermie hervorgerufene erhöhte Insulinresistenz sowie erhöhte Blutzuckerwerte nachweisen. Zusätzlich zeigte sich in ihrer und einer weiteren Studie, dass eine hyperglykämische Stoffwechsellage zum Zeitpunkt der Aufnahme oder während der mHT zu einer erhöhten Mortalität führt (Kim et al. 2014).

Diese schlechtere Überlebenswahrscheinlichkeit besteht laut RO et al. (2015) nach kardiopulmonaler Reanimation und milder therapeutischer Hypothermie für Diabetiker weiter fort. In ihrer Studie konnten 42,3\% der Nicht-Diabetiker und lediglich 33,2\% der Diabetiker lebend entlassen werden $(p<0,01)$. Auch nach Adjustierung durch verschiedene Komor- 
biditäten (Hypertension, Schlaganfall, Herzinsuffizienzen etc.) blieb ein Unterschied bezüglich der Mortalität und der DM-Erkrankung erhalten.

Gemäß diesen Erkenntnissen kann vermutet werden, dass eine Störung des Glukosestoffwechsels mit einer geringeren Überlebenswahrscheinlichkeit nach ROSC einhergeht und die milde Hypothermie keinen positiven Einfluss auf die Mortalität dieser Subgruppe ausübt. Die gleichbleibende Mortalitätsrate für Diabetiker nach Durchführung der mHT in der vorliegenden Studie wäre durch diesen Effekt erklärbar. Zur genaueren Analyse sind weitführende prospektive Studien notwendig.

Vergleicht man das Outcome nach erfolgreicher Wiederbelebung unter Berücksichtigung der einzelnen Risikofaktorklassen, ergab sich für zwei Subgruppen eine signifikant geringere Auftretenswahrscheinlichkeit für die CKI. In der Subgruppe mit Patienten, die keinen Risikofaktor aufwiesen, konnte durch die milde Hypothermie das absolute Risiko für eine CKI um 17,4 \% gesenkt werden $(\mathrm{p}=0,0071)$. Für Patienten mit mehr als einem Risikofaktor lag die ARR mit 17,1 \% auf annähernd dem gleichen Niveau $(p=0,0112)$. Studienteilnehmer, die einen Risikofaktor aufwiesen, profitierten ebenfalls von der milden Hypothermie (AAR $11,8 \%$ ), jedoch war der Unterschied zwischen der mHT- und Kontrollgruppe nicht signifikant $(\mathrm{p}=0,0875)$. Geht man von der oben beschriebenen Annahme aus, dass die CKI eine mögliche Folge des akuten Nierenversagens ist, könnte die geringere Inzidenz des ANV nach milder Hypothermie in den Risikofaktorklassen weiterhin eine Erklärung für die geringere Auftretenswahrscheinlichkeit des CKI sein. Um eine genauere Aussage treffen zu können, bedarf es jedoch weiterer wissenschaftlicher Untersuchungen.

Für die Mortalität bestand in jeder Risikofaktorklasse eine Reduktion des Risikos. Diese variierte (ARR 1,1\% - 10,8 \%) jedoch von Klasse zu Klasse stark und keines der Ergebnisse war signifikant niedriger im Vergleich zu der Kontrollgruppe. Den höchsten positiven Effekt erzielte die mHT-Gruppe mit nur einem Risikofaktor.

Vorangegangene Studien konnten einen Zusammenhang zwischen der Anzahl an Komorbiditäten und der Überlebenswahrscheinlichkeit nachweisen. Je höher die Anzahl an Vorerkrankungen war, desto unwahrscheinlicher war die Chance, nach erfolgreicher Reanimation das Krankenhaus lebend zu verlassen. Somit stellt sich die Komorbidität als signifikanter Einflussfaktor für die Mortalität heraus (Hallstrom et al. 1996, Carew et al. 2007, Lee et al. 2011). Dies steht im Kontrast zu den Ergebnissen der vorliegenden Arbeit. Blieb die Sterblichkeitsrate der Kontrollgruppe bei annähernd $51 \%$ unabhängig von den Risikofaktoren, hatten Patienten ohne Risikofaktoren mit ca. $50 \%$ eine beinahe unveränderte Mortalitätsrate innerhalb der milden Hypothermiegruppen. Somit scheint es möglich, dass die 
Risikofaktoren keinen direkten Einfluss auf die Überlebenswahrscheinlichkeit ausüben. Auch dieses Ergebnis bedarf einer weiteren wissenschaftlichen Untersuchung in einer prospektiven Studie. 


\subsection{Einfluss der milden therapeutischen Hypothermie auf die errechnete glomeruläre Filtrationsrate}

Vergleicht man die errechnete durchschnittliche GFR des milden Hypothermiekollektivs $(66,14 \mathrm{ml} / \mathrm{min}) \mathrm{mit}$ dem Kontrollkollektiv $(62,42 \mathrm{ml} / \mathrm{min})$, ergeben sich für beide Kollektive zum Untersuchungsbeginn annähernd die gleichen Ausgangswerte $(\mathrm{p}=0,614)$. Am dritten Tag zeigte sich jedoch bereits, dass das mHT-Kollektiv signifikant bessere Mittelwerte aufwies als das Kontrollkollektiv (0,0174). Der positive Effekt verstärkte sich zunehmend über den Verlauf. Zum Endzeitpunkt erreichte das mHT-Kollektiv eine durchschnittliche GFR von $88,56 \mathrm{ml} / \mathrm{min}$ und erholte sich damit deutlich besser als das Kontrollkollektiv mit $64,06 \mathrm{ml} / \mathrm{min}(\mathrm{p}<0,0001)$.

Dies lässt konkludieren, dass die mHT in der vorliegenden Untersuchung zu einem möglichen positiven Effekt auf die errechnete glomeruläre Filtrationsrate des mHT-Kollektivs führte.

Als einen Vorteil gegenüber anderen Untersuchungen analysierte diese Studie die glomeruläre Filtration kontinuierlich über einen Zeitraum von 14 Tagen. Ein Großteil der bereits publizierten Arbeiten betrachtet die Serum-Kreatininwerte lediglich über die ersten Stunden bis maximal 72 Stunden nach erfolgreicher kardiopulmonaler Reanimation (Bernard et al. 2002, Kämäräinen et al. 2009, Yang et al. 2010). Die Studien, die ihren Beobachtungszeitraum auf 7 oder 28 Tage nach dem Wiederherstellen eines spontanen Kreislaufes erweiterten, konnten keine Aussage zu dem Verlauf der Nierenfunktionsparameter während des Untersuchungszeitraumes treffen (Zeiner et al. 2004, Guluma et al. 2010).

Als Einschränkung in der vorliegenden Studie ist die Bestimmung der glomerulären Filtration anhand der MDRD-Formel zu sehen. Aufgrund einiger limitierender Faktoren der MDRDFormel wäre es für das optimale Studiendesign vorteilhaft gewesen, die Inulin-Clearance für jeden einzelnen Patienten zum jeweiligen Untersuchungszeitpunkt zu bestimmen (Botev et al. 2009). Durch die Retrospektive war dies nachträglich nicht mehr möglich. Für eine zukünftige Studie wäre die Nierenfunktionsbestimmung anhand des Cystatin-C oder des neutrophilengelatinase-assoziierte Lipocalin (NGAL) als Alternative vorstellbar. Diese Parameter zeigen eine höhere Sensitivität gegenüber der Nierenschädigung sowie eine höhere analytische Aussagekraft im Vergleich zur errechneten GFR (Grubb et al. 1985, Newman et al. 1995, Mishra et al. 2003).

Vergleicht man die Ergebnisse der vorliegenden Studie mit bereits publizierten, früheren Studien, zeigt sich für die Initialphase ein ähnlicher Verlauf. Patienten, welche einen HerzKreislaufstillstand erlitten und erfolgreich reanimiert werden konnten, haben im Vergleich zur gleichaltrigen, gesunden Population zum Zeitpunkt der Aufnahme eine reduzierte Nierenfunk- 
tion. Liegt die durchschnittliche GFR laut National Kidney Foundation für die Altersgruppe der 60- bis 69-Jährigen bei $81 \mathrm{ml} / \mathrm{min}$, war sie in dieser Studie - bezogen auf das mittlere Lebensalter von ca. 67 Lebensjahren - zwischen 62,42 ml/min und 66,14 ml/min deutlich niedriger (Kampmann et al. 1974). Es ist anzunehmen, dass es bereits sofort nach Herz-Kreislaufstillstand zu einer Verringerung der Nierenfunktion und zum Abfall der glomerulären Filtrationsrate kommt. Mehrere vorangegangene Untersuchungen konnten diesen Effekt bestätigen (Izzat et al. 1996, Domantovits et al. 2001, Bernard et al. 2002, Zeiner et al. 2004). Betrachtet man den Verlauf der Nierenfunktion über das Zeitintervall, ergab sich für das milde Hypothermiekollektiv im Vergleich zum Kontrollkollektiv eine bessere errechnete glomeruläre Filtrationsrate. ZEINER et al. konnten 2004 in ihrer retrospektiven Auswertung der HACA-Studiendaten ebenfalls niedrigere Nierenretentionsparameter für ihre Hypothermiegruppe nachweisen. Lag die Gruppe, welche eine milde Hypothermie nach kardiopulmonaler Reanimation erhielt, nach 24 Stunden nach Aufnahme bei einem mittleren Serum-Kreatininspiegel von $0,78 \mathrm{mg} / \mathrm{ml}$, erreichte die Normothermiegruppe lediglich einen Durchschnittswert von $1,00 \mathrm{mg} / \mathrm{ml}$. In beiden Gruppen nahmen zwar die SerumKreatininwerte $a b$, jedoch erreichte die Hypothermiegruppe niedrigere Werte als die Normothermiegruppe. Ob der Unterschied nach 24 Stunden zwischen den beiden Gruppen signifikant war, wurde in der Studie nicht angegeben. Zumindest bestätigte sich für die ersten 24 Stunden die Annahme, dass die mHT zu einer Reduktion des Serum-Kreatinins führt. Für die vorliegende Studie bedeutet dies im Rückschluss, dass eine Erhöhung der mittels MDRDFormel errechneten glomerulären Filtrationsrate plausibel ist. Es wird dabei angenommen, dass die Serum-Kreatininwerte im exponentiellen Verhältnis zu der errechneten glomerulären Filtrationsrate stehen. Für den Zeitraum zwischen dem ersten und 28. Tag führten ZEINER et al. (2004) keine Auswertung durch.

Zusätzlich untersuchten sie in ihrer Arbeit die Kreatinin-Clearance der ersten 24 Stunden anhand der gemessenen Kreatininausscheidung im Urin. Die Werte zum Zeitpunkt der Aufnahme waren niedriger als erwartet, korrelierten jedoch mit den erhöhten SerumKreatininwerten des Aufnahmezeitpunktes beider Gruppen. Im Verlauf normalisierte sich die durchschnittliche Kreatinin-Clearence der Normothermiegruppe schneller als die der Hypothermiegruppe. Vergleicht man die beiden Nierenfunktionsparameter miteinander, zeigte sich ein konträrer Verlauf. Als Ursache wurde vermutet, dass es durch die milde Hypothermie zu einem geringeren muskulären Metabolismus mit verminderter Kreatininsynthese kommt und konsekutiv die Serum-Kreatininwerte in dieser Gruppe niedriger liegen. Nach 28 Tagen 
erfolgte die Bestimmung der Kreatinin-Clearance anhand der Cockcroft-Gault-Formel - es konnte kein signifikanter Unterschied zwischen beiden Gruppen gemessen werden.

Betrachtet man die Endzeitpunkte der angeführten Studie mit den Ergebnissen der vorliegenden Untersuchung, besteht eine Diskrepanz in Bezug auf die glomeruläre Filtrationsrate. Konnten ZEINER et al. (2004) zum Endzeitpunkt keinen Unterschied feststellen, bestand in dieser Studie ein signifikanter Unterscheid zwischen beiden Kollektiven. Dies kann, wie bereits in Kapitel 4.2 angeführt, an den ungleichen Einschlusskriterien beider Studien und der daraus resultierenden geringeren Inzidenz für eine Nierenfunktionsstörung begründet sein. Ein weiterer Grund für das differente Endergebnis könnte durch den doppelt so langen Untersuchungszeitraum der oben angeführten Studie begründet sein. Berücksichtigt man den Zeitpunkt des Auftretens (1.-2. Tag) des akuten Nierenversagens und die durchschnittliche Regenerationsdauer von 4,5 Tagen, überschreitet der Beobachtungszeitraum von 28 Tagen den Erkrankungszeitraum um ein Vielfaches (Han et al. 2013). Diese lange Intervallpause kann dazu geführt haben, dass eine Mehrzahl der SerumKreatininwertänderungen nicht detektiert wurde und dies die Diskrepanz zwischen den beiden Untersuchungen begründet.

Betrachtet man die glomeruläre Filtrationsrate in Abhängigkeit von den Kofaktoren, Geschlecht, DM und der Risikofaktorklassen, zeigt sich, auf den Endzeitpunkt und die Subgruppen bezogen, für drei Kofaktoren ein signifikant besserer Verlauf. Männer, Diabetiker und Studienteilnehmer, welche einen oder mehr als einen Risikofaktor in sich trugen, zeigten über den gesamten Untersuchungszeitraum keinen signifikanten Unterschied zwischen der Nierenfunktion und ihrer Vergleichsgruppe auf.

Das Geschlecht scheint einen Einfluss auf den positiven Effekt der milden Hypothermie und die GFR auszuüben. Männliche Studienteilnehmer erreichten in der milden Hypothermiegruppe zwar im Durchschnitt eine bessere GFR (88,49 ml/min) als die Kontrollgruppe (70,63 $\mathrm{ml} / \mathrm{min}$ ), ein signifikanter Unterschied ergab sich jedoch zu keinem Zeitpunkt ( $\mathrm{p}=0,491)$. Für weibliche Studienteilnehmer bestand - auf den Endzeitpunkt bezogen - ein signifikanter Unterschied in der GFR zwischen der mHT- und der Kontrollgruppe ( $p=0,0484)$. Frauen scheinen somit mehr von einer milden Hypothermie zu profitieren als Männer. Begründet könnte dies durch die bereits in Kapitel 4.2 angeführte höhere Resistenz gegenüber nephrotoxischen Einflüssen sowie eine Verstärkung dieses Effektes durch die milde Hypothermie sein.

Für die mHT-Gruppe mit einem vordiagnostizierten DM lag nach 14 Tagen die durchschnittliche GFR bei $69,35 \mathrm{ml} / \mathrm{min}$ und in der Kontrollgruppe bei $64,80 \mathrm{ml} / \mathrm{min}(\mathrm{p} \approx 1)$. 
Hieraus lässt sich insbesondere in Konklusion mit den Ergebnissen aus Kapitel 4.2 vermuten, dass Patienten, die bereits vor kardiopulmonaler Reanimation an einem DM litten, nicht von der mHT profitieren. Der Grund für diesen Effekt kann in der höheren Sensitivität gegenüber nierenschädigenden Faktoren liegen. Laut GRENFELL (1986) besteht für Diabetiker eine deutlich erhöhte Empfindlichkeit gegenüber radiologischem Kontrastmittel und der renalen Papillennekrose. Als ein weiterer Grund kann das generell erhöhte Risiko von Diabetikern gegenüber der CKI sein. Ihr Anteil liegt laut dem United States Renal Data System in den Vereinigten Staaten bei fast $44 \%$ und ist somit als der Hauptfaktor für die Entstehung dieser Erkrankung zu bewerten (USRDS 2004). Eine weitere Studie belegt, dass durch die milde Hypothermie das neurologische Outcome und die Mortalität gesenkt werden kann, dies jedoch für Diabetiker nicht zutrifft (Ro et al. 2015). Aufgrund dieser Studienergebnisse und dem in der vorliegenden Studie erhobenen Ergebnis bleibt zu eruieren, ob eine mHT bei Patienten mit einer DM-Erkrankung zu einer besseren Prognose führt.

Studienteilnehmer, die einen oder mehr als einen Risikofaktor für die Entstehung einer CKI aufwiesen und mittels milder Hypothermie nach CPR behandelt wurden, hatten zum Endzeitpunkt der Untersuchung ebenfalls keine signifikant bessere glomeruläre Filtrationsrate $(\mathrm{p} \approx 1)$. Dies kann dadurch bedingt sein, dass beinahe die Hälfte der Patienten der mHTGruppe (32/76), die einen Risikofaktor aufwies, an einem DM litten und diese Subgruppe, wie zuvor vermutet, nicht von einer milden Hypothermie profitiert. Betrachtet man die Subgruppe der Nicht-Diabetiker und die Subgruppe, in welcher kein Risikofaktor für das Erleiden einer CKI vorlag, ergaben sich für beide Gruppen hochsignifikante Unterschiede zwischen der milden Hypothermiegruppe und der Kontrollgruppe.

Folglich ist ein durch die Erkrankung DM ausgelöster prozessrelevanter Bias innerhalb der beiden Risikofaktorklassen (= $1 \mathrm{RF},>1 \mathrm{RF}$ ) nicht auszuschließen.

Betrachtet man das Gesamtkollektiv und die deutlich bessere durchschnittliche glomeruläre Filtrationsrate des mHT-Kollektivs unter Berücksichtigung der angeführten Studienlage, ist der in dieser retrospektiven Studie aufgezeigte positive Effekt auf die Nierenfunktion durchaus relevant. Dieser protektive Mechanismus kann jedoch durch bestimmte Kofaktoren beeinflusst werden. Als besonders bedeutsamer Faktor stellt sich in der vorliegenden Studie eine DM-Erkrankung heraus. Diese Vermutung deckte sich mit den Ergebnissen von RO et al. (2015). Des Weiteren scheinen Frauen im Vergleich zu Männern besser von der milden therapeutische Hypothermie nach kardiopulmonaler Reanimation zu profitieren. Aufgrund der 
uneinheitlichen Datenlage bedarf es zur weiteren Klärung der genauen pathophysiologischen Mechanismen und der zukünftigen klinischen Relevanz weiterer wissenschaftlicher Studien. 


\section{$5 \quad$ Zusammenfassung}

Jährlich erleiden in Europa circa 350000 Menschen einen Herz-Kreislaufstillstand und müssen präklinisch kardiopulmonal reanimiert werden. Die dardurch bedingte Mortalität und das neurologische Outcome konnten durch die Einführung der milden Hypothermie als Standardverfahren für die Postreanimationsphase signifikant verbessert werden. Eine weitere schwerwiegende Komplikation nach erfolgreicher Wiederbelebung stellt das akute Nierenversagen dar. Ziel der vorliegenden retrospektiven Studie war es, die Inzidenz des akuten Nierenversagens nach erfolgreicher kardiopulmonaler Reanimation und initiierter mHT zu evaluieren. Dem Vergleich diente ein Kontrollkollektiv ohne die Durchführung dieses therapeutischen Verfahrens.

Grundlage der Analyse waren die Aktendokumentation von 346 erfolgreich reanimierten Patienten, welche zur Bildung eines milden Hypothermiekollektivs $(n=202)$ und eines Kontrollkollektivs $(\mathrm{n}=144)$ in dichotome Gruppen geteilt wurden. Die statistische Auswertung der erhobenen Daten erfolgte unter der Berücksichtigung der Kofaktoren: Geschlecht, DM und der Risikofaktoren für die Entstehung einer CKI.

Die Inzidenz des akuten Nierenversagens konnte durch die Einführung der milden Hypothermie signifikant von $45,8 \%$ im Kontrollkollektiv auf 29,2\% im mHT-Kollektiv gesenkt werden $(p=0,0015)$. Für die Erkrankungswahrscheinlichkeit einer CKI zum Zeitpunkt der Entlassung ergab sich durch die initiierte Therapie eine ARR von 15,9\% $(\mathrm{p}<0,0001)$. Die errechnete glomeruläre Filtrationsrate zeigte über den zeitlichen Verlauf zunehmend bessere Werte in dem mHT-Kollektiv und lag zum Endzeitpunkt signifikant höher als im Kontrollkollektiv ( $\mathrm{p}$ <,0001). Unter Berücksichtigung der Kofaktoren blieb ein protektiver Effekt der milden Hypothermie in beinahe allen Subgruppen bestehen. Der positive Einfluss war jedoch nicht durchweg signifikant.

Zusammenfassend gesagt, konnte diese retrospektive Untersuchung zur mHT einen schützenden Effekt auf die Nierenfunktion nach erfolgreicher kardiopulmonaler Reanimation aufzeigen. Insbesondere scheint das weibliche Geschlecht die protektiven Mechanismen dieser Therapie positiv zu beeinflussen. Eine Diabetes-mellitus-Erkrankung stellte sich in der vorliegenden Studie, besonders in Bezug auf die glomeruläre Filtrationsrate, als negativer Einflussfaktor heraus. Die Ergebnisse der vorliegenden retrospektiven Arbeit müssen durch weiterführende prospektive klinische Studien überprüft werden. 


\section{Tabellenverzeichnis}

Tabelle 1: Klassifikation des akuten Nierenversagens nach AKIN ....................................... 4

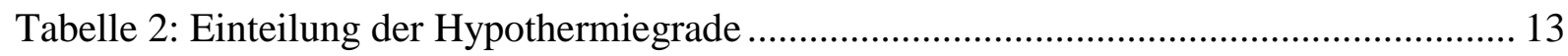

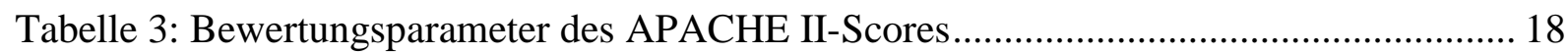

Tabelle 4: Altersbewertung für den APACHE II-Scores ..................................................... 19

Tabelle 5: Berechnungsmethodik des Glasgow Coma Scale ............................................... 19

Tabelle 6: Bewertungsskala des chronischen Gesundheitsstatus ......................................... 20

Tabelle 7: Überlebenswahrscheinlichkeit nach APACHE II-Scores ..................................... 21

Tabelle 8: Globale Häufigkeitsverteilung des akuten Nierenversagens................................ 40

Tabelle 9: Häufigkeitsverteilung des akuten Nierenversagens in Abhängigkeit vom

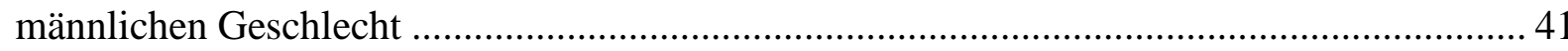

Tabelle 10: Häufigkeitsverteilung des akuten Nierenversagens in Abhängigkeit vom

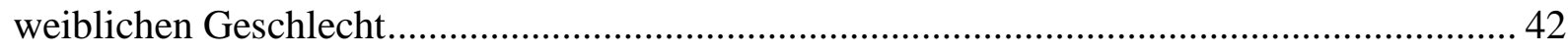

Tabelle 11: Häufigkeitsverteilung des akuten Nierenversagens bei Nicht-Diabetikern .......... 43

Tabelle 12: Häufigkeitsverteilung des akuten Nierenversagens bei Diabetes-mellitus-

Erkrankung....

Tabelle 13: Häufigkeitsverteilung des akuten Nierenversagens bei Studienteilnehmern ohne additive Risikofaktoren

Tabelle 14: Häufigkeitsverteilung des akuten Nierenversagens bei Studienteilnehmern mit einem Risikofaktor.... 46

Tabelle 15: Häufigkeitsverteilung des akuten Nierenversagens bei Studienteilnehmern mit mehr als einem Risikofaktor

Tabelle 16: Globale Häufigkeitsverteilung des Outcomes. 50

Tabelle 17: Häufigkeitsverteilung des Outcomes in Abhängigkeit vom männlichen

Geschlecht

Tabelle 18: Häufigkeitsverteilung des Outcomes in Abhängigkeit vom weiblichen

Geschlecht

Tabelle 19: Häufigkeitsverteilung des Outcomes bei Nicht-Diabetikern

Tabelle 20: Häufigkeitsverteilung des Outcomes in Abhängigkeit von einer Diabetes-mellitus-

Erkrankung. 
Tabelle 21: Häufigkeitsverteilung des Outcomes bei Studienteilnehmern ohne additive

Risikofaktoren 55

Tabelle 22: Häufigkeitsverteilung des Outcomes bei Studienteilnehmern mit einem

Risikofaktor 56

Tabelle 23: Häufigkeitsverteilung des Outcomes bei Studienteilnehmern mit mehr als einem Risikofaktor 57

Tabelle 24: Approximierte MDRD-Werte der männlichen Studienteilnehmer 60

Tabelle 25: Approximierte MDRD-Werte der weiblichen Studienteilnehmerinnen ..... 61

Tabelle 26: Approximierte MDRD-Werte der Nicht-Diabetiker. 62

Tabelle 27: Approximierte MDRD-Werte der Diabetiker 63

Tabelle 28: Approximierte MDRD-Werte der Studienteilnehmer ohne aditive

Risikofaktoren 64

Tabelle 29: Approximierte MDRD-Werte der Studienteilnehmer mit einem Risikofaktor...... 65

Tabelle 30: Approximierte MDRD-Werte ( $\mathrm{ml} / \mathrm{min})$ der Studienteilnehmer mit mehr als einem Risikofaktor 65 


\section{$7 \quad$ Abbildungsverzeichnis}

Abbildung 1: Pathophysiologische Aspekte des akuten Nierenversagens ............................. 11

Abbildung 2: Pathophysiologische Effekte der milden therapeutischen Hypothermie ........... 17

Abbildung 3: Häufigkeitsverteilung des Geschlechtes ......................................................... 32

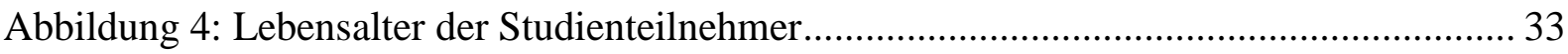

Abbildung 5: Lebensalter der Studienteilnehmer gruppiert nach Kollektiv und Geschlecht .. 34

Abbildung 6: Häufigkeitsverteilung des APACHE II-Scores ............................................. 35

Abbildung 7: Häufigkeitsverteilung des APACHE II-Scores gruppiert nach dem Kollektiv

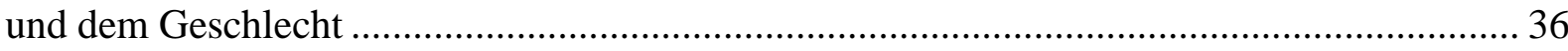

Abbildung 8: Häufigkeitsverteilung der vordiagnostizierten Diabetes-mellitus-

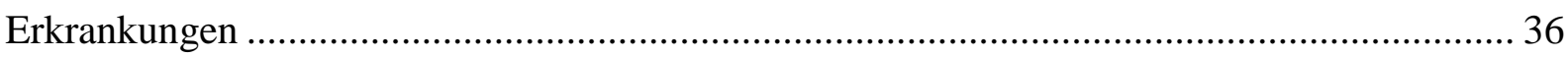

Abbildung 9: Häufigkeitsverteilung der Risikofaktoren für eine chronische

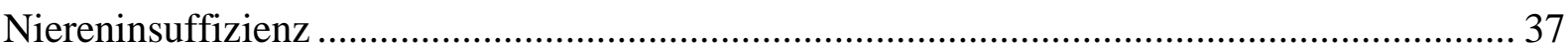

Abbildung 10: Liegedauer des Patientenkollektivs auf der Intensivstation ........................... 38

Abbildung 11: Liegedauer des Kontrollkollektivs auf der Intensivstation ............................. 38

Abbildung 12: Glaobale Häufigkeitsverteilung des akuten Nierenversagens ........................ 40

Abbildung 13: Häufigkeitsverteilung des akuten Nierenversagens für männliche

Studienteilnehmer

Abbildung 14: Häufigkeitsverteilung des akuten Nierenversagens für weibliche

Studienteilnehmer

Abbildung 15: Häufigkeitsverteilung des akuten Nierenversagens bei Nicht-Diabetikern ..... 43

Abbildung 16: Häufigkeitsverteilung des akuten Nierenversagens bei Diabetikern

Abbildung 17: Häufigkeitsverteilung des akuten Nierenversagens für Studienteilnehmer ohne additive Risikofaktoren

Abbildung 18: Häufigkeitsverteilung des akuten Nierenversagens für Studienteilnehmer mit einem Risikofaktor

Abbildung 19: Häufigkeitsverteilung des akuten Nierenversagens für Studienteilnehmer mit mehr als einem Risikofaktor

Abbildung 20: Zeitlicher Beginn des akuten Nierenversagens ............................................ 48

Abbildung 21: Globale Häufigkeitsverteilung des Outcomes.................................................. 50 
Abbildung 22: Häufigkeitsverteilung des Outcomes für männliche Studienteilnehmer.......... 51

Abbildung 23: Häufigkeitsverteilung des Outcomes für weibliche Studienteilnehmer........... 52

Abbildung 24: Häufigkeitsverteilung des Outcomes bei Nicht-Diabetiker ............................ 53

Abbildung 25: Häufigkeitsverteilung des Outcomes bei Diabetiker ....................................... 54

Abbildung 26: Häufigkeitsverteilung des Outcomes für Studienteilnehmer ohne additive

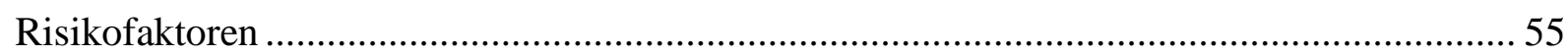

Abbildung 27: Häufigkeitsverteilung des Outcomes für Studienteilnehmer mit einem

Risikofaktor

Abbildung 28: Häufigkeitsverteilung des Outcomes für Studienteilnehmer mit mehr als einem

Risikofaktor 57

Abbildung 29: Verlaufskurve der approximierten MDRD-Werte

Abbildung 30: Verlaufskurve der approximierten MDRD-Werte in Abhängigkeit von dem

Geschlecht 60

Abbildung 31: Verlaufskurve der approximierten MDRD-Werte in Abhängigkeit von einer

Diabetes-mellitus-Erkrankung 62

Abbildung 32: Verlaufskurve der approximierten MDRD-Werte in Abhängigkeit von der

Risikofaktorklasse 66 


\section{$8 \quad$ Literaturverzeichnis}

Adielsson A, Hollenberg J, Karlsson T, Lindqvist J, Lundin S, Silfverstolpe J, Svensson L, Herlitz J (2011): Increase in survival and bystander CPR in out-of-hospital shockable arrhythmia: bystander CPR and female gender are predictors of improved outcome. Experiences from Sweden in an 18-year perspective. Heart 97, 1391-1396

Adler C, Reuter H, Seck C, Hellmich M, Zobel C (2013): Fluid therapy and acute kidney injury in cardiogenic shock after cardiac arrest. Resuscitation 84, 194-199

Agardh CD, Zhang H, Smith ML, Siesjö BK (1991): Free radical production and ischemic brain damage: influence of postischemic oxygen tension. Int J Dev Neurosci $\underline{9}, 127-138$

Aibiki M, Maekawa S, Yokono S (2000): Moderate hypothermia improves imbalances of thromboxane A2 and prostaglandin $\mathrm{I} 2$ production after traumatic brain injury in humans. Crit Care Med 28, 3902-3906

Arrich J, Sterz F, Fleischhackl R, Uray T, Losert H, Kliegel A, Wandaller C, Köhler K, Laggner AN (2006): Gender modifies the influence of age on outcome after successfully resuscitated cardiac arrest: a retrospective cohort study. Medicine (Baltimore) $\underline{85}$, 288294

Beilin B, Shavit Y, J. Razumovsky, Wolloch Y, Zeidel A, Bessler H (1998): Effects of mild perioperative hypothermia on cellular immune responses. Anesthesiology $\underline{89}, 1133-1140$

Bellomo R (2005): Defining, quantifying, and classifying acute renal failure. Crit Care Clin $\underline{21}, 223-237$

Berdowski J, Berg RA, Tijssen JGP, Koster RW (2010): Global incidences of out-of-hospital cardiac arrest and survival rates: Systematic review of 67 prospective studies. Resuscitation $\underline{81}, 1479-1487$

Bernard SA, Gray TW, Buist MD, Jones BM, Silvester W, Gutteridge G, Smith K (2002): Treatment of Comatose Survivors of Out-of-Hospital Cardiac Arrest with Induced Hypothermia. NEJM $\underline{346}, 557-563$

Bierbrauer A von, Riedel S, Cassel W, Wichert P von (1998): Validierung des Acute Physiology and Chronic Health Evaluation (APACHE) III Scoringsystems und Vergleich mit APACHE II auf einer deutschen Intensivstation. Anaesthesist 47, 30-38 
Bonomini V, Stefoni S, Vangelista A (1984): Long-term patient and renal prognosis in acute renal failure. Nephron $\underline{36}, 169-172$

Bonventre JV (1993): Mechanisms of ischemic acute renal failure. Kidney Int $\underline{43}, 1160-1178$

Botev R, Mallié J-P, Couchoud C, Schück O, Fauvel J-P, Wetzels JFM, Lee N, De Santo NG, Cirillo M (2009): Estimating glomerular filtration rate: Cockcroft-Gault and Modification of Diet in Renal Disease formulas compared to renal inulin clearance. Clin J Am Soc Nephrol 4, 899-906

Brüx A, Girbes ARJ, Polderman DKH (2005): Kontrollierte milde und moderate Hypothermie. Anaesthesist 54, 225-244

Bunch TJ, Hammill SC, White RD (2005): Outcomes after ventricular fibrillation out-ofhospital cardiac arrest: expanding the chain of survival. Mayo Clin Proc $\underline{80}, 774-782$

Carew HT, Zhang W, Rea TD (2007): Chronic health conditions and survival after out-ofhospital ventricular fibrillation cardiac arrest. Heart $\underline{93}, 728-731$

Chen L, Piao Y, Zeng F, Lu M, Kuang Y, Ki X (2001): Moderate hypothermia therapy for patients with severe head injury. Chin J Traumatol $\underline{4}, 164-167$

Chua H-R, Glassford N, Bellomo R (2012): Acute kidney injury after cardiac arrest. Resuscitation $\underline{83}, 721-727$

Cueni-Villoz N, Devigili A, Delodder F, Cianferoni S, Feihl F, Rossetti AO, Eggimann P, Vincent J-L, Taccone FS, Oddo M (2011): Increased blood glucose variability during therapeutic hypothermia and outcome after cardiac arrest. Crit Care Med 39, 2225-2231

Deakin CD, Nolan JP, Soar J, Sunde K, Koster RW, Smith GB, Perkins GD (2010): European Resuscitation Council Guidelines for Resuscitation 2010 Section 4. Adult advanced life support. Resuscitation $\underline{81}$, 1305-1352

Domanovits H, Schillinger M, Müllner M, Thoennissen J, Sterz F, Zeiner A, Druml W (2001): Acute renal failure after successful cardiopulmonary resuscitation. Intensive Care Med 27, 1194-1199

Gekle M, Singer D: Wäremhaushalt und Temperaturregulation. In: Physiologie, 7. Auflage; hrsg. v. Klinke R, Pape HP, Kurtz A, Silbernagel S; Thieme, Stuttgart 2014, 567-584 
Goligorsky MS, DiBona GF (1993): Pathogenetic role of Arg-Gly-Asp-recognizing integrins in acute renal failure. off. Proc Natl Acad Sci USA 90, 5700-5704

GRC, German Resuscitation Council, Deutscher Rat für Wiederbelebung e.V.; SOP Hypothermie: Die Behandlung von Patienten nach Herz-Kreislaufstillstand und primär erfolgreicher Reanimation, Köln 2012; online: http://www.grc-org.de/sop aufgerufen am 03.03 .2015

Grenfell A (1986): Acute renal failure in diabetics. Intensive Care Med 12, 6-12

Grubb A, Simonsen O, Sturfelt G, Truedsson L, Thysell H (1985): Serum concentration of cystatin C, factor D and beta 2-microglobulin as a measure of glomerular filtration rate. Acta Med Scand 218, 499-503

Guluma KZ, Liu L, Hemmen TM, Acharya AB, Rapp KS, Raman R, Lyden PD (2010): Therapeutic hypothermia is associated with a decrease in urine output in acute stroke patients. Resuscitation $\underline{81}, 1642-1647$

HACA, The Hypothermia after Cardiac Arrest Study Group (2002): Mild Therapeutic Hypothermia to Improve the Neurologic Outcome after Cardiac Arrest. New England Journal of Medicine $\underline{346}, 549-556$

Haller M, Schelling G (2000): Akutes Nierenversagen. Der Anaesthesist 49, 349-352

Hallstrom AP, Cobb LA, Yu BH (1996): Influence of Comorbidity on the Outcome of Patients Treated for Out-of-Hospital Ventricular Fibrillation. Circulation 93, 2019-2022

Han SS, Kim S, Ahn SY, Lee J, Kim DK, Chin HJ, Chae D-W, Na KY (2013): Duration of acute kidney injury and mortality in critically ill patients: a retrospective observational study. BMC Nephrol $\underline{14}, 133$

Hasper D, von Haehling S, Storm C, Jorres A, Schefold JC (2009): Changes in serum creatinine in the first 24 hours after cardiac arrest indicate prognosis: an observational cohort study. Crit Care $\underline{13}$, R168

Herlitz J, Engdahl J, Svensson L, Young M, Angquist K-A, Holmberg S (2004): Is female sex associated with increased survival after out-of-hospital cardiac arrest? Resuscitation $\underline{60}$, $197-203$ 
Herlitz J, Svensson L, Engdahl J, Silfverstolpe J (2008): Characteristics and outcome in outof-hospital cardiac arrest when patients are found in a non-shockable rhythm. Resuscitation $\underline{76}, 31-36$

Hoedemaekers CW, Ezzahti M, Gerritsen A, van der Hoeven JG (2007): Comparison of cooling methods to induce and maintain normo- and hypothermia in intensive care unit patients: a prospective intervention study. Crit Care 11, R91

Holzer M: Herz-Kreislauf-Stillstand. In: Medizinische Therapie 2005|2006; hrsg. v. Schölmerich PDJ, Burdach S, Drexler H, Hallek M, Hiddemann W, Hörl WH, Klein H, Landthaler M, Lenz K, Mann K et al.; Springer, Berlin/Heidelberg 2005, 1459-1466

Hutchens MP, Nakano T, Kosaka Y, Dunlap J, Zhang W, Herson PS, Murphy SJ, Anderson S, Hurn PD (2010): Estrogen Is Renoprotective via a Nonreceptor-dependent Mechanism after Cardiac Arrest In Vivo. Anesthesiology 112, 395

Izzat NN, Hawkins EP, Rosborough JP, Pate TD (1996): Renal function following cardiac arrest and resuscitation in the canine. Resuscitation $\underline{32}, 251-261$

Johnson KJ, Weinberg JM (1993): Postischemic renal injury due to oxygen radicals. Curr Opin Nephrol Hypertens $\underline{2}$, 625-635

Kämäräinen A, Hoppu S, Silfvast T, Virkkunen I (2009): Prehospital therapeutic hypothermia after cardiac arrest - from current concepts to a future standard. Scand J Trauma Resusc Emerg Med 17, 53

Kampmann J, Siersbæk-Nielsen K, Kristensen M, Hansen JM (1974): Rapid Evaluation of Creatinine Clearance. Acta Med Scand 196, 517-520

Keller DCK, Geberth DSK: Akutes Nierenversagen. In: Praxis der Nephrologie; Springer Berlin 2010, 181-198

Kelly KJ, Burford JL, Dominguez JH (2009): Postischemic inflammatory syndrome: a critical mechanism of progression in diabetic nephropathy. Am J Physiol Renal Physiol 297, F923-931

Kim SH, Choi SP, Park KN, Lee SJ, Lee KW, Jeong TO, Youn CS, Korean Hypothermia Network Investigators (2014): Association of blood glucose at admission with outcomes in patients treated with therapeutic hypothermia after cardiac arrest. Am J Emerg Med $\underline{32}$, 900-904 
Klausner JM, Paterson IS, Goldman G, Kobzik L, Rodzen C, Lawrence R, Valeri CR, Shepro D, Hechtman HB (1989): Postischemic renal injury is mediated by neutrophils and leukotrienes. Am J Physiol 256, F794-802

Knaus WA, Zimmerman JE, Wagner DP, Draper EA, Lawrence DE (1981): APACHE-acute physiology and chronic health evaluation: a physiologically based classification system. Crit Care Med 9, 591-597

Knaus WA, Draper EA, Wagner DP, Zimmerman JE (1985): APACHE II: a severity of disease classification system. Crit Care Med 13, 818-829

Koushanpour E, Kriz W: Regulation of Renal Blood Flow and Glomerular Filtration Rate. In: Renal Physiology; Springer, New York 1986, 73-95

Lameire N, Vanholder R (2001): Pathophysiologic Features and Prevention of Human and Experimental Acute Tubular Necrosis. JASN 12, S20-S32

Lameire N, Van Biesen W, Vanholder R (2005): Acute renal failure. The Lancet $\underline{365}$, 417430

Larrey DJ: Memoirs of Military Surgery, and Campaigns of the French Armies, on the Rhine, in Corsica, Catalonia, Egypt, and Syria, at Boulogne, Ulm, and Austerlitz; in Saxony, Prussia, Poland, Spain, and Austria, 2. Auflage; Joseph Cushing, Baltimore 1814

Larsson M, Thorén A-B, Herlitz J (2005): A history of diabetes is associated with an adverse outcome among patients admitted to hospital alive after an out-of-hospital cardiac arrest. Resuscitation 66, 303-307

Lee CC, Tsai M-S, Fang C-C, Chen Y-J, Hui-Ming M, Huang C-H, Chen W-J, Chen S-C (2011): Effects of pre-arrest comorbidities on 90-day survival of patients resuscitated from out-of-hospital cardiac arrest. Emerg Med J 28, 432-436

Levey AS, Bosch JP, Lewis JB, Greene T, Rogers N, Roth D (1999): A more accurate method to estimate glomerular filtration rate from serum creatinine: a new prediction equation. Modification of Diet in Renal Disease Study Group. Ann Intern Med 130, 461-470

Levey AS, Coresh J, Balk E, Kausz AT, Levin A, Steffes MW, Hogg RJ, Perrone RD, Lau J, Eknoyan G (2003): National Kidney Foundation Practice Guidelines for Chronic Kidney Disease: Evaluation, Classification, and Stratification. Ann Intern Med 139, 137-147 
Lo LJ, Go AS, Chertow GM, McCulloch CE, Fan D, Ordoñez JD, Hsu C (2009): Dialysisrequiring acute renal failure increases the risk of progressive chronic kidney disease. Kidney Int $\underline{76}$, 893-899

Mahmood MA, Zweifler RM (2007): Progress in shivering control. J Neurol Sci 261, 47-54 Mattana J, Singhal PC (1993): Prevalence and determinants of acute renal failure following cardiopulmonary resuscitation. Arch Intern Med 153, 235-239

Mehta RL, Kellum JA, Shah SV, Molitoris BA, Ronco C, Warnock DG, Levin A (2007): Acute Kidney Injury Network: report of an initiative to improve outcomes in acute kidney injury. Crit Care 11, R31

Metz C, Taeger K (2000): Schädelhirntrauma und zerebrale Hypoxie Diagnostik - Monitoring - Therapie. Anaesthesist 49, 332-339

Mishra J, Ma Q, Prada A, Mitsnefes M, Zahedi K, Yang J, Barasch J, Devarajan P (2003): Identification of Neutrophil Gelatinase-Associated Lipocalin as a Novel Early Urinary Biomarker for Ischemic Renal Injury. JASN 14, 2534-2543

Molitoris BA, Dahl R, Geerdes A (1992): Cytoskeleton disruption and apical redistribution of proximal tubule $\mathrm{Na}(+)-\mathrm{K}(+)-A T P a s e$ during ischemia. Am J Physiol 263, F488-495

Moore EM, Nichol AD, Bernard SA, Bellomo R (2011): Therapeutic hypothermia: benefits, mechanisms and potential clinical applications in neurological, cardiac and kidney injury. Injury $\underline{42}, 843-854$

Morgera S, Kraft AK, Siebert G, Luft FC, Neumayer H-H (2002): Long-term outcomes in acute renal failure patients treated with continuous renal replacement therapies. Am $\mathbf{J}$ Kidney Dis $\underline{40}, 275-279$

Müller V, Losonczy G, Heemann U, Vannay Á, Fekete A, Reusz G, Tulassay T, Szabó AJ (2002): Sexual dimorphism in renal ischemia-reperfusion injury in rats: Possible role of endothelin. Kidney Int $\underline{62}, 1364-1371$

Newman DJ, Thakkar H, Edwards RG, Wilkie M, White T, Grubb AO, Price CP (1995): Serum cystatin $\mathrm{C}$ measured by automated immunoassay: a more sensitive marker of changes in GFR than serum creatinine. Kidney Int $\underline{47}, 312-318$

Nielsen N, Wetterslev J, Cronberg T, Erlinge D, Gasche Y, Hassager C, Horn J, Hovdenes J, Kjaergaard J, Kuiper M, et al. (2013): Targeted temperature management at $33^{\circ} \mathrm{C}$ versus $36^{\circ} \mathrm{C}$ after cardiac arrest. N Engl J Med $\underline{369}, 2197-2206$ 
Nilsson L, Kogure K, Busto R (1975): Effects of hypothermia and hyperthermia on brain energy metabolism. Acta Anaesthesiol Scand 19, 199-205

Nolan JP (2003): Therapeutic Hypothermia After Cardiac Arrest: An Advisory Statement by the Advanced Life Support Task Force of the International Liaison Committee on Resuscitation. Circulation $\underline{108}, 118-121$

Nolan JP, Deakin CD, Soar J, Böttiger BW, Smith G (2005): European Resuscitation Council guidelines for resuscitation 2005. Section 4. Adult advanced life support. Resuscitation 67 Suppl 1, S39-86

Novack TA, Dillon MC, Jackson WT (1996): Neurochemical mechanisms in brain injury and treatment: a review. J Clin Exp Neuropsychol 18, 685-706

Pell JP, Sirel JM, Marsden AK, Ford I, Walker NL, Cobbe SM (2003): Presentation, management, and outcome of out of hospital cardiopulmonary arrest: comparison by underlying aetiology. Heart $\underline{89}, 839-842$

Perers E, Abrahamsson P, Bång A, Engdahl J, Lindqvist J, Karlson BW, Waagstein L, Herlitz J (1999): There is a difference in characteristics and outcome between women and men who suffer out of hospital cardiac arrest. Resuscitation $\underline{40}$, 133-140

Petroianu G, Osswald P: Alveoloarterielle Sauerstoffdifferenz. In: Anästhesie in Frage und Antwort, 3. Auflage; Springer, Berlin 2000, 5-8

Petursson P, Gudbjörnsdottir S, Aune S, Svensson L, Oddby E, Sjöland H, Herlitz J (2008): Patients with a history of diabetes have a lower survival rate after in-hospital cardiac arrest. Resuscitation $\underline{76}, 37-42$

Polderman KH (2009): Mechanisms of action, physiological effects, and complications of hypothermia. Critical Care Medicine 37, S186-S202

Polderman KH, Herold I (2009): Therapeutic hypothermia and controlled normothermia in the intensive care unit: practical considerations, side effects, and cooling methods. Crit Care Med 37, 1101-1120

Popp E, Sterz F, Böttiger BW (2005): [Therapeutic hypothermia after cardiac arrest]. Anaesthesist 54, 96-106 
Racusen LC, Fivush BA, Li YL, Slatnik I, Solez K (1991): Dissociation of tubular cell detachment and tubular cell death in clinical and experimental ,acute tubular necrosis“. Lab Invest $\underline{64}, 546-556$

Reichel RR (2014): Acute Kidney Injury: Quoi de Neuf? Ochsner J 14, 359-368

Reinikainen M, Oksanen T, Leppänen P, Torppa T, Niskanen M, Kurola J, Finnish Intensive Care Consortium (2012): Mortality in out-of-hospital cardiac arrest patients has decreased in the era of therapeutic hypothermia. Acta Anaesthesiol Scand 56, 110-115

Ro YS, Shin SD, Song KJ, Lee EJ, Lee YJ, Kim JY, Jang DB, Kim MJ, Kong SY (2015): Interaction effects between hypothermia and diabetes mellitus on survival outcomes after out-of-hospital cardiac arrest. Resuscitation 90, 35-41

Rosomoff HL, Holaday DA (1954): Cerebral blood flow and cerebral oxygen consumption during hypothermia. Am J Physiol 179, 85-88

Safar P, Tisherman SA, Behringer W, Capone A, Prueckner S, Radovsky A, Stezoski WS, Woods RJ (2000): Suspended animation for delayed resuscitation from prolonged cardiac arrest that is unresuscitable by standard cardiopulmonary-cerebral resuscitation. Crit Care Med $\underline{28}$, N214-218

Schwab S, Schellinger P, Werner C, Unterberg A, Hacke W: NeuroIntensiv 2. Auflage. Springer, Berlin 2012

Seldin DW, Giebisch GH: The Kidney, 3. Auflage; Lippincott Williams and Wilkins Verlag, New York 2000

Sevanian A, Kim E (1985): Phospholipase A2 dependent release of fatty acids from peroxidized membranes. J Free Radic Biol Med 1, 263-271

Siesjö BK, Bengtsson F, Grampp W, Theander S (1989): Calcium, excitotoxins, and neuronal death in the brain. Ann N Y Acad Sci $\underline{568}, 234-251$

Silbernagl S: Die Funktion der Niere. In: Physiologie; hrsg. v. Klinke R, Pape HP, Kurtz A, Silbernagel S; 6- Auflage; Thieme, Stuttgart 2010, 330-383

Singbartl K, Ley K (2004): Leukocyte recruitment and acute renal failure. J Mol Med $\underline{82}$, 91101 
Snowdowne KW, Borle AB (1985): Effects of low extracellular sodium on cytosolic ionized calcium. $\mathrm{Na}+\mathrm{Ca} 2+$ exchange as a major calcium influx pathway in kidney cells. J Biol Chem 260, 14998-14507

Spencer AJ, LeFurgey A, Ingram P, Mandel LJ (1991): Elemental microanalysis of organelles in proximal tubules. II. Effects of oxygen deprivation. J Am Soc Nephrol 1, 1321-1333

Stahl RAK, Harendza S, Panzer U, Schneider A, Thaiss F, Wenzel U: Niere und ableitende Harnwege. In: Klinische Pathophysiologie: 239 Tabellen; hrsg. v. Siegenthaler W, Blum H, Amann-Vesti BR; 9. völlig neu bearb. Auflage; Thieme, Stuttgart 2006, 915-980

Stapleton RD, Ehlenbach WJ, Deyo RA, Curtis JR (2014): Long-term outcomes after inhospital CPR in older adults with chronic illness. Chest 146, 1214-1225

Sterz F, Safar P, Tisherman S, Radovsky A, Kuboyama K, Oku K (1991): Mild hypothermic cardiopulmonary resuscitation improves outcome after prolonged cardiac arrest in dogs. Crit Care Med 19, 379-389

Susantitaphong P, Alfayez M, Cohen-Bucay A, Balk EM, Jaber BL (2012): Therapeutic hypothermia and prevention of acute kidney injury: a meta-analysis of randomized controlled trials. Resuscitation $\underline{83}, 159-167$

Teasdale G, Jennett B (1974): Assessment of coma and impaired consciousness: a Practical Scale. The Lancet $\underline{304}, 81-84$

Teodorescu C, Reinier K, Uy-Evanado A, Ayala J, Mariani R, Wittwer L, Gunson K, Jui J, Chugh SS (2012): Survival advantage from ventricular fibrillation and pulseless electrical activity in women compared to men: the Oregon Sudden Unexpected Death Study. J Interv Card Electrophysiol 34, 219-225

Thadhani R, Pascual M, Bonventre JV (1996): Acute renal failure. N Engl J Med 334, 14481460

Thomas C, Thomas L (2009): Renal Failure-Measuring the Glomerular Filtration Rate. Dtsch Arztebl Int 106, 849-854

Thurau K, Schnermann J (1965): The sodium concentration in the macula densa cells as a regulating factor for glomerular filtration (micropuncture experiments). Klin Wochenschr $\underline{43}, 410-413$ 
Tortorici MA, Kochanek PM, Poloyac SM (2007): Effects of hypothermia on drug disposition, metabolism, and response: A focus of hypothermia-mediated alterations on the cytochrome P450 enzyme system. Crit Care Med 35, 2196-2204

Trummer G, Donauer M, Beyersdorf F (2009): Herz-Kreislauf-Stillstand und kardiopulmonale Reanimation auf der herzchirurgischen Intensivstation. Z Herz- ThoraxGefäßchir 르, 33-40

Uchino S, Kellum JA, Bellomo R, Doig GS, Morimatsu H, Morgera S, Schetz M, Tan I, Bouman C, Macedo E, et al. (2005): Acute renal failure in critically ill patients: a multinational, multicenter study. JAMA $\underline{294}, 813-818$

United States Renal Data System; USRDS 2007 Annual Data Report: Atlas of End-Stage Renal Disease in the United States, National Institutes of Health, National Institute of Diabetes and Digestive and Kidney Diseases, Bethesda 2007; online: http://www.usrds.org/atlas07.aspx aufgerufen am 02.03.2015

Van der Wal G, Brinkman S, Bisschops LLA, Hoedemaekers CW, van der Hoeven JG, de Lange DW, de Keizer NF, Pickkers P (2011): Influence of mild therapeutic hypothermia after cardiac arrest on hospital mortality. Crit Care Med 39, 84-88

Vincent J-L, Singer M (2010): Critical care: advances and future perspectives. The Lancet $\underline{376}, 1354-1361$

Wei Q, Wang M-H, Dong Z (2005): Differential gender differences in ischemic and nephrotoxic acute renal failure. Am J Nephrol 25, 491-499

Weih M, Prassl K, Ruscher K, Trendelenburg G, Dirnagl U, Riepe MW, Meisel A (2001): Ischämietoleranz Modell für die Forschung, Hoffnung für die Klinik? Nervenarzt $\underline{72}$, $255-260$

Wilhelm W: Praxis der Intensivmedizin: konkret, kompakt, interdisziplinär, 2. Auflage; Springer, Berlin 2013

Wolff B, Machill K, Schumacher D, Schulzki I, Werner D (2009): Early achievement of mild therapeutic hypothermia and the neurologic outcome after cardiac arrest. Int J Cardiol $\underline{133}, 223-228$

Xu L, Yenari MA, Steinberg GK, Giffard RG (2002): Mild hypothermia reduces apoptosis of mouse neurons in vitro early in the cascade. J Cereb Blood Flow Metab 22, 21-28 
Yang L, Zhao X-M, Liu L-J (2010): Mild hypothermia in improving multiple organ dysfunction after cardiac arrest. World J Emerg Med 1, 196-200

Zager RA, Gmur DJ, Bredl CR, Eng MJ (1989): Degree and time sequence of hypothermic protection against experimental ischemic acute renal failure. Circ Res $\underline{65}$, 1263-1269

Zeiner A, Holzer M, Sterz F, Behringer W, Schörkhuber W, Müllner M, Frass M, Siostrzonek P, Ratheiser K, Kaff A, Laggner AN (2000): Mild Resuscitative Hypothermia to Improve Neurological Outcome After Cardiac Arrest A Clinical Feasibility Trial. Stroke $\underline{31}$, 86941269

Zeiner A, Sunder-Plassmann G, Sterz F, Holzer M, Losert H, Laggner AN, Müllner M (2004): The effect of mild therapeutic hypothermia on renal function after cardiopulmonary resuscitation in men. Resuscitation $\underline{60}$, 253-261 


\section{Danksagung}

Einen ganz besonderen Dank möchte ich meiner Doktormutter und wissenschaftlichen Betreuerin Frau Prof. Dr. med. S. Blaschke für ihre exzellente und stets konstruktive Zusammenarbeit aussprechen. Mein Dank gilt weiterhin der Abteilung für Medizinische Statistik und insbesondere Herrn Dr. rer. nat. Simon Schneider für die Unterstützung in der statistischen Auswertung mit dem Computerprogramm SAS. 


\section{Lebenslauf}

Am 10.04.1987 wurde ich als dritter Sohn (Nicholas John, Philip Tobias) eines britischen Offiziers, Christopher John Barclay-Steuart, und einer deutschen Offizierstochter Barbara Irene (geb. Dietze) in Münster geboren.

Meine Schulzeit verbrachte ich in Burgdorf bei Hannover. Dort besuchte ich ab 1994 die örtliche Grund- und Orientierungsschule und wechselte anschließend auf die Realschule Burgdorf. Nach meinem erweiterten Realschulabschluss 2003 entschied ich mich, auf das Fachgymnasium nach Celle zu wechseln. An der Axel-Bruns-Schule Celle absolvierte ich 2006 erfolgreich meine Allgemeine Hochschulreife.

Nach diversen Praktika in verschieden Krankenhäusern der Region Hannover entschloss ich mich für das Studienfach der Humanmedizin. Während der Wartezeit auf einen Studienplatz begann ich 2007 meine Berufsausbildung zum Gesundheits- und Krankenpfleger an der Medizinischen Hochschule Hannover.

Im Wintersemester 2008/09 erhielt ich einen Studienplatz für das Fach Humanmedizin an der Georg-August-Universität Göttingen und brach daraufhin meine Berufsausbildung ab. Nach erfolgreichem Physikum im Sommersemester 2010 entschloss ich mich, an der Medizinischen Fakultät in Göttingen weiter zu studieren. Bereits während des klinischen Studienabschnitts entwickelte sich mein Interesse für den Bereich der Notfall- und Intensivmedizin, und ich begann mit der Ausarbeitung dieser Dissertationsarbeit. Mein Praktisches Jahr absolvierte ich in der Unfallchirurgie am Groote Schuur Hospital Cap Town (Südafrika), auf der internistischen Notaufnahme des Spitals Thun STS AG (Schweiz) und in der Anästhesie und Intensivmedizin des Klinikums Bremen Mitte. Mein Studium der Humanmedizin an der Georg-August-Universität Göttingen schloss ich erfolgreich im November 2014 ab.

Im Jahr 2015 begann ich meine fachärztliche Ausbildung im Zentrum der Anästhesiologie und Intensivmedizin am Universitätsklinikum Hamburg-Eppendorf 